Volume 1, Issue 2, December 2019

"The value of pedagogical knowledge:

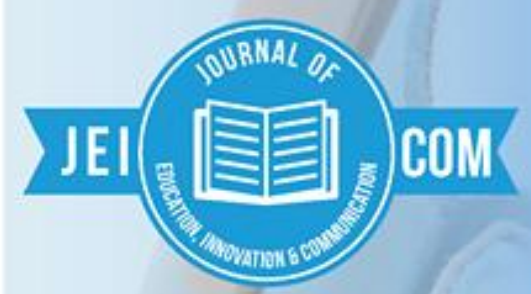

an international perspective"

Journal of

EDUCATION

INNOVATION and

COMMUNICATION

Edited by

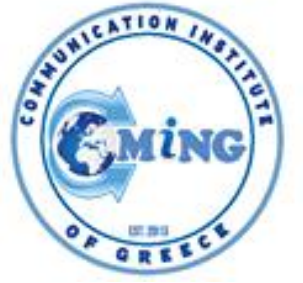

COMMUNICATION INSTITUTE OF GREECE 
Volume 1, Issue 2, December 2019 Journal of Education, Innovation, and Communication (JEICOM) 
Journal of Education, Innovation, and Communication (JEICOM)

Volume 1, Issue 2, December 2019

\section{"The value of pedagogical knowledge: an international perspective"}

https://coming.gr/volume-1-issue-2-december-2019/

ISSN: 2654-0746 (listed in the National Library of Greece)

DOI: 10.34097/jeicom-volume-1-issue-2-december-2019

https://doi.org/10.34097/jeicom-volume-1-issue-2-december-2019 
Volume 1, Issue 2, December 2019 Journal of Education, Innovation, and Communication (JEICOM) 
Journal of Education, Innovation, and Communication (JEICOM)

Volume 1, Issue 2, December 2019

The value of pedagogical knowledge: an international perspective

\begin{tabular}{|c|c|}
\hline Table of Contents & \\
\hline Editors\& Editorial Team & 7 \\
\hline Mission \& President's Message & 9 \\
\hline $\begin{array}{l}\text { Preface } \\
\text { International Pedagogical Practices: New media and the value of } \\
\text { pedagogical knowledge } \\
\text { Fotini Diamantidaki, Margarita Kefalaki }\end{array}$ & 11 \\
\hline $\begin{array}{l}\text { History of Education and Contemporary Education: Reflections on Jewish } \\
\text { Education } \\
\text { Yehuda Bitty }\end{array}$ & 15 \\
\hline $\begin{array}{l}\text { Facilitating and Improving Speaking Accuracy through Self-correction and } \\
\text { Self-awareness in TOEFL Independent Speaking Tasks } \\
\text { Davood Souri, Ali Merç }\end{array}$ & 21 \\
\hline $\begin{array}{l}\text { Integrated Social Media into Mobile-Assisted Foreign Language Learning } \\
\text { Ling Luo }\end{array}$ & 37 \\
\hline $\begin{array}{l}\text { Motivation and Vision: A Survey of British Learners on the Mandarin } \\
\text { Excellence Programme } \\
\text { Qing Li }\end{array}$ & 47 \\
\hline $\begin{array}{l}\text { The Effect of Face-to-Face and non-Face-to-Face Synchronously } \\
\text { Collaborative Writing Environment on Student Engagement and Academic } \\
\text { Performance } \\
\text { Mengying Han, Yushun Li }\end{array}$ & 65 \\
\hline $\begin{array}{l}\text { Investigating the Relationships among College Students' Online Self- } \\
\text { Regulated Learning, Grit and 5C Competences } \\
\text { Wei Sun, Chang Xu, Yan Dong }\end{array}$ & 75 \\
\hline
\end{tabular}




\section{Editors}

-Dr Margarita Kefalaki, President, Communication Institute of Greece \& Professor, Hellenic Open University of Greece Institute of Greece

-Dr Fotini Diamantidaki, Lecturer, UCL Institute of Education, University of London, UK \&VicePresident of Research and Academic Affairs, Communication Institute of Greece

\section{Editorial Team}

-Dr Hazel Crichton, Lecturer in Modern Languages, The School of Education, The University of Glasgow, Glasgow

-Dr Shirley Lawes, Lecturer, Department of Culture Communication and Media, UCL Institute of Education, UK

-Dr Robert J. Bonk, Professor of Professional Writing, School of Human Service Professions, Widener University, Chester, USA

-Dr Anne Palmer, PGDip Education \& BA(Hons) (UWA) Murdoch Singapore Pte Ltd, Singapore

-Dr Nikleia Eteokleous, Assistant Professor in Educational Technology, School of Education and Social Sciences\& Head of the Distance Learning Committee Coordinator of M.Ed. in Curriculum Development and Instruction, Co-founder Robotics Academy, Cyprus

-Dr Sophie Karanicolas, Associate Professor, Adelaide Dental School, Adelaide Health and Medical Sciences, The University of Adelaide, Australia

-Dr Paraskevi Kontoleon, Lecturer, University of South Australia, Australia

-Dr Jurgen Rudolph, Head of Research \& Academic Partner Liaison, Kaplan Higher Education, Singapore \& Editor, JALT Journal, Singapore

-Dr Matt Glowatz, Assistant Professor, University College Dublin, Ireland

-Dr Max Caruso, Western Co Principal, Yew Wah International Education School of Zhejiang Tongxiang, China

-Dr Yuan Ying Caruso, Chinese Co Principal YWIES Shanghai, China

-Dr Eirini Daskalaki, Academic Director \& Head of Research Centre at ACC Akademia College, Research Fellow at Cyprus Institute of Marketing (CIM), Cyprus

-Dr Jane Jones, Senior Lecturer, Subject Director MFL Teacher Education, Department of Education and Professional Studies, University of Kings College London, UK

-Dr Frances Weightman, Associate Professor, University of Leeds, UK

-Dr. Jennifer Eddy, Associate Professor and program director, World Language Education, Queens College, City University, USA

-Dr Dean Cleavenger, Lecturer, School of Business Administration, Department of Management, University of Central Florida, USA

-Dr Francine Hultgren, Professor and Chair, University of Maryland, Department of Teaching and Learning, Policy and Leadership, United States, USA

-Dr Lydia Lymperis, Doctoral Researcher in Education, UK

-Dr Bill Baker, Lecturer, University of Tasmania, College of Arts, Law and Education, School of Education, Australia 
-Dr John F. Covaleskie, Professor Emeritus, ELPS, Women and Gender Studies, Center for Social Justice, University of Oklahoma, USA

-Dr Michael Nevradakis, Communications Instructor, Deree-American College of Greece, Department of Communications, Greece

-Dr Lia-Paschalia Spyridou, Assistant Professor, Faculty of Communication and Media, Cyprus University of Technology, Cyprus

-Dr Carolin Rekar Munro, Professor, School of Business, Faculty of Management, Royal Roads University, Victoria, British Columbia, Canada

-Dr Michael A. Altamirano, Professor, King Graduate School, Monroe College, Bronx, New York, USA

-Dr Carlos E. Rios-Collazo, Professor, Monroe College, New York, NY, USA

-Dr Nathan Herbst, Ph.D., Team Coordinator, Great Commission Alliance, USA

-Dr Karl-Heinz Pogner, Associate Professor, Department of Management, Society, and Communication, Copenhagen Business School, Denmark 
Journal of Education, Innovation, and Communication (JEICOM)

Volume 1, Issue 2, December 2019

\section{"The value of pedagogical knowledge: an international perspective"}

https://coming.gr/volume-1-issue-2-december-2019/

ISSN: 2654-0746 (listed in the National Library of Greece)

DOI: 10.34097/jeicom-volume-1-issue-2-december-2019

https://doi.org/10.34097/jeicom-volume-1-issue-2-december-2019 


\section{Mission/ Presidents Message}

The publications of the Communication Institute of Greece, such as the "Journal of Education, Innovation, and Communication (JEICOM)", are open access without any costs for the authors or the readers.

JEICOM is a Fully Peer-Reviewed, Open Access journal, publishing articles from all areas of education, innovation and communication, independent of the events organized by the Communication Institute of Greece.

JEICOM's scope is to provide a free and open platform to academics, researchers, professionals, and postgraduate students to communicate and share knowledge in the form of high quality empirical and theoretical research that is of high interest not only for academic readers but also for practitioners and professionals. JEICOM welcomes theoretical, conceptual and empirical original research papers, case studies, book reviews that demonstrate the innovative and dynamic spirit for the education and communication sciences, from researchers, scholars, educators, policy-makers, and practitioners in education, communication, and related fields. Articles that show scholarly depth, breadth or richness of different aspects of social pedagogy are particularly welcome.

The numerous papers presented every year during the conferences organized by the Communication Institute of Greece, enables us to have access to a plethora of papers. Following a rigorous peerreview process, only a selection of these papers submitted is published biannually. In addition, to the papers presented in the Institute's conference, we do encourage independent submissions of papers too. Nevertheless, before you submit, please make sure to respect the guidelines and templates provided.

The current issue of the "Journal of Education, Innovation, and Communication (JEICOM)", is our Second Issue for 2019 (December 2019).

We consider that education and fruitful exchange can improve our lives with the view to nurture intercultural communication. Academics can contribute significantly to the quality of the educational experience and help educate, communicate, exchange, meet new cultures, create and collaborate!

We wish you an excellent reading and for the year to come soon, 2020, Health, Love, Knowledge, Education, Prosperity, Communication and Exchange!

Dr. Margarita Kefalaki

President, Communication Institute of Greece 
Volume 1, Issue 2, December 2019 Journal of Education, Innovation, and Communication (JEICOM) 


\section{Preface}

\section{The value of pedagogical knowledge: an international perspective}

Pedagogy is an applied social science which initially derived from Philosophy and is mainly associated with the research associated with children. Pedagogy refers to the holistic development of the child involving the body, mind and soul. As a discipline it is strongly associated with Psychology too and it is a theoretical and practically applied science.

Pedagogy holds its roots back in ancient times with a first definition involving the 'child' ' $\pi \alpha \delta^{\prime}$ ' ped- and the teaching of the child ' $\alpha \gamma \omega \gamma \eta$ ' -agogy. In fact, ' $\alpha \gamma \omega \gamma \eta$ ' means the orthodox - 'right way' of teaching. This statement can have many interpretations overtime and according to context. It makes us think what is the 'right education' for a child, who determines what is right? The context the child lives in or the one who shares the knowledge?

The term has evolved over the years and the literature recently focuses on the teaching practices adopted by the teacher (Windschitl et al., 2012 \& Kazemi et al., 2009). Teaching practices can become procedural and eventually be considered as the 'right' way of doing things (Bourdieu 1990, Foucault 1980a).

The selection of the articles for the current issue underpins the above values on pedagogy and will aim to challenge what should be 'right', challenge the conception that what is new is seen as 'right', and appreciate reading different pedagogical practices from around the world, with a view to examine what connects us all and what is really, actually new.

How pedagogical knowledge is constructed is brought to us with the first article where the author shares the paradigm from the history of Jewish education. Bitty (2019) discusses examples he shares with his students during his lectures and where he tries to build their own identity as future teachers. In his words '...through historical sources, the students discover that the old and distant narrative is actually quite close to the reality that they face in their classrooms: the same dilemmas, the same difficulties and sometimes ... even the same educational solutions' (Bitty, 2019: 15). It makes us think with the illustration of a classroom back in the day featured in the article, whether we are any better today. Two groups of students, doing differentiated work in the same classroom. Maybe the classroom is not then as traditional as we might have thought in the first place, even though this happened centuries ago. How teachers have constructed pedagogical knowledge over the years is deeply rooted into practice and into the classroom. Hence, we open the issue with such a dilemma and thinking: is what we see now happening in the classrooms new and better?

The next article in the sequence travels us back to our times and examines the challenges faced by the TOEFL -IBT test during the speaking assessment. A challenge that derives from the automaticity of the environment, where there is not enough time for self-correction and what's even more, the candidate talks to a machine. The pedagogical practices are then developed whilst preparing students to take such a test. Souri and Merç (2019) discuss the ways teachers can overcome the challenge of such a standardised test by making the student more aware of their own mistakes, teaching them to step back and self-reflect on their errors before trying it again. Students can improve their performance if teachers provide them feedback on what they did wrong and what 
they can do to improve it. This pedagogical practice resonates entirely with the Assessment for Learning (AFL) concept (Black \& Jones 2007) whereby one of the principles during the teaching practice is to promote feedback via formative means and provide feedback on a summative test, such as the one in the article, in order to improve learning and eventually the assessment outcome of the student.

A subsequent article by Luo (2019) contributes to the discussion on pedagogy in an innovative way, as it considers revolutionising the teaching of Mandarin Chinese via the WeChat app. The article is an empirical study which persuasively proves the benefits of social media and the impact on pedagogical practices. According to the research, WeChat's communicative functions can enhance the learning experience and have a positive impact on student attainment. Live chat facility between teacher and student, group chat amongst students, multimedia input by the teacher and document transmissions make the learning process interactive and at the same time taking learning away from the classroom. Learning becomes instant, achronic, with the teacher on the other side of the device ready to provide feedback and instructions. Even in this virtual situation, pedagogical practices are applied throughout and the study proves that this model 'works' and foreign language learners get better results.

Qing (2019) investigates learners' motivation and vision in learning Mandarin Chinese amongst different year groups in secondary schools in the UK. Language learning is seen from the students' perspective and we learn from their point of view what motivates them to learn Mandarin and how they envisage themselves. The group of selected students are part of the Mandarin Excellence Programme (MEP) a government funded programme with intensive weekly teaching offered in many secondary schools in the UK. The programme also offers the opportunity for learners to go to China and immerse themselves in the culture they are learning about. Indeed, one of the main motivating factors is that students love to discover the culture of the language they are studying. The recommendation for pedagogical practices lies then with the teachers in order to include cultural input in their lessons as a result.

Han \& Li (2019) explore more specifically one aspect of language learning - writing - and how students can improve their writing via the use of a new app called Cooperpad. The article discusses applications for both face to face and online learning environments. Cooperpad, promotes collaborative learning with a group awareness functionality, which continuously gathers group members' writing behaviour, analyses and visualizes their engagement intensity for group members to compare their participation with that of others. The results showed that the Cooperpad writing system is more helpful to enhance the student engagement and improve students' academic performance as well as promoting learning initiative and teamwork ability. We observe that the app enhances and improves many pedagogical aspects during teaching and learning where interaction becomes key, in a traditionally very difficult skill to master.

Wei, Chan, Yan (2019) through their investigation of grit and self-regulation and their impact on the five competencies: communication, collaboration, critical thinking, complex problem solving and creativity, they found something very valuable and indeed timeless. According to their findings, teachers should teach their students to never give up, to persevere with their goals. A teachers' job is to teach their students the way to growth, teach them that difficulties will occur but through selfreflection and seeking for help the students should be able to overcome their difficulties. Teachers, 
the pedagogues, should guide their students to set their own targets, choose suitable strategies to solve problems and when they meet difficulties they should know who to ask for help so that they can self-reflect and evaluate.

The last article takes us back to basics, and reminds us what is important in pedagogy and effectively timeless; even though these results were obtained through very modern means, the value of pedagogical knowledge lies within us, human beings. Each human being is unique, every learning experience is unique and we, human beings make it happen. That is what connects us all and makes us who we are.

To conclude this issue's introduction, we consider the importance of the pedagogical knowledge as a priority for educators. Diamantidaki (2019) discussed that the main goal of education should not be achievement in examinations; rather, the starting point should be the human qualities and capabilities we wish to nurture and what kind of society we hope for.

Education is defined and redefined by who we are and what we do matters to achieve a better society. Nelson Mandela shares that, "Education is the most powerful weapon which you can use to change the world"!

This issue is organized with the view to help readers think about education and provide examples as to feel more empowered and confident to paint a colorful and valuable passage in this world (Kazantzakis ${ }^{1}$ ).

We wish you an excellent reading and we hope to have added, with this issue and all our other activities $^{2}$, a small building block to the edifice of pedagogical knowledge! Thank you!

\section{Dr Fotini Diamantidaki \& Dr Margarita Kefalaki}

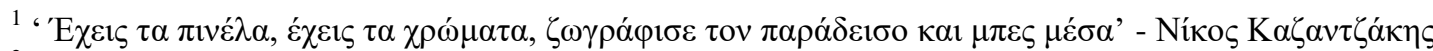

${ }^{2}$ See activities of the Communication Institute of Greece at https://coming.gr/
} 


\section{References}

Black B. \& Jones J. (2006). Formative assessment and the learning and teaching of MFL: sharing the language learning road map with the learners, The Language Learning Journal, 34:1, 49, DOI: $10.1080 / 09571730685200171$

Bourdieu, P. (1990). Structures, habitus, practices. In: Bourdieu, P (ed.) The Logic of Practice. Stanford, CA: Stanford University Press, pp. 52-79.

Diamantidaki, F. (Ed.). (2019). Teaching literature in modern foreign languages. London, UK: Bloomsbury

Foucault, M. (1980a) History of Sexuality, vol. 1. London: Penguin Press.

Kazemi, E., Franke, M., \& Lampert, M. (2009). Developing pedagogies in teacher education to support novice teachers' ability to enact ambitious instruction. In Crossing divides: Proceedings of the 32nd annual conference of the Mathematics Education Research Group of Australasia (Vol. 1, pp. 12-30). Adelaide, SA: MERGA.

Windschitl, M, Thompson, J, Braaten, M, Stroupe, D. (2012). Proposing a core set of instructional practices and tools for teachers of science. Science Education, 96(5), 878 903. https://doi.org/10.1002/sce.21027. 


\title{
History of Education and Contemporary Education: Reflections on Jewish Education
}

\author{
Yehuda Bitty ${ }^{3}$
}

\begin{abstract}
This research paper describes how pedagogical knowledge is constructed sharing the paradigm from the history of Jewish education. We discuss examples shared with my students during my lectures and where I try to build their own identity as future teachers.
\end{abstract}

Keywords: pedagogical knowledge construction, sharing paradigm

\section{Introduction}

It seems that the discipline of "the history of education" has no chance; it has no "home". Historians see it as a subject in the science of education, while education specialists see it as a category in the field of history. Even if some scholars are studying the history of education, who is really interested in their research and who is interested in this field?

John S. Brubacher (1947) answers: "professional students of education will have an interest in the history of their profession because it illuminates the contemporary problems with which they have to deal". This paper aims to report on the evaluation of a course on the history of Jewish education that I taught for several years as part of the master's studies tract, at a Teacher's College, in Jerusalem, Israel: Herzog Academic College.

Twenty teachers - men and women - participate each year in this course. They are general teachers in elementary schools or teach various subjects in high schools. Most of them have no previous knowledge in the field of history - let alone the history of Jewish education - other than what they learned while they themselves were in school.

Each week during the course, they analyze a historical source that reveals an aspect of the history of Jewish education: from the Jewish communities of medieval Christian Europe to pre-modern North Africa, and from the Jewish school of the Italian Renaissance to the eighteenth century Jewish ghetto in Lublin. Using these historical sources, the students discover that the old and distant narrative is actually quite close to the reality that they face in their classrooms: the same dilemmas, the same difficulties and sometimes ... even the same educational solutions. Exposure to the history of Jewish education becomes an empowering experience and strengthens their professional identity as teachers (Cochran-Smith, 2003).

${ }^{3}$ Senior Lecturer, Dept. of Jewish Education, Herzog Academic College, Jerusalem, Israel, e-mail: yehudab@herzog.ac.il 
To illustrate this argument, I will present two historical sources that we study in this course. The first one, written 1,500 years ago, describes the transition from familial education to institutional education in Ancient Israel. The second one is an image of a class in a Jewish school in Lithuania, at the end of the 19th century.

\section{Towards Formal Education}

In the Talmud Babli, the central text of Rabbinic Judaism and the primary source of Jewish religious law and Jewish theology, we can read this interesting testimony about the establishment of schools in Ancient Israel:

(1) "If not for Joshua ben Gamla, may his memory be blessed, the Torah would have been forgotten by Israel.

(2) Originally, children who had a father - their father taught them the Torah, but orphans did not study.

(3) The Sages then instituted that the teachers of Jerusalem taught the children, but that was still not enough: children who had a father - their father would take them to Jerusalem, but orphans - were not brought and did not study.

(4) Finally, Joshua ben Gamla instituted that teachers in all cities will teach all children".

According to this historical source, the original framework of education is the family (Ebner 1956). Teaching Judaism to the new generation is one of the parents' duties, in each family and not only in rich families, as was customary in Ancient Greece, for example. Not a cultural duty or a civil duty but a religious duty. The creation of schools "for all children", as we have today, is due to the fact that the family model "does not work": "orphans - did not study". At this point, the society takes over and organizes an educational system that also includes "children who had a father", to continue the basic duty of education for all the children and perhaps also to improve it by having professional teachers in place of fathers...

According to the curriculum potential theory (Ben-Peretz 1990), what is the curriculum potential of this historical source when we study it with young teachers interested in the current educational system and not that of 2000 years ago? This is an opportunity to develop a discussion on the role of parents in the modern education system: what kind of cooperation do we expect from them? Only to bring their children to school - as the laws of Western civilization specify - or actively participate in the educational process? Additionally, is it important for the teacher to be in contact with both parents of the child or only one of them? Which of them? The father? The mother? And what does a child who is studying with his parents feel? How does this activity affect the parent/child relationship? What does the parent think of his own parental responsibility?

These are some of the issues that occupy us after studying this historical document.

\section{Tradition and Modernity}

At the end of the 19th century, most of the Jewish children in Europe were schooled. In France, England, Italy and Germany - where the emancipatory process moved quickly, most of most of the Jewish children studied in state schools, alongside their non-Jewish fellow students. However, in Eastern Europe - where the emancipatory process evolved slowly, many are the children continued studying in the Heder, the traditional elementary school in these countries, teaching the basics of Judaism and the Hebrew language (Katz 1987).

Usually only boys attended classes at the age of five. After learning to read Hebrew, they 
immediately began studying the Torah. They generally began to learn Mishnah around the age of seven and the Talmud as soon as they mastered the Mishnah. Repeating and learning the holy texts by heart were the main technics used by the teacher, known as Melamed. The age of 13 or 14 would mark the end of a Heder boy's education.

At the traditional "Heder", the classes took place in one of the local synagogue rooms ("Heder", literally "room") or even at the teacher's house. According to periods and regions, the teacher's salary was paid by the Jewish community or directly by children's parents.

Contrary to the position of the Rabbi, which was very respectable because of his high level of Torah learning, the social condition of the Melamed was at the bottom of the economic scale, in part becauseof the large competition: everybody could work as a Melamed (Stamfer 1988). If you know how to read, you can teach reading, without professional training, without particular tools. The Siddur - the daily prayer book - was the only textbook that you needed...

Most of the Maskilim (Jewish Enlightenment leaders) who studied in the Heder harshly criticized this type of educational institution and they participated - or encouraged - in the establishment of modern Jewish schools where secular as well religious subjects were taught: geography, history, arithmetic, German grammar and Russian language. They also denigrated the absence of suitable conditions for learning (dirty location, unsuitable furniture, unventilated space) and the fact that teachers lacked any pedagogical training and sometimes used physical violence instead of a didactic approach. In 1840, there were four modern Jewish schools in all of Russia (in Riga, Odessa, Kishinev and Uman) and the russification politicians viewed them as the main model for all Jewish communities.

However, for most of the Jewish population in Eastern Europe, this educational initiative was too radical. Jewish historiography typically views the emancipatory process as a slow, gradual and continuous transition from communal life in a traditional Jewish society, to a new life in a modern non-Jewish one. Throughout the 19th century, Eastern European Jewry found itself in a complex reality in which a spirit of modernity entered Jewish communities that still adhered to the values of past tradition, especially in the field of education.

In this historical and sociological context, the emergence of a new educational framework, nicknamed "the revised Heder" is very interesting and not so well known, because it has not received much attention in historical research (Halevy 1976, Zipperstein 1983). The founders of the "revised Heder" wanted to create a new concept. On one hand a "Heder", a classroom for children from religious families, where most of the daily study would continue to be traditional learning, and on the other hand, a "revised" classroom, where instruction is based on modern pedagogic principles about teaching and learning.

This is the vision of the "revised Heder". However, in practice, how did it look? More like a Heder or more similar to a modern school? The information about the "revised Heder" that historians have is primarily based on polemical literature and fragments of memoirs. It is clear that these sources are subjective, reflecting an ideological context and they do not correctly translate the reality, even if they have a historical core.

Another interesting kind of historical source is a corpus of more than one hundred textbooks, which were used in this kind of school. Teaching by using textbooks specially written for children was an innovation in the world of Jewish traditional education. Browsing through these books allows you to be impressed by the general atmosphere of the class and to imagine teachers, pupils, benches, 
tables, etc. Some of them even include illustrations of children's daily life, such as home utensils, clothes, animals and toys.

\section{Pedagogy as a Self- Professional Experience}

Abraham Baruch Temkin was a modern teacher in Vilna at the end of the $19^{\text {th }}$ century and he wrote several textbooks based on his professional experience. In one of his books - called Ha-torah Vehasafa (the Torah and the Language) - Temkin intended to teach both Biblical texts and Hebrew language - and by the way Russian language too - to Yiddish-speaking Jewish children. This is not the regular curriculum of the traditional Heder! This textbook is intended to the "revised Heder", as we can see on the illustration that appears on the inside title page of the book.

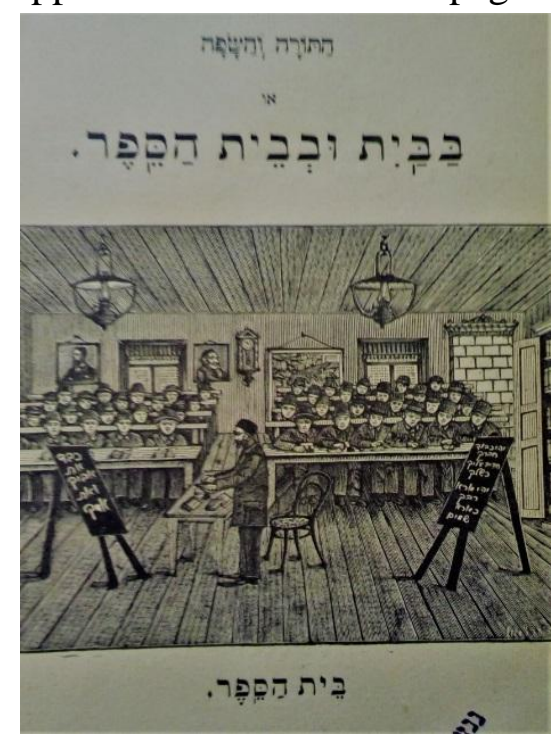

This classroom is a real modern classroom: with a large, clean and tidy room, with windows that can be opened, with oil lamps to light when it's dark and with a big wood stove for cold winter days. Pupils wear uniforms, they sit on benches and their books and notebooks are laying on school desks. The teacher has a special chair, he writes on the blackboard, and books arranged orderly in the bookcase. Of course, he's the only one who can look at the clock hanging on the wall behind the students and know when he should finish the lesson...

However, something is disturbing in the organization of this class: the teacher is not facing the pupils. Similarly, another curious detail requires our attention: there are two blackboards in this class - and not only one, as we use today. Why? It seems that this class is actually divided into two groups. On our left, these pupils are looking at the teacher who's teaching them, and only them. During this time, the pupils from the second group had a writing assignment: their hands are on the desk and not under the desk, like the first group. This is the reason why there are two blackboards in this classroom: two boards for two different groups in the same class. Even today, separating the class into distinct groups is a technic recommended for teachers who teach a class with many students or a multilevel class (Snow 1995). The difference between then and today is, that today, teachers apply what they learned during pre-service training, compared to those days - when the teacher came to this insight himself, based on his own professional experience or on his colleagues' professional experience that they shared with him (Shulman 2007).

But every teacher who tried this technic knows that in practice it does not work very well ...pupils who are supposed to write the exercise listen to the second group's lesson and cannot always focus 
on their task. What is the solution that the teacher in the picture found for this difficulty? Looking at the two blackboards in the picture: there are two different sentences, one is short (only 5 words), and the other one is longer. The shorter one is a verse from the Bible (Honor your father and your mother, Exodus, 20, 12), the second one is a quote from an ethical tractate of Oral Law (Let the honor of the other be as dear to you as your own, and the reverence for your master as the reverence for Heaven, Avot, 2,10). Two different sentences from two different sources but around the same main idea and the same keyword: honor and respect. The solution that the teacher in the picture found to help his pupils focus on their task is to teach two subjects that are close to one another - despite the different levels of knowledge - and not to teach two different subjects. Thus, the pupil writing does not hear something completely different but words and ideas from the same vocabulary and the same semantic field. This solution is not a piece of pedagogical knowledge learned in a course in pedagogy or in a book on education and teaching. This solution is indicative of a pedagogical sense and of the teacher's ability to understand the difficulty of his students and to find a creative and useful solution. Teachers at the "revised Heder" did not learn pedagogy but they knew what pedagogy is.

However, what is, in fact, the topic of this lesson? Bible? Not exactly: half of the pupils are not studying Bible. Oral law? Not really: half of the pupils are studying Bible! The title of this lesson his "Honor and respect": Respect parents, respect teachers, respect everyone! Honor and respect as moral and social values. In fact, the subject of this lesson is values as the basis of an ethical society. But, honor and respect are a Jewish value or an universal value? The "revised Heder"'s answer is clear: even universal values are learned from the sources of Judaism. Judaism has a special way to approach universal values. When the illustrator decided to share with us the special atmosphere of this educative framework, he thought what to write on the board. He could have written "In the beginning Godcreated the heaven and the earth" (the first and famous sentence in the Bible, Genesis, 1,1) - to accentuate the traditional nature of the "revised Heder" or he could prefer an arithmetic exercise to prove the modern orientation of this framework. Nevertheless, he chose another option that expresses the special combination that symbolizes the essential character of this new educational initiative. This kind of image is not a naïve illustration: it should be seen as an ideological statement in which each component is well-planned.

\section{Conclusion}

For young Israeli teachers, pedagogical knowledge, self-learning experience, modern identity and tradition values are contemporary education issues. Both of these examples clearly illustrate the challenges of Jewish education today.

According to Fox (2005), the primary purpose of Jewish education is not only to continue the existence of the Jewish people, but also to give meaningful content to the Jewish identity. This content is derived from the textual sources of Jewish culture but at the same time has meaning that is relevant to people living in modern society and identifying with the values of this society. Fox often built his own teaching and educational analysis around Joseph Schwab's "four commonplaces," the key elements that obtain in any educational situation: the teacher, the learner, the subject matter and the "milieu" (Schwab, 1978). Of the four commonplaces, Fox himself acknowledged that the milieu was the least explained and most in need of conceptual development. For him, the "milieu" is the social and cultural environment where the didactic triangle is played out: the teacher, the learner, the material. The milieu influences the interpretation of the text, thus 
distancing itself from its historical significance. If this deviation is negative in the eyes of the historian, it is necessary to the pedagogical approach of the educator.

The study of the historical sources of Jewish education among Israeli teachers must therefore take into consideration the particular "milieu" and its role as cultural agent: in one side - professional identity development and in the second side - Jewish identity definition in a modern world. The two examples presented in this short article illustrate the "translation" needed to carry out this educational challenge. In the words of Jonathan Cohen (2008): "Translating from principles deriving from the tradition of Jewish thought to educational thought and practice is a most complex matter".

\section{Bibliography}

Beijaard D., N. Verloop \& J. D. Vermunt (2000). Teachers' Perceptions of Professional Identity: An Exploratory Study from a Personal Knowledge Perspective. In Teaching and Teacher Education, 16 (pp. 749-764).

Ben-Peretz M. (1990). Research on Teacher Education in Israel: Topics, Methods and Findings. In M. F. Wideen \& R. Tisher (Eds.), Research in Teacher Education: International Perspectives (pp 207-225). London: Falmer Press.

Ben-Peretz M. (1990). The Teacher-Curriculum Encounter: Freeing Teachers from the Tyranny of Texts, Curriculum Issues and Inquiries. Albany: State University of New York Press.

Brubacher J. S. (1947). A History of the Problems of Education (pp. 12). New-York: McGraw-Hill Book Company.

Cochran-Smith M. (2003). Learning and Unlearning: The Education of Teacher Educators. In Teaching and Teacher Education, 19 (pp. 5-28).

Cohen, J. (2008). Introduction. In J. Cohen \& E. Holzer (Eds.), Modes of Educational Translation (pp. 10-18). Jerusalem: The Hebrew University Magnes Press.

Ebner E. (1956). Elementary Education in Ancient Israel. New York: Bloch Pub. Co.

Katz J. (1987). Toward Modernity. New Brunswick: Transaction Books.

Schwab, J. J. (1978). The practical 3: Translation into curriculum. In I. Westbury \& N. J. Wilkof (Eds.), Science, Curriculum, and Liberal Education (pp. 365-383). Chicago: University of Chicago Press.

Shulman L. (2007). Practical Wisdom in the Service of Professional Practice. In Educational Researcher, 36 (9), (pp.560-563).

Snow R. E. (1995). Individual Differences and Instruction. In T. Husen 8: T. N. Postlethwaite (Eds.), The International Encyclopedia of Education (2nd Ed., Vol 5, pp. 2759-2769). Oxford: Pergamon.

Stampfer S. (1988). Heder Study, Knowledge of Torah, and the Maintenance of Social Stratification in Traditional Est European Jewish Society. In Studies in Jewish Education, 3 (pp. 271-289). 


\title{
Facilitating and Improving Speaking Accuracy through Self-correction and Self- awareness in TOEFL Independent Speaking Tasks
}

\author{
Davood Souri $^{4}$ \\ Ali Merç ${ }^{5}$
}

\begin{abstract}
Assessing the speaking skills of language learners has always been in the agenda considering the fact that speaking correspondingly involves comprehension, and interaction is almost impossible without comprehension in the target language. During the independent speaking tasks of the TOEFL-IBT test, candidates often make grammar mistakes, and since they have limited time for self-correction, they cannot answer the questions fully, and eventually they run out of time finishing the task completely. These mistakes directly affect candidates' speaking negatively, and they often seek ways to make fewer mistakes so that they can focus more on supporting their ideas and fluency. The purpose of this study is to find out if a TOEFL test candidate is likely to use the target language more efficiently in the successive and subsequent trials based on self-correction and selfawareness of errors. For this purpose, a Turkish learner of English preparing to take TOEFL-IBT test in a private English language school was assessed on an 8-step speaking test trial for the 14 speaking questions for the independent speaking tasks of the TOEFL-IBT test. After each trial, the participant's reflections were analysed through coding under three themes: lexis, elaboration, and structure. The results of this study indicated that, through awareness raising and self-correction, the participant's speaking skills improved in terms of vocabulary range, elaboration, using discourse linkers based on the raters' judgments, however, there was no noticeable improvement regarding sentence structure. The participant also reported that self-correction was an effective way to remember the errors and considered the raters' feedback useful in becoming more aware of certain areas. The interview results revealed that the learner preferred discovery learning rather than rote.
\end{abstract}

Keywords: speaking accuracy, self-correction, self-awareness, TOEFL IBT testing

\section{Introduction}

Interaction and production are the two indispensable components of speaking skills in a foreign language. Considering the fact that speaking involves comprehension, interaction is almost impossible without comprehension in the target language. According to Rivers (1984), adults spend 25 to 30 percent of communication through an oral production of language. Therefore, assessing the speaking skills of language learners has always been in the agenda. Most speaking tests known worldwide such as IELTS and FCE are of interactive forms. To illustrate, the examiner asks some questions and the examinee answers them, and then the language produced by the examinee is analyzed based on specific rubrics of the test and then scored. However, when it comes to the TOEFL-IBT independent speaking section, this interaction is absent. In other words, the specific feature that makes the TOEFL-IBT speaking test different from other international tests such as

\footnotetext{
${ }^{4}$ PhD Candidate, Anadolu University, Turkey, e-mail: dsouri53@gmail.com

${ }^{5}$ Assoc. Prof. Dr., Anadolu University, Turkey, e-mail: amerc@anadolu.edu.tr
} 
IELTS is that candidates do not speak to a real person, instead they speak to a computer and their voices are recorded for future scoring. This lack of real life interaction makes the speaking test a challenge for test takers, and the limited time given to candidates to prepare their answers makes them stressed which eventually may negatively affect their fluency and accuracy.

In the TOEFL-IBT speaking section, there are six tasks: two independent and four integrated ones. The first task is a personal preference task on a familiar topic, and the second one is a personal choice task. For each one, the candidates will hear the speaking task, and they can also see the question, then they need to provide reasons and support their answers. In the second task, candidates are given two choices, and they are required to choose one and give reasons to support their ideas. For each task, they only have 15 seconds to prepare their answers and 45 seconds to speak. Candidates' answers are recorded for future analysis and scoring.

Tasks 3 to 6 are integrated speaking tasks. In task 3, candidates must read a short passage, then they must listen to a conversation on a campus issue, and finally, they must speak based on what they have read and heard and summarize the speakers' opinions on the campus situation in 60 seconds. In task 4, candidates must read a passage on an academic topic, then they must listen to a lecture, and finally, they must speak based on what they have read and heard in 60 seconds. In task 5, candidates only listen to a conversation, there is no reading passage in task 5, on a campus issue and then they must speak about the problem and the solutions mentioned in the conversation and at times explain which solution they think is the best in 60 seconds. In task 6 , candidates only listen to a lecture on an academic topic, there is no reading passage, and they must summarize and mention the key point of the lecture in 60 seconds. Candidates are given 30 seconds to prepare their response for tasks 3 and 4 and 20 seconds for tasks 5 and 6.

For scoring the speaking section in the TOEFL-IBT, raters score the candidates responses on a 0 to 4 scale. Raters will be looking for three main categories while scoring candidates' responses. The first category is related to fluency and phonology. Raters look for how fluent and clear the candidates' responses are. In this part, raters take clear and acceptable pronunciation, intonation as well as natural pace into account. The second category revolves around the structure and lexis of English language, and the third category is mainly about pragmatics. The raters look for how fully the candidate's response is, in other words, how clearly he/she has expressed and connected his ideas in a way that is easy to follow. The following paragraphs discuss the main issues regarding speaking skills namely assessing speaking skills, error correction and metacognition.

\section{Assessing speaking skills}

Assessing speaking skills has always been a controversial and complex issue among English teachers and test raters since there are no clear-cut rubrics for speaking assessment, and EFL learners have idiosyncratic characteristics, and when it comes to computer based language testing it becomes more complicated. Brown (2001) states that it is not simple and easy to determine valid, reliable, and practical methods to assess oral proficiency traits. It should also be noted that the speaking raters' internal consistency and reliability make speaking assessment more complicated. Brown (2001) believes that a good testing oral proficiency should have four main characteristics. First, it should be a live performance rather than a recorded one. Second, the test-taker relationship should be of one-on-one. Third, a careful specification of the task should be accomplished during 
the test, and fourth, a descriptive scoring rubric should be provided. There are several components such as grammar, vocabulary, pronunciation, intonation, fluency, and appropriateness of the language, to be taken into account in speaking tests and such components make assessment extremely complicated since there are strong disagreements among ELT teachers and test raters on how to evaluate and assess the mentioned components. Madsen (1985) claims that many teachers are not sure what criteria to select to assess oral communication and at times they even do not try to evaluate their students' speaking skills. There is another area of controversy in terms of assessing English language learners 'speaking proficiency. Some claim that there are differences in terms of rating learners' speaking proficiency between raters who are native speakers of English and nonnative speakers of English; however, studies show similarities and almost no significant difference when it comes to rating learners' speaking proficiency between native and non-native speakers of English. Zhang and Elder's (2014) conducted a research in which they explored the judgments of native and non-native English speaking teachers on oral proficiency based on the College English Test-Spoken English Test. The results of their study showed that although both native and nonnative English speaking teachers differed in terms of their approaches to rating, they were similar when it came to overall rating of both groups. Ekmekçi (2016) also conducted a similar research comparing native and non-native English language teachers' judgments on oral proficiency of 80 EFL students attending preparatory classes. The results revealed that raters had high inter-rater reliability coefficients and there was no statistically significant difference in overall scores given by the two groups of raters.

\section{Error correction}

Making errors is an indispensable part of a learner's learning process and correction of such errors by teachers is a very complicated issue since there are disagreements among teachers on how errors and when errors should be treated. Some teachers as well as teacher trainers believe that teachers should only correct their students' errors when they cannot correct themselves. However, language learners expect their teachers to correct their errors that is why error correction is still a controversial issue. In a research conducted by Makino (1993) on 62 EFL students, he tried to find out whether teacher hints could help their students correct their own errors made in their written compositions. The results revealed that students' linguistic competence was activated by the cues given to them by their teacher to correct their own mistakes. Another important issue regarding error correction amongst English teachers is that their students sometimes avoid structures which they are uncertain of, so English teachers are not fully aware of their students' errors which in turn makes error correction a complicated issue. Chaudron (1977) came up with a new term which he defined as "corrective feedback" which laid emphasis on teachers' reactions to errors students make. He believed that due to the reaction of teachers on learners' errors, they tended to transform and improve their utterances. Based on the feedback learners receive, they tend to respond differently. Corrective feedback is of different types such as explicit correction, recasts, elicitation, and repetition of error, clarification, and metalinguistic feedback. Some educators such as Truscott (1996) believe that oral correction of grammar mistakes interferes with meaning making; on the contrary, some other educators such as Ming-chu and Hung- chun (2009) claim that learners whose grammar mistakes are corrected orally are less likely to make the same mistakes in real life. It should be noted that students and teachers' opinions on error correction vary considerably, and 
when both teachers and students' expectations move towards the same point, teachers are more likely to guide their students to successful language learning. If their expectations diverge, it may end up with dissatisfaction (MacIntyre \& Gardner, 1994). One of the most important issues regarding error correction is the time at which correction is provided. The literature classifies error correction in two broad categories: immediate and delayed feedback. Behavioristic psychologists such as Skinner strongly supported immediate feedback. In behavioristic view, error correction is considered as a reinforcement for correct responses. However, some other scholars and linguistics strongly disagree with immediate error correction. They claim that errors if corrected later, can be better recalled and retained. According to Lemley (2005) instant error correction interferes with learners' abilities to better understand the correct answer. If learners' errors are corrected later, learners will have enough time to forget the initial incorrect responses and will be able to replace the correct ones with the incorrect ones. However, Hendrickson (1978) believes that one cannot say what time is the most appropriate and the best time for error correction. According to a research conducted by Farahani and Salajegheh (2015) 460 English teachers and EFL students completed Fukuda's (2004) questionnaire on error correction. The results revealed that teachers preferred immediate error correction while the students had a strong preference for delayed one.

\section{Metacognition and awareness raising}

When it comes to speaking, the important role of metacognition becomes more obvious. Canale and Swain (1980) in their communicative competence framework claim that there are certain abilities through which one can achieve speaking proficiency. These abilities include grammatical competence (morphology, semantics, syntax, and phonology), discourse competence (sociocultural rules and discourse), and strategic competence (verbal and non-verbal communication strategies). The grammatical and strategic competence types are directly related to metacognition. Flavell (1979) was the first person who presented a formal model of metacognition. He defined metacognition as someone's knowledge which concerns his/her cognitive processes and products. Wenden (2001) related metacognition to long term memory which contains learners' awareness and knowledge about the process of learning. Regarding speaking skills, the steps EFL learners take and the decisions they make directly affect their speaking. This lays emphasis on the fact that the more learners are aware of learning the better decisions they may make in speaking. Vandergrift (1999) believes metacognitive strategies which include planning, monitoring and evaluating help learners to regulate and direct their learning process. It should be noted that metacognition falls into two main categories which should not be regarded as similar ones. The first category is metacognitive knowledge. According to Brown et al. (1983), this category is related to information which is acquired by learners about their learning. However, the second category, the metacognitive strategies, refers to general skills through which learners plan, monitor, and evaluate their learning. It is wise to say that without awareness and knowledge, learners cannot come up with efficient and effective strategies. Ellis and Sinclair (1989) also claim that learners' awareness of their language learning process helps them acquire learning strategies. Dormer (2013) divides awareness into two main categories: motivation and input. According to this categorization, there are three subcategories for each main category. For the motivation category, first, learners should be aware of their language deficiencies, then they should be made aware of the significance of such deficiencies and finally, they should come to this conclusion that change is possible. For the input category, 
initially, learners should be aware of the structures and meaning connections, then they need to find out their personal needs in the use of language and why they are using the language and finally, they need to be made aware of details in receptive language.

\section{Statement of the problem and the research question}

During the independent speaking tasks of the TOEFL-IBT test, candidates often make grammar mistakes, and since they have limited time for self-correction, they cannot answer the questions fully, and eventually they run out of time to finish the task completely. One of the main concerns of the learners preparing for the test is the grammar mistakes that make them anxious, directly disaffecting their speaking performance. They, then, often seek ways to make less mistakes so that they can focus more on supporting their ideas and fluency. Hendrickson (1978) believes that error correction can help EFL/ESL students improve their proficiency level. He further points out that only those errors which are made frequently and the ones which stigmatize English learners as well as inhibit communication should be corrected. Considering the related literature, the following research question was formed:

Is a TOEFL test candidate likely to use the target language more correctly in the successive and subsequent trials based on his self-correction and self-awareness of the errors?

\section{Methodology}

The research design: The present study was designed in the form of an action research as this type of a design looks for an organized route followed by educational practitioners to collect evidence about and afterwards develop their teaching and their students' learning (Mills, 2000). As Creswell (2012) points out, this research study aims to address a specific and real problem within the teaching/learning context specified in the present inquiry and to examine the actual practices of the researchers. The following sections describe the methods used in the present investigation. 2.2.

The participant: The subject of this study was a male Turkish learner of English (27 years old) preparing to take TOEFL-IBT test in a private English language school in Istanbul. He had completed his upper-intermediate level in the same school, and he was highly motivated to take a high score in the test. Gaining university admission for master's degree and improving his career were the two main reasons why he had decided to take the test. The school had given permission to the author of this paper to conduct the research.

Data collection and instruments: The present study made use of a qualitative design. The reason for this study was to evaluate the extent to which the test taker's self-correction and self-awareness of his errors would affect the improvement and development of his speaking skills in preparation for the TOEFL-IBT independent speaking tasks. The instruments used in this study included 14 speaking questions for the independent speaking tasks of the TOEFL-IBT test. The first question in each task was a personal preference question on a familiar topic, and the second question was a personal choice one. For each question, the participant heard the speaking task and at the same time, he could also see the question. Then he had 15 seconds to prepare his response and 45 seconds to speak. It should be noted that Cambridge Preparation for the TOEFL Test book provides a CD on which there are seven complete mock tests. The speaking questions were all from the CD. The following steps were taken each time the participant spoke on the task for seven consecutive weeks. 
Step 1: The test taker heard and saw the first independent speaking question of the TOEFL-IBT test on the computer monitor, then he prepared his response within actual time limit (15 seconds for preparation and 45 seconds to speak) and then he spoke. After that, he heard and read the second independent speaking question and did the same process. His speaking was recorded for both questions.

Step 2: The researcher sent the recorded speaking tasks file as an attachment to the participant's e-mail right after the speaking part was over.

Step 3: The participant corrected his mistakes at home later and emailed the actual transcribed speaking and its correction as an attachment to the researcher.

Step 4: Two native speakers of English (one American and one New Zealander) rated the test taker's speaking based on the TOEFL-IBT speaking rubrics and then gave him a score between 0 and 4. They both listened to the learner's speaking recording twice each time.

Step 5: Before each trial, the researcher provided feedback and helped the participant correct his errors if and only if he had not noticed his errors. Long (1977) draws a distinction between error correction and error feedback. He believes teachers' feedback is error detection rather than error correction which eventually promotes correction, and it is not correction in itself. The participant was also asked to read the rater's comments on his speaking parts. In this step, the researchers explained some terms written by the raters such as elaboration, compound, complex structures, and intelligibility. The researcher also tried to help the student add additional grammatical points such as, linkers and conjunctions, based on the raters' comments, through eliciting and awareness raising rather than direct instruction.

Step 6: The participant was asked to write his reflection on each trial.

Step 7: These steps were repeated seven times; however, each time the student spoke about new questions.

Step 8: The researcher compared the raters' scores through the whole process to find out to what extent self-correction and self-awareness of the student had helped the participant improve his speaking for the TOEFL-IBT test in the end.

\section{Data analysis procedure}

The qualitative data regarding the participant's reflections were organized by the researcher initially and later were analyzed through coding. By the use of the codes, the researcher identified three themes in the participant's reflections namely lexis, elaboration, and structure. Under the lexis theme, there was only one subtheme, namely limited range of vocabulary. However, under the elaboration theme, there were two subthemes as examples and linkers. The third theme was sentence structure with repetition of the same structure and using simple structures as subthemes.

\section{Findings}

The participant's reflections: The following themes were identified and labelled based on the participant's reflections.

Lexis: The participant mentioned in his reflections that he needed more vocabulary for the task.

I couldn't use phrase and enough vocabulary.

I should be relaxed and think of more different examples and words.

According to Harris (1974) speaking as a complex skill requires five important components one of which is vocabulary. He believes these five components are used simultaneously which makes 
speaking a challenging skill to master. The researcher helped the participant be more aware of using examples to support his ideas through eliciting. He asked "Is it enough just to answer the question?" and when the answer was 'No', the researcher asked the participant how he would support his idea/s. At this point the participant mentioned that he could support his ideas by using examples. Although the participant may have used examples to support his ideas in the past, he was not aware of the importance of examples and how using examples could help him use better vocabulary while answering the question. Moreover, the researcher asked the participant if repeating the words would help him use a wide range of vocabulary. This question made the participant more aware of the fact that he needed a wide range of new vocabulary rather than repeating the same words. This awareness became more apparent in his further reflections which the researcher labelled it repetition as a new theme.

Elaboration: The participant mentioned several times in his reflections that he needed to elaborate his speaking more through using examples and discourse linkers.

Examples:

I am not able to elaborate my speech and give more examples.

I didn't give more examples and it was the reason I did not elaborate my speech.

I should be relaxed and think of more different examples and words.

I need to give more examples and make myself clearer.

Linkers:

I don't use linkers when I speak.

I also need to practice on linking words.

In 5th trail I am able to use different linkers.

In the 6th trial I have some irrelevant linkers.

My linker should cause elaboration of text.

In the last trial, I wrote down some linkers and while I was speaking, I could use them.

The raters' feedback helped the participant be more aware of the lack of discourse linkers and examples in his speaking to better elaborate on his reasons.

Sentence Structure: The participant mentioned that he repeated himself in terms of both vocabulary and grammar as follows:

Also, I repeated myself. I used the same sentences.

I am repeating my words.

I repeated the modal should frequently

\section{Analysis of the trials}

Through a detailed analysis of all the seven trials, three themes were identified: vocabulary range, cohesive devices, structure.

The consistency of the raters' scores: The table below provides a clearer visual comparison between the two raters' scores. As can be clearly seen, it shows the scores given by the raters after each speaking trial. For similar scores the researcher gave 1 and for the different one 0 . Then the total number of similar scores (6) was divided by the total number of trials (7) to find out how consistent the raters' scores were. 6/7: 0.85 . 
Table 1. Scores given by the raters after each speaking trial

\begin{tabular}{|c|c|c|c|c|c|c|c|}
\hline & $\begin{array}{c}\text { Trial } \\
1\end{array}$ & Trial 2 & Trial 3 & Trial 4 & Trial 5 & Trial 6 & Trial 7 \\
\hline First rater & $2 / 4$ & $2 / 4$ & $3 / 4$ & $3 / 4$ & $3 / 4$ & $3 / 4$ & $3 / 4$ \\
\hline Second rater & $2 / 4$ & $2 / 4$ & $2 / 4$ & $3 / 4$ & $3 / 4$ & $3 / 4$ & $3 / 4$ \\
\hline $\begin{array}{c}\text { Similar: 1 } \\
\text { Different: 0 }\end{array}$ & 1 & 1 & 0 & 1 & 1 & 1 & 1 \\
\hline $\begin{array}{c}\text { Raters' } \\
\text { consistency }\end{array}$ & 0.85 & & & & & & \\
\hline
\end{tabular}

Comparing and contrasting raters' comments: By comparing the raters' comments, and taking the number of vocabulary and discourse linkers, and complexity of sentence structures used by the participant's through the seven trials, it can be claimed that the participant improved in his speaking skill in terms of discourse linkers, lexis, and organization. The tables below indicate the participant's progress through the seven speaking trials. In order to show the participant's progress more clearly, the first and the seventh trials are presented here to make a direct comparison (Table 2). It should be mentioned that the first trial was regarded as the baseline data for comparison of subsequently acquired data.

Table 2. The raters' comments on the first trial

\begin{tabular}{|c|c|}
\hline First rater $2 / 4$ & Second rater $2 / 4$ \\
\hline - $\quad$ Basic Grammar (limited control on & - $\quad$ Basic structure \\
\hline Grammar) & - $\quad$ Simple lexis \\
\hline - $\quad$ Using Chunks & - $\quad$ Lack of linkers \\
\hline Simple vocabulary & It was intelligible \\
\hline Limited elaboration & It was on/off the task \\
\hline
\end{tabular}

The raters' comments on the seventh trial

\begin{tabular}{|l|ll|}
\hline \multicolumn{1}{|c|}{ First rater 3/4 } & Second rater 3/4 \\
\hline - Speech is generally clear & $\bullet$ & More organized \\
- $\begin{array}{l}\text { Fairly effective use of grammar and } \\
\text { vocabulary, and fairly coherent }\end{array}$ & $\bullet$ & Using more linkers \\
\hline
\end{tabular}


Volume 1, Issue 2, December 2019 Journal of Education, Innovation, and Communication (JEICOM)

\begin{tabular}{|l|ll|}
\hline expression of relevant ideas & $\bullet$ & Speech is intelligible \\
- Relationships between ideas may at & $\bullet$ & Good use of vocabulary \\
times not be immediately clear. & & \\
- It is organized & & \\
\hline
\end{tabular}

Across the seven trials, only on the third trial, the co-raters' score did not match. The second rater believed that the participant did not elaborate well in the second part of the speaking and the answer was rather short, however, the first rater still believed that it deserved $3 / 4$ since it was well-organized, and the participant had used wider vocabulary range. Table 3 shows this mismatch.

Table 3. The raters' comments on the third trial

\begin{tabular}{|c|c|}
\hline First rater $3 / 4$ & Second rater $2 / 4$ \\
\hline $\begin{array}{ll} & \text { Frequent pauses- } \\
\text { - } & \text { Vocabulary+ } \\
\text { - } & \text { Simple structure-only one complex } \\
\text { - } & \text { Bore linkers and cohesive devices+ } \\
\text { - } & \text { Wider vocabulary range }\end{array}$ & $\begin{array}{ll}\text { - } & \text { cohesive devices+ } \\
\text { - } & \text { lexis+ } \\
\text { - } & \text { simple structure-just one complex } \\
\text { - } & \text { short answers } \\
& \text { second part not well-elaborated }\end{array}$ \\
\hline
\end{tabular}

Vocabulary range: In the first trial, mainly basic words were used by the participant, and some of which were repeated. Some examples are as follows:

When I was at high school and primary school I was reading book and always I was not spending my time on technology internet and TV. But now because of technology I spend and I don't read book. And one effect... I can reach more information about everything what I want.

I prefer to have different friends than me. About characteristic ... I don't know when I have different friends I can get some experience from them. While I am spending my time with similar friend always I get bored.

However, the range of vocabulary became wider as the participant got closer to final trial. Also. words were not frequently repeated as in the fifth trial and the seventh, the last, trial:

In my opinion most famous person is Atatürk. He influenced on our country's people for independence and our education and our economy. Because we were in the First World War. We did not have power to fight against anybody and we did not have any literacy people and he made a lot of institutions to give education.

I agree with second statement because every student deserve education it does not matter they are poor or they are best student, intelligent and if they do not get education their children will not have knowledge if best student get best education it will be some kind of class society. 
I agree that in just some way. First young generation they do not have enough communication with each other and their family ties are weak and second they do not have job and they should compete with each other when they do it they feel themselves selfish and it makes them alone It forces them selfish people.

I have taken an English course before in some way it help me so it make me think different way when I talk about something and secondly it separates me from other people and also I can gain more resource about newspaper on internet and other hand I can watch movie without subtitle or dublaj and the main factor in English I can speak with native speaker.

Cohesive devices: Cohesive devices were more limited in the first and second trials, and the participant mainly used coordinating conjunctions most of which were repeated. Below is an example for the repetition of basic conjunctions:

I was reading book and always I was not spending my time on technology internet and TV. But now because of technology I spend and I don't read book. And one effect.... I can reach more information about everything what I want. That's why it is positive effects. But sometimes it affects me negatively

In my opinion, most famous person is Atatürk. He influence on our country's people for independence and our education and our economy. Because we were in the First World War. (The fourth trial)

Also they do not have time to read book. (The fourth trial)

I agree that in just some way. First young generation they do not have enough communication with each other and their family ties are weak and second they do not have job and they should compete with each other when they do it they feel themselves selfish and it makes them alone It forces them selfish people (The seventh trial)

In some way it help me so it make me think different way when I talk about something and secondly it separates me from other people and also I can gain more resource about newspaper on internet and other hand I can watch movie without subtitle (The seventh trial)

Structure: The analyses revealed no noticeable improvement regarding the structures the participant produced during the course of seven weeks. Most of the sentence structures were of simple and compound ones, and when the participant produced complex structures, they were mainly limited to adverbial clauses. In addition, at times, the participant repeated the same structure while trying to support his idea. The following samples are from different trials:

When I was at high school and primary school I was reading book and always I was not spending my time on technology internet and TV. (The first trial)

Sometimes I imagine if I had large money what would I do. (The second trial)

We must analyze technology and information because world is going to forward. (The third trial)

If they do not get education their children will not have knowledge if best student get best education it will be some kind of class society. (The fifth trial) 
Sometimes when I work on hospital some worker comes to doctors and present their medicine. (The sixth trial)

When I talk about something and secondly it separates me from other people. (The seventh trial)

For example they should have general culture and make their students aware of what is going on in world and they should have different hobby they can spend with their students enjoy time. They should know and learn about literature and history they can advise their students.

\section{The interview}

In the last week of the study, the researcher conducted a semi-structured interview to find out more on what the participant thought of the study, and how his ideas and thoughts corresponded with his reflections throughout the study. There were four main questions in the interview revolving around four main topics. The questions were:

\section{Question 1}

First one is.....you know after each speaking task, you transcribed your speaking, and corrected your own errors. Did you find this self-correction useful or not?

\section{Question 2}

How would you compare this Independent speaking task regarding TOEFL-IBT with daily life speaking? Are they similar or different?

Question 3

You know after each trial, I told you about raters' feedback. Did you find the feedback useful?

Question 4

Finally, have you found yourself more aware of the areas you need to improve when it comes to TOEFL-IBT Independent speaking tasks?

Can you give me an example? Can you elaborate which areas do you need to improve?

The answers of the participant to the above questions were analyzed qualitatively. The analysis revealed four main themes based on the participant responses to the questions. These themes are explained below.

Discovery learning: According to constructivists, learners build up new information on the existing information. Through discovery learning, learners discover the relationships between old and new information and through frequency of use these relationships are strengthened. In order to discover a new language feature, learners need to notice the new information through awareness raising or even explicit instruction. When learner's focal attention is drawn to a new feature in language, learning takes place. In this study, guided learning was used to draw the participant's attention on some new linguistic features such as discourse linkers.

Yes I found it very useful because it's better than someone teach you because when you teach yourself, it remains constantly.

According to the participant's response, self-awareness and self-correction of the errors were found to be helping the participant to store the corrected ones in his long term memory.

Comparison and contrast: 
I think it's different because in daily speaking sometimes I speak some foreigners and my friends and if I make correct it's ok because I can correct in same time but in TOEFL must control time and it's fifty seconds and ten seconds and I don't have time to correct in same time, but if I practice always, I'll be able to eeee not make mistakes.

Importance of raters' feedback:

After each trial I made a correction part. I noticed that something I did... I made mistake, I correct myself but when someone else correct, looks over and tell me what's eeee lack of your conversation,

The test taker mentioned that when he was not aware of the areas he needed to improve when it came to speaking and the raters' feedback was of a great assistance.

Metacognition:

I found out my eeeee what I eeee don't good at

I think its elaboration part and make more ,,,,complex sentence because I spoke sometimes with relative clause and the longer sentence and I think I must do that and may be use more different linkers because there is no just like also and that kind of there are more different linker word, I need to use them.

\section{Discussion of the data}

Although this study focused on all categories of scoring the candidate responses in the independent speaking part of the TOEFL-IBT speaking test, more emphasis was laid on the second and third scoring categories namely, structure, lexis as well as pragmatics. It should be noted that EFL teachers helping their students preparing for the TOEFL-IBT test sometimes give them templates to follow or sometimes record their students' speaking and then point out their mistakes, however, TOEFL-IBT test takers tend to repeat their mistakes corrected by their teachers. In this study, the researcher tried to make the test taker become more aware of his own speaking mistakes through the grades and feedback given to him by two raters based on the TOEFL-IBT speaking rubrics as well as his own reflection on his speaking. Carter (2003) defined language awareness as "the development in learners of an enhanced consciousness of and sensitivity to the forms and functions of language" (p. 64).

In other words, metacognitive knowledge and metacognitive strategies play a significant role in improving speaking skills. Flavell (1979) defines metacognition as someone's knowledge which concerns his/her cognitive processes and products. Horwitz (1988) believes that investigation of metacognitive knowledge can be useful, because it helps teachers become more aware of the different types of learners and better understated their needs and expectations, during the teaching process.

The present study aimed to make the participant become aware of both metacognitive strategies and metacognitive knowledge, and how they could both be used concurrently in EFL context. The test taker tried to find out his own errors through self-error correction. The learner then tried to selfmanage his stress and anxiety as well as the time limit. In this stage, the learner became aware of the significance of time and stress management in the TOEFL-IBT independent speaking task. He also did his best not to repeat the mistakes he had made through self-correction and the feedback he received. The test taker also paid more attention to the language he produced in details. He tried to 
be independent of his/her teachers and become more autonomous. To illustrate, the participant mentioned this improvement in his final reflection:

Now I am able to make the test much easier. In the last trial, I wrote down some linkers and while I was speaking, I could use them. Also, I am able to elaborate my speaking. My speaking is not off the topic anymore.

It should be noted that the researcher only guided the test taker to identify the fossilized errors and the ones he was not aware of. According to Selinker (1972), an English psychological linguist, when second language learners tend to retain items, rules and subsystems in their interlanguage while they are in the process of learning a particular target language fossilization occurs. These items, and rules require considerable effort to be eliminated regardless of explanation or instruction. Furthermore, the test taker learnt how to take responsibility when it came to decision making. In fact, he was the only person to make his own choices when it came to answering a question rather than using prefabricated chunks and speaking templates which are generally taught and given to the candidates by teachers in TOEFL preparation classes. In a nutshell, this study was based on the cognitive approach rather than a mechanical and behavioristic one. Halfway through the study, it was noticeable that the participant used more linkers and discourse markers. He had also noticed the importance of discourse linkers in speaking by mentioning several times in his reflections that he needed to use more linkers to better illustrate his reasons.

This study aimed to evaluate the extent to which transcription of speaking tasks, would affect the improvement and development of TOEFL-IBT test takers' speaking skills in terms of accuracy and fluency. In preparation for the independent speaking tasks, the study took into account the learners' self - correction as well as teachers' guidance, and self-awareness of errors made by the student based on raters' feedback. Nobuyoshi and Ellis (1993) stated that the accuracy gained through selfcorrection and self-awareness tended to remain over a longer period. Stones (2012) did a similar study to the present study on IELTS exam test takers. The results revealed that the participants used their own corrections more than corrections done by their teacher; however, this study aimed to focus on independent speaking tasks of TOEFL-IBT, which are completely different from IELTS speaking parts. In IELTS speaking task, the examinees speak to the examiners, however, in TOEFL-IBT speaking tasks, the candidates do not speak to a real person; in contrast, in the first two independent speaking tasks, the candidates read and hear two questions on the computer, and they should answer and support their ideas by giving reasons. According to Thornbury and Slade (2006), speaking is a multi-sensory activity because speaking involves paralinguistic features such as facial expressions, body language, eye contact and pitch variation and so on and so forth, however, some of these features are absent when it comes to TOEFL-IBT independent speaking task. Another difference is that in the IELTS speaking section, test takers are not required to finish their speaking within a very specific time frame (only in section two, the examinees should speak between one to two minutes). The examiner decides when to interrupt the examinee; however, as mentioned above, in the TOEFL-IBT independent speaking parts, candidates have only 15 seconds to prepare their answers and 45 seconds to respond. 


\section{Conclusion}

The researcher of this study investigated whether self-correction and self-awareness could help the participant of the study improve his speaking skills for the TOEFL-IBT speaking section. The results of this study provided evidence that through raising awareness and self-correction the participant's speaking skills improved in terms of vocabulary range, elaboration, using discourse linkers based on the raters' judgments, however, there was no noticeable improvement regarding sentence structure. Taking the raters' comments and scores into account, this study was found to have a positive effect on the participant's speaking skills. Based on the results obtained from the interview, it became clear that the participant became more aware of the areas he needed to improve for the independent speaking tasks. Moreover, the participant found self-correction an effective way to remember and avoid future errors later in his speaking. He also found the raters' feedback useful in that he became more aware of the ways the learner preferred to be instructed, which focused on discovery learning rather than rote.

Awareness raising and getting English language learners on the discovery-learning path can eventually smooth the path towards autonomous learning. Since learners' needs, motivation, and background knowledge are different, English language teachers and instructors, before planning their lessons, should take different ways and techniques leading language learners to discovery learning into account. One of the possible ways to achieve this goal is through reflection. Through reflection, language learners can develop and enhance their grammatical and strategic competence, which will eventually help them become more autonomous in their communicative competence. Another way to get language learners to become more aware of their errors and the areas they need to improve is providing them with feedback. Once, the learners have reflected on their speaking and corrected themselves, it is time for English language teachers to provide them with feedback concerning the learners' correction and the points they have skipped correcting due to their insufficient English language knowledge or lack of enough attention. This, then, should be frequently done by the teachers in follow-up lessons to ensure the learners' improvement based on the given feedback.

Teaching, learning, and assessment are intertwined closely and should be seen as a continuous cycle. Teaching and assessment facilitate learning if teachers and learners make use of the feedback received from the assessment effectively that in turn may result in positive decisions and actions about learning. Since such decisions and actions are conscious ones, learners become more aware of what they are learning which in turn helps them feel more secure and less stressed particularly when it comes to speaking skills. Some teachers assess their learners to see how much they have improved at the end of a course. This kind of assessment focuses on the result, however, some other teachers tend to assess their learners' process of learning. Lantolf and Thorne (2006) called the latter one dynamic assessment. According to the Zone of Proximal Development proposed by Lev Vygotsky, there is a distance between what learners can do independently and without help and what they can do with help and guidance from more capable learners or teachers. Ongoing and dynamic assessment along with feedback assist learners in moving from their actual developmental level to the level of potential development. Assessment and feedback can be viewed as scaffolding in this regard which helps learners achieve goals which would not be achieved without teachers' assistance. Vygotsky (1987) in "Thinking and Speech" laid emphasis on the importance of the ZPD in instructional practices. According to him, instructional practices should be in accordance with students' ZPD rather than the actual level of their development. In this case, learners feel far less stressed during the learning process and Dynamic Assessment and instruction are not independent from one another. Once learning has improved through ongoing assessment, learners start to notice the positive and beneficial effect of assessment in the learning process and their fears and lack of 
confidence in dealing with assessment medium start to fade away. Therefore, constant assessment in the long term would help learners view assessment as facilitating rather than a debilitating medium in learning.

This study has some limitations that may lead to certain issues. Since this action study was limited to only one subject, the result of the study is not obviously generalizable. The other limitation of this study was that the co-raters were from two different countries namely the US and New Zealand in which English is spoken with different variations. This might have influenced the co-raters' judgements. Finally, the participant was not selected based on a proficiency placement test, but rather his English level which he had completed in the language school where this study took place.

\section{References}

Brown, A., Bransford, J.D., Ferraraand, R., \& Campione, J.C. (1983). Learning, remembering and understanding. In J. H. Flavell and E. M. Markman (Eds.), Carmichael s manual of child psychology Volume 1, New York: Wiley.

Brown, H. D. (2001). Teaching by Principles: An interactive approach to language pedagogy. White Plains, NY: Longman.

Canale, M., \& Swain, M. (1980). Theoretical bases of communicative approaches to second language teaching and testing. Applied Linguistics, 1, 1-47.

Carter, R. (2003). Language awareness. ELT Journal, 57(1), 64-65. doi:10.1093/elt/57.1.64

Chaudron, C. (1977). A descriptive model of discourse in the corrective treatment of learners' errors, Language Learning, 27(1), 29-46.

Creswell, J. W. (2012). Educational research: Planning, conducting, and evaluating quantitative and qualitative research (4th ed.). Boston, MA: Pearson.

Dormer, J. E. (2013). Improving speaking. accuracy through awareness. Journal. of Adult Education,42(1), 16-22.

Ekmekçi, E. (2016). Comparison of native and non-native English language teachers' evaluation of EFL learners' speaking skills: Conflicting or identical rating behavior? English Language Teaching, 9(5), 98-105. doi:10.5539/elt.v9n5p98

Ellis, G., \& Sinclair, B. (1989). Learning to learn English: A course in learner training. Cambridge: Cambridge University Press.

Fukuda, Y. (2004). Treatment of spoken errors in Japanese high school oral communication classes (Unpublished Master's thesis). California State University, San Francisco, CA.

Farahani, A. A. \& Salajegheh, S. (2015). Iranian EFL teachers' and learners' perspectives of oral error correction: Does the timeline of correction matter? Latin American Journal of Content and Language Integrated Learning, 8(2), 184-211. doi:10.5294/lacli1.2015.8.2.6

Flavell, J. H. (1979). Metacognition and cognitive monitoring: A new area of cognitivedevelopmental inquiry. American Psychologist, 34, 232-911.

Gilman, R., \& Moody, R. (1984). What practitioners say about listening: Research implications for the classroom. Foreign Language Annals, 17(4), 331-334. doi: 10.1111/j.19449720.1984.tb03236.x

Harris, D. P. (1974). Testing English as a second language. New York, NY: Mc GrawHill Book Company.

Hendrickson, J. (1978). Error correction in foreign language teaching: Recent theory, research, and practice. Modern Language Journal, 62(8), 387-398. doi:10.1111/j.15404781.1978.tb02409.x 
Horwitz, E. K. (1988). The beliefs about language learning of beginning university foreign language students. Modern Language Journal, 72(3), 283-294. doi:10.1111/j.15404781.1988.tb04190.x

Lantolf, J.P., \& Thorne, S. (2006). Sociocultural Theory and the Genesis of Second Language Development. Oxford: Oxford University Press.

Lemley, D. C. (2005). Delayed versus immediate feedback in an independent study high school setting (Unpublished doctoral dissertation). Brigham Young University, Provo, UT.

Long, M. (1977). Teacher feedback on learner error: Mapping cognitions. On TESOL, 77, 278-294.

MacIntyre, P., \& Gardner, R. (1994). The subtle effects of induced anxiety on cognitive processing in the second language. Language Learning, 44, 283-305.

Madsen, H.S. 1983: Techniques in testing. Oxford: Oxford University Press.

Makino, T. Y. (1993). Learner self-correction in EFL written compositions. ELT Journal, 47(4), 337-341.

Mills, G. E. (2000). Action research: A guide for the teacher researcher. Princeton, NJ: PrenticeHall.

Ming-chu, L., \& Hung-chun, W. (2009). Perception differences of EFL teachers and students in grammar instruction and error correction. English Teaching \& Learning, 33(1), 101-146.

Nobuyoshi, J., Ellis, R. (1993). Focused communication tasks and second language acquisition. ELT Journal, 47(3), 203-210. doi: 10.1093/elt/47.3.203

Rivers, W. M. (1984). Communicating naturally in a second language: Theory and practice in language teaching. Cambridge: Cambridge University Press.

Selinker, L. (1972). Interlanguage. IRAL - International Review of Applied Linguistics in Language Teaching, 10(1-4). doi: 10.1515/iral.1972.10.1-4.209

Stones, T. (2012). Transcription and the IELTS speaking test: facilitating development. ELT Journal, 67(1), 20-30. doi: 10.1093/elt/ccs051

Thornbury, S., \& Slade, D. (2006). Conversation: From description to pedagogy. Cambridge, UK: Cambridge University Press.

Truscott, J. (1996). The case against grammar correction in L2 writing classes. Language Learning, 46(2), 327-69.

Vandergrift, L. (1999). Facilitating second language listening comprehension: Acquiring successful strategies. ELT Journal, 53(3). doi:10.1093/elt/53.3.168

Vygotsky, L.S. (1987). Thinking and Speech. In The Collected Works of L. S.

Wenden, A. L. (2001). Meta-cognitive knowledge in SLA: The neglected variable. In M. P Breen (Ed.), Learner contributions to language learning: New directions in research (pp. 45). Harlow, Essex, United Kingdom: Pearson.

Zhang, Y., \& Elder, C. (2014). Investigating native and non-native English-speaking teacher raters' judgements of oral proficiency in the College English Test-Spoken English Test (CETSET). Assessment in Education: Principles, Policy \& Practice, 21(3), 306-325. doi:10.1080/0969594X.2013.845547 


\title{
Integrated Social Media into Mobile-Assisted Foreign Language Learning
}

\author{
Ling Luo ${ }^{6}$
}

\begin{abstract}
In today's college campuses, having a smartphone and being active on social media has become a fashion. Though many mobile apps have been designed for learning languages, there are few studies on applying social media based mobile apps to promote the effective learning of foreign languages. As an emerging social media mobile app, WeChat is the most popular social tool in Chinese community around the world. The WeChat app has many communication functions: live chat, group chat, and multimedia input and document transmission, which are essential for language learning. In this research project, we integrate WeChat into a mobile-assisted Mandarin learning app that we have designed. WeChat and the mobile app allow effective communication among instructors and students, and student groups. It offers a variety of communication methods, including voice, text, graphic (abundant icons) and video, which fits the needs of language learning and practices. This integration between WeChat and the mobile app helps to expand the traditional language teaching and learning outside of the classroom. Instructors can provide students instant instructions and feedback, and students can learn and practice the exercises anywhere. We have piloted this new approach and conducted various experiments in two sections of Chinese level I in a US college to assess its effectiveness.
\end{abstract}

\section{Key Words}

Social media, Mobile App, WeChat, Mandarin Chinese, Language learning

\section{Introduction}

Current college-level Chinese language students belong to the cohort of Generation Z. An important characteristic of this generation is global, social, visual and technological. They are the most connected, educated and sophisticated generation ever. Generation $\mathrm{Z}$ is the first cohort to have Internet technology readily available at a young age (Prensky, 2001). As technology became more compact and affordable, the popularity of smart phones in the United States grew exponentially. Anthony Turner characterizes Generation $\mathrm{Z}$ as having a 'digital bond to the Internet', and argues that it may help young people to escape from the emotional and mental struggles they face offline (Borca et al., 2015).

\footnotetext{
${ }^{6}$ Associate Professor, Modern Languages Department, The City University of New York (BMCC), NY, USA, $\underline{\text { LLUO@bmcc.cuny.edu }}$
} 
In 2015, an estimated 150,000 apps were educational and aimed at children up to college level. The researchers and educators realize that young people use the Internet as a way to gain access to information and to interact with others. Mobile technology, social media, and Internet use have become increasingly important to modern adolescents over the past decade (Turner, 2015). Mobileassisted language learning (MALL) was first introduced in 1993 and became a sub-area of the growing field of mobile learning research. It has inspired learners to make use of the "anytime" and "anywhere" technology, the key concepts in MALL, in language learning, including the Rosetta Stone, Duolingo and Busuu. Though they prove to be effective to learn a language (Vesselinov, 2008, 2012 and 2016), the study only targets Spanish language and it does not target college students and their users are very motivated groups (only $45 \%$ of participants have completed the study and $70 \%$ of them have BA or higher degrees). In addition, these apps are not easily adopted within the college curriculum, because (a) the apps are designed for self-pace learning and not for use within the context of a course and the curriculum in the apps cannot be modified; (b) these language apps don't allow instructors to edit language content and customize exercises.

In order to tackle these challenges, we proposed a new MALL framework, which integrates a social media app WeChat, into a mobile language app called ICE to function for all learning activities.

\section{Literature Review}

\subsection{Mobile-assistant language learning}

While Mandarin is considered one of most difficult languages (according to the language difficulty rankings by US Foreign Service Institute), it is also one of the most popular foreign languages in the world. Unlike other foreign languages, we lack enough qualified instructors and supplementary teaching materials (Wen 2017). Mobile technology has become an essential element of our daily life. It has changed our lifestyle, and more importantly, our learning style.

Mobile-assisted language learning (MALL) was first introduced in 1993 and became a sub-area of the growing field of mobile learning research (Stockwell 2014, Burston 2014, McCarty 2017). It has inspired the learner to make use of this "anytime" and "anywhere" technology, the key concepts in MALL language learning. Thornton and Houser (2005) showed that mobile devices can indeed be effective tools for delivering language learning materials to the students. Studies have commonly emphasized the mobility of MALL devices, which allow learners to use the devices wherever and whenever they want. Learning, similarly, is not restricted to four-wall classrooms in this type of learning. This unique feature of mobile devices results in many other advantages in language learning (Cherian \& Williams, 2008; Chinnery, 2006; Kennedy \& Levy, 2008; Kukulska-Hulme, 2009; Power \& Shrestha, 2009; Wishart, 2008).

\subsection{WeChat in Mandarin learning}

WeChat is a Chinese multi-purpose messaging, social media and mobile payment app developed by Tencent. It was first released in 2011, and by 2018 it was one of the world's largest standalone mobile apps by monthly active users with over 1 billion monthly active users - 902 million daily active users (Osman, 2011). WeChat provides many features that can be used for language learning, such as: text messaging, hold-to-talk voice messaging, broadcast (one-to-many) messaging, video calls and conferencing, video games, sharing of photographs and videos, and location sharing. Since 
smartphones and mobile social media platforms have become part of life and education amongst college students in the U.S., it is reasonable to expect that they would welcome WeChat as a part of their Chinese language learning.

WeChat has another important feature - a subscription account. WeChat users are allowed to create a subscription account, which enables them to push feeds to subscribers, interact with subscribers and provide them with services. This feature is very convenient for instructors to send messages and connect with the students. Under the traditional teaching mode, students rarely get first-hand teaching materials such as lesson plans and courseware. However, using a Wechat subscription account, teachers can push the prepared classroom materials to each student in time. It is convenient for students to check and verify immediately when they find problems. On the other hand, it is difficult for teachers to intervene in the after-school summarization stage (Chiang, 2013). After the introduction of WeChat teaching, any problems encountered by students in the class can be answered quickly. Teachers can guide students in a timely and effective manner.

\subsection{Proposed method}

Due to the limitations of current language learning mobile apps, we have designed an app called ICE and then integrated Webchat's functions to assist students to learn Mandarin. ICE allows the instructor to assign exercises via a mobile app, while WeChat enables the instructor to assign audio and video exercises where students and instructor have direct communication via WeChat.

\section{Methodology}

\subsection{Integration of ICE and WeChat}

To tackle the above problems, we have developed a mobile app called ICE that combines with WeChat to teach Mandarin (iChineseExercise on Android and iOS) since 2016. We are conducting preliminary experiments in a Chinese I class and ICE and WeChat received positive feedback from student participants for its ease of use and instant feedback.

Compared to the regular MALL apps, the integration of ICE and WeChat has three unique features: (a) ICE allows instructors to customize learning materials according to the adopted textbook; hence, it seamlessly aligns with the curriculum

(b) WeChat allows instructors to assign and grade exercises of listening and speaking, and students easily submit their answers and receive feedback from the instructor

(c) WeChat allows students to chat with the instructor (1 Vs 1) and their classmates (1 vs N), hence it extends the classroom learning outside the classroom. 

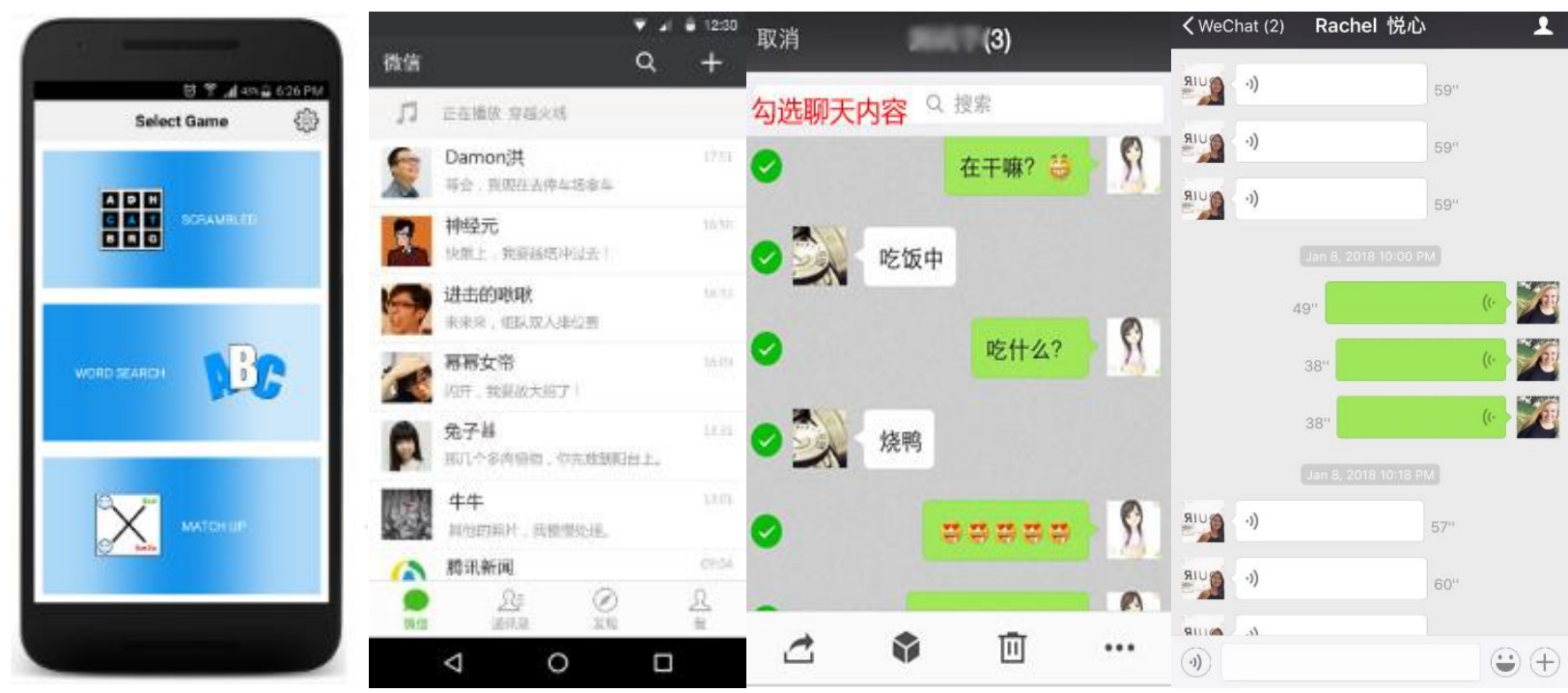

Figure 1. The interface of ICE mobile app and Wechat. a) three different mini-games available for students practicing vocabulary and sentences, b) the main interface of the Wechat app, c) The screenshot of text message on WeChat, and d) The screenshot of voice message on WeChat.

ICE includes two modules, the instructor web portal and the student mobile app. In the mobile app, all the exercises will be available for student to preview, review and post-review. Currently, there are three simple games-based exercises available (Figure 1a). The instructor's web portal (Figure 1b) allows instructors to customize language materials, which includes vocabulary, sentences and grammar. Whenever the instructors assign exercises via ICE, the students receive notifications via WeChat text messages and start working on it at any time and any location with any number of attempts. The grades will be available to the instructor via web portal.

In order to use WeChat, we first set up a WeChat group in the class. All the students in a same class join a group and get the same information at the same time; there are various functions of WeChat to learn Chinese as presented below:

1. Instructors distribute learning materials, especially multimedia materials, such as video and audio.

2. Students submit their video and audio assignment via WeChat (Figure $2 \mathrm{a}$ and $2 \mathrm{~b}$ ).

3. Students share their learning experiences with their classmates.

4. Students receive feedback from the instructor and classmates.

5. Besides the group activities, students still can have communication one-to-one with the instructor and other classmates. 

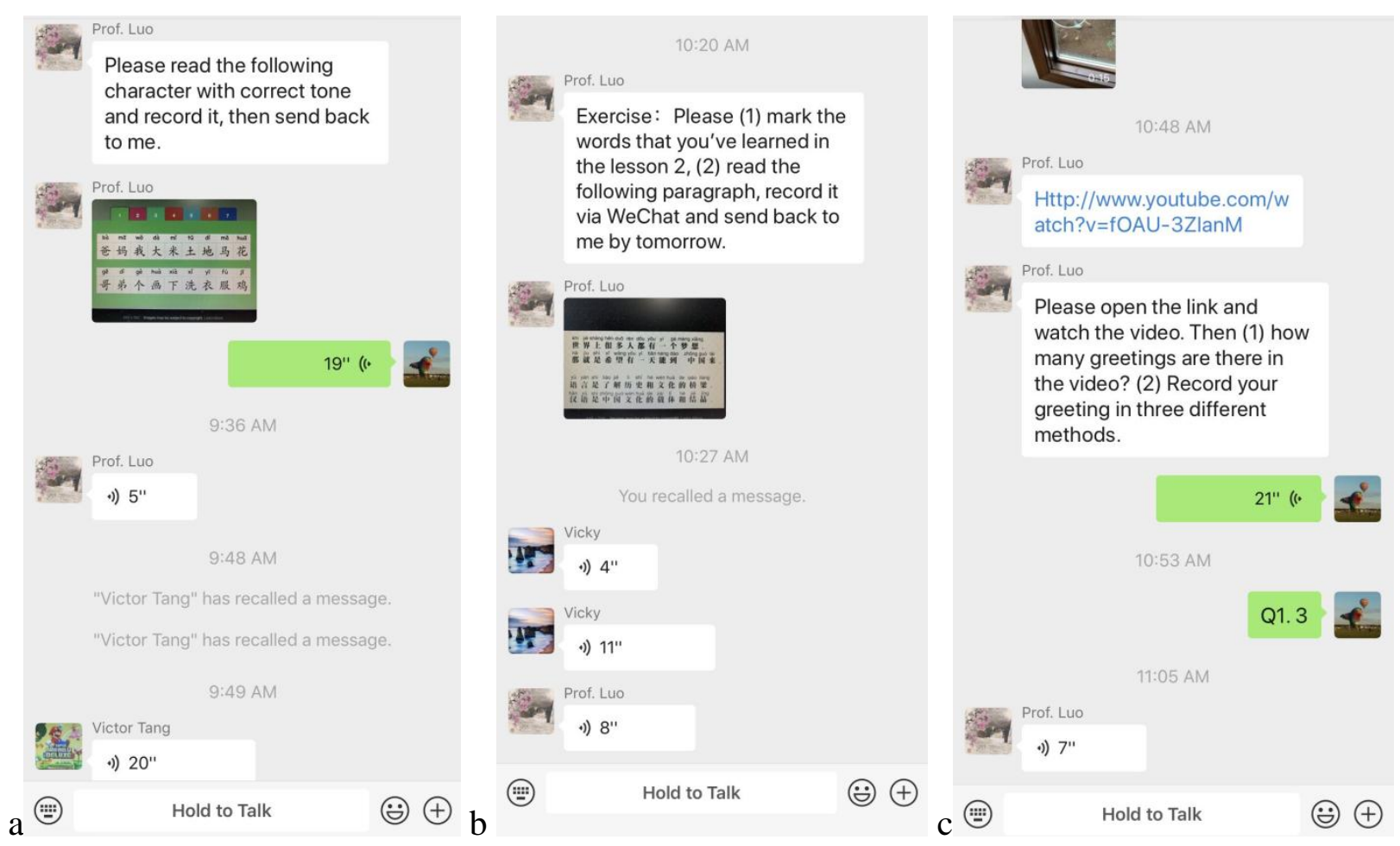

Figure 2. Screenshot of different exercises using WeChat. a) students practice pinyin and tones by voice recording via WeChat; b) students practice pinyin and Chinese characters via voice recording via WeChat; c) students watch a Youtube video of authentic Chinese greetings and then practice greetings in Chinese via WeChat.

Beside exercises in a textbook or workbook, WeChat also allows instructors to easily include other supplementary learning materials into the language learning. Two examples are listed as follows:

Example 1: an instructor plans to share a handout (问候 greeting) from a book, he/she can simply take a picture of the handout and share the picture in the WeChat group.

Example 2: an instructor can send students a video as supplementary learning material "The song of the number" ${ }^{7}$, (Figure 2c) the students can follow the video to practice how to count numbers in Chinese. After the students finish learning exercises, they can record their speech and send back to the instructor to get the quick feedback through WeChat video/voice chat.

ICE and WeChat are very useful to help students to improve their language skills. Besides the content of the materials, the students can use it whenever they have time. This benefit is very important in language learning.

After the students finish an exercise, they can record what they learnt and send back to the instructor to get the feedback through WeChat video and voice chat. For example: when students are learning Pinyin, the instructor can send students an exercise to practice pinyin and tones (Figure 2a). Students will practice both pinyin and Chinese characters learned in the class (Figure 2b). In 
Figure 2c, students watch a video which includes four authentic Chinese greetings that are not used very often, afterwards students are asked to record three greetings in Mandarin.

\section{Experiments}

Given the ethical concerns to have one group of students potentially advantaged by the use or nonuse of a technology, we will use a matrix approach, where the two different groups are given access to the app at different times during the course (before and after the $8^{\text {th }}$ week). Both groups of students have had access to the same technology, the timing in which this access occurs is necessarily going to have some kind of effect, be it on the content which is taught.

\section{Experimental design}

In the spring semester of 2018 (15 weeks) and the fall semester of 2018 (15 weeks), we chose a Chinese I class, 30 students in each class, to conduct our experiment. We split one class into two groups, each group will have 15 students. One group was given access to the app and using WeChat before the $8^{\text {th }}$ week. They used the app to practice out of classroom and complete their homework; while another group was assigned regular homework and exercises. After the $7^{\text {th }}$ week, two groups are switched.

Here are two quizzes to test how the students performed after they used App and WeChat.

Quiz 1: Write the following words in Chinese according to the English meaning.
1. student
2. he/him
3. teacher
4. you
5. good/fine

This quiz would check the students' performance after they practiced all exercises via ICE. The result of two semesters is as follows: (Figure 3)

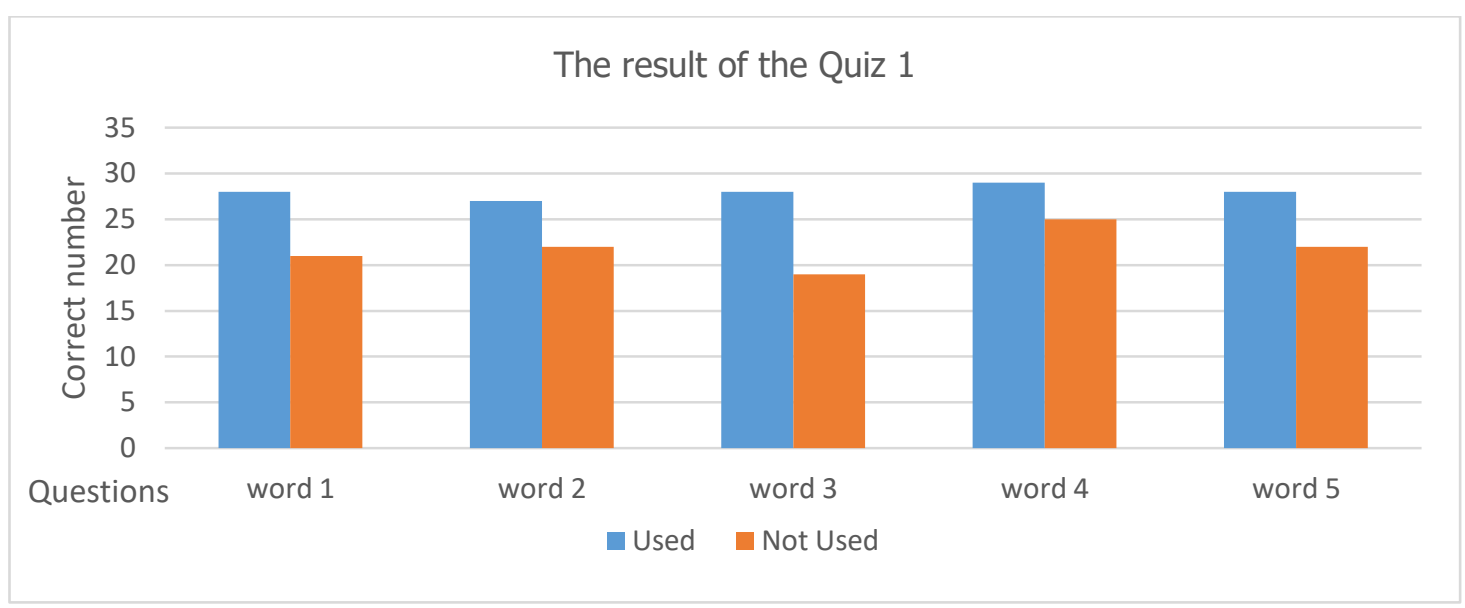

Figure 3. The comparison of result of quiz 1. The students used the apps did a better job for all 5 questions (blue bars) than the students who did not use the apps.

Quiz 2: Record the answers in full Chinese sentence after you listen to the question.

\section{1. 你贵姓?}




\section{2. 你叫什么名字?}

\section{3. 你是学生吗?}

\section{4. 她是谁?}

\section{5. 你的中文名字是什么?}

This quiz would check the students' performance after they practiced all exercises via ICE. The result of two semesters is showed below (Figure 4).

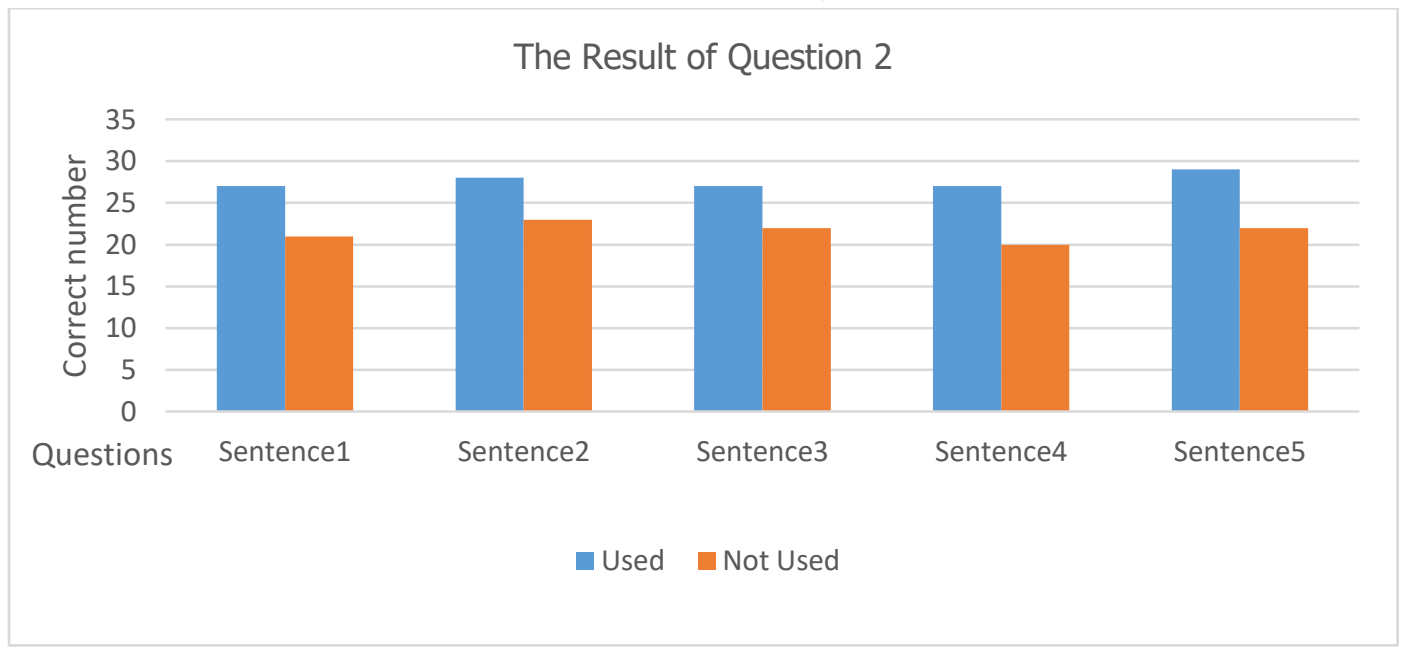

Figure 4. The comparison of result of quiz 2. The students used the apps did a better job for all 5 questions (blue bars) than the students who did not use the apps.

The exam score of students using ICE and WeChat before the exam are the results from the experimental group, the exam score of students without using the app before the exam are results of the control group. The final exam covers lesson 1-6. We used Chinese Link (2010) as our textbook.

The routine works that have been assigned to the students to use ICE and WeChat are:

1) Assign new vocabulary in the web-portal and then ICE generates new exercise of the vocabulary for students.

2) Students start to do the exercises on the App, and then record the new vocabulary or sentences using WeChat and submit to instructor.

3) Instructor gives an instant feedback to student according to the recording using WeChat.

4) Students continue to work on their assignment in ICE, and record short audio and video exercise using the new vocabulary and sentences to the instructor on WeChat.

5) Instructor will select and share some student's work in the WeChat group.

6) All the students can give their feedback and comments to other student's work in the WeChat group. Each one is required to submit feedback of two questions submitted by other students.

The goal we designed ICE and WeChat is to test how they support foreign language teaching. ICE can be used to distribute reading and writing assignments to students. WeChat can be used to assign the listening and speaking assignments to students. Listening, speaking, reading and writing are the 
four aspects of language learning. We use both of ICE and WeChat to assist students to learn the foreign language from various aspects.

\section{Analysis}

In this section the formative and/or summative assessment strategies to measure research outcomes and the effectiveness of the experimental design are discussed.

The design of the exam questions goes as follows: Students should be familiar with the meaning, know words related to the term (phrase and sentence), and have flexibility with using it in both written and oral forms. It is clear that to master a word is more than to know its definition. The following five dimensions theory (Cronbach, 1942) were used to create the exam questions:

- Generalization: The ability to define a word

- Application: Selecting an appropriate use of the word

- Breadth: Knowledge of multiple meanings of the word

- Precision: The ability to apply a term correctly to all situations

- Availability: The ability to use the word productively

The statistical analysis of exam scores: the dependent variable is the score statistics of both exams between two groups. After the final exam, I collected the final grades of all students and made a comparison. 60 students took the test, which included 30 students who used ICE App and WeChat, and other 30 students who didn't. The comparison of the data is visible in the following chart (Figure 5).

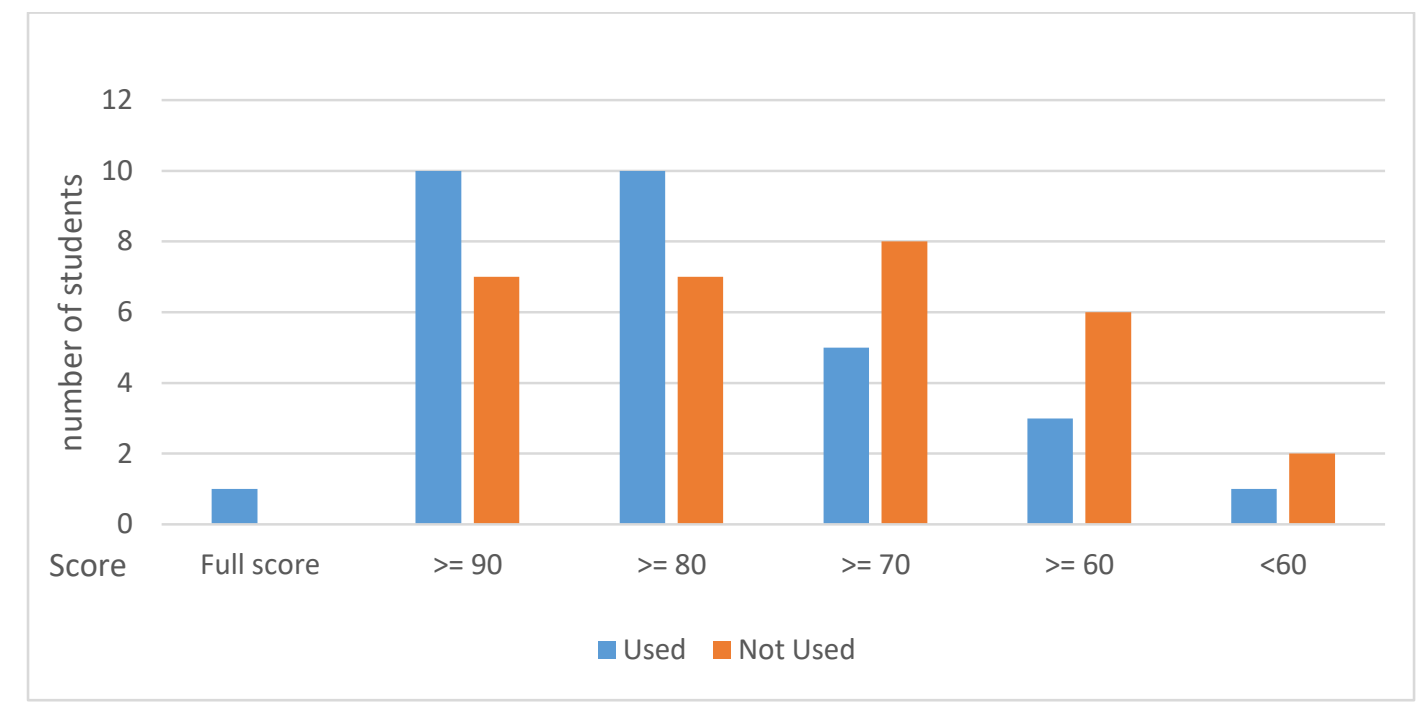

Figure 5. The result of the final Exam.

The average scores of the final exam are 84.5 (using the apps) vs 77.6 (without using the apps) and the full credit is 100 . The result analysis clearly shows the students that used the apps performed better than the students that didn't use the apps.

Additionally, at the end of each semester, we also conducted a survey. Table 3 shows the result of the survey. 
- Number of students who participated: 60

- Age of participants: first year Chinese language students

- Level of language: 1

- Number of valid surveys: 58

Table 1: The survey result

\begin{tabular}{|l|l|l|l|}
\hline Interesting to play & Easy to play & Benefit for learning & Want to play more \\
\hline 46 & 52 & 42 & 58 \\
\hline $79.3 \%$ & $89.6 \%$ & $72.4 \%$ & $82.7 \%$ \\
\hline
\end{tabular}

\section{Conclusion and Future Work}

In this project, we integrated a social media app WeChat into a language learning App ICE in a college level Mandarin course. Vocabulary exercises were assigned in ICE, whilst more multimedia exercises and materials were easily assigned via WeChat. The proposed method allowed students to receive instant feedback from instructor and other students. The experimental result after a yearlong experiment showed that the proposed method is effective in helping students master language concepts. In the future, we plan to disseminate ICE and WeChat, collect more data and conduct data analytics. In general, the first-year Chinese language students who participated in this project expected that other instructors continue using these apps to assist Chinese language teaching in the next level Mandarin course. Among the different learning activities, students considered the video and audio exercises in WeChat as the most helpful and the writing experiences as the least helpful. The survey data showed that students perceived the App and the WeChat project to have helped them expand the time of learning Chinese, improve their Chinese linguistic skills, promote Chinese cultural learning, enhance Chinese language learning motivation, and create a supportive Chinese language learning community. The participants also identified a number of feedback and proposed suggestions for improvement.

Future studies may need to examine student production data as generated in the language learning process to assess the usefulness of ICE and WeChat more objectively. In using the App and WeChat in Chinese language teaching needs supplementary monitoring from the instructor. Ideally, every assignment using ICE and WeChat need to be planned and spelled out in the syllabus, ensuring that the assignment is systematically implemented in language teaching.

\section{References}

Prensky, M. (2001). Digital Natives, Digital Immigrants Part 1, On the Horizon, Vol. 9 Issue: 5, pp.1-6 https://doi.org/10.1108/10748120110424816

Turner, A. (2015). Generation Z: Technology and Social Interest. Journal of Individual Psychology. 71 (2): $\quad$ 103-113. doi:10.1353/jip.2015.0021 
Borca, G.; Bina, M.; Keller, P.; Gilbert, L.R.; Begotti, T. (1 November 2015). "Internet use and developmental tasks: Adolescents' point of view". Computers in Human Behavior. 52: 49 58. doi:10.1016/j.chb.2015.05.029

Wen. X.H. (2017). Challenge and Change in Teaching Chinese as the Second Languages in USA, Chinese Teaching in the World Journal 2017 Vol 4, pp 23-35

Stockwell, G. (2012). Computer-Assistant Language Learning, Cambridge University Press March 2012 ISBN 9781139060981

Burston, J., Mall (2014). The pedagogical Challenges, Computer Assisted Language Learning Journal Pages 344-357 Published 14 May 2014

Thornton, P., \& Houser, C., (2005). Using mobile phones in English education in Japan, Journal of Computer Assisted Learning 21, pp217-228, Blackwell Publishing Ltd 2005

Cherian, E.J, Williams, P. Mobile Learning: The Beginning of the End of Classroom Learning , Proceedings of the World Congress on Engineering and Computer Science, October 22 - 24, 2008, San Francisco, USA

Chinnery,G.M. (2006). Emerging technologies going to the MALL: mobile assisted language learning Language, Learning and Technology Journal 10(1) · January 2006

Chinese Link, http://wps.prenhall.com/wl wu chinese link 2nd edition/

Kenney, C., \& Levy M. (2008). Using SMS to support beginners' language learning, European Association for Computer Assisted Language Learning,Vol. 20 (3), Sept. 2008 , pp. 315-330

Kukulska-Hulme, A. (2007). Mobile Usability in Educational Contexts: What have we learnt? International Review of Research in Open and Distributed Learning, Vol 8, No 2 (2007)

Power, T., \&Shrestha, P.N. (2009). Is there a role for mobile technologies in open and distance language learning? 8th International Languages and Development Conference, 23-25 June 2009

Wishart, J.M. (2008).Challenges faced by modern foreign language teacher trainees in using handheld pocket PCs (Personal Digital Assistants) to support their teaching and learning, ReCALL, vol 20(3), pp. 348 - 360.2008

Burston, J. (2014). The Reality of MALL: Still on the Fringes, CALICO Journal, Vol. 31, No. 1, 2014, pp. $103-125$

Brown, S. (2011). Second Language Acquisition Myths: Applying Second Language Research to Classroom Teaching 1st Edition, University of Michigan Press ELT; 1 edition (March 15, 2012)

Osman, M.,\&Chung, P. W (2011). Language learning using texting and wiki: a Malaysian context, eCASE and e-Tec 2011

Chiang, D. (2013). The International Workshop on Language Preservation: An Experiment in Text Collection and Language Technology, Language Documentation and Conservation, Vol. 7 (2013), pp. 155-167

Cho, S. (2009). Smartphones used for foreign language learning. Multimedia-Assisted Language Learning, 12(3), 211-228.

Godwin-Jones, R. (2011). Emerging Technologies Autonomous Language, Language Learning \& Technology, October 2011, Volume 15, Number 3 pp. 4-11, 2011

Vesselinov, R. and J. Grego (2016). The Busuu Efficacy Study. http://comparelanguageapps.com/documentation/The_busuu_Study2016.pdf last access June 2019

Vesselinov, R. and J. Grego (2012). Duolingo Effectiveness Study. http://comparelanguageapps.com/documentation/DuolingoReport_Final.pdf, last access June 2019 
Vesselinov, R. (2008). Measuring the Effectiveness of Rosetta Stone®. http://comparelanguageapps.com/documentation/MeasuringTheAttitudeandMotivationofRSUsers.p

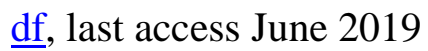

\title{
Motivation and Vision: A Survey of British Learners on the Mandarin Excellence Programme
}

\author{
Qing $\mathbf{L i}^{8}$
}

\begin{abstract}
This study investigates learners' motivation and vision in learning Mandarin Chinese (hereafter Mandarin $^{9}$ ) as a second language in the UK context. Firstly, the current study aims to present the view of the learners' motivation and find out whether motivation differs between groups according to gender and the length of time studying Mandarin. Secondly, it further investigates the relationship between motivation and intended effort. Thirdly, this survey explores the role that vision played in motivation. In order to meet these aims, 40 participants from a secondary school located in London took part in this study. The participants were on the Mandarin Excellence Programme, which is a project that provides intensive Mandarin courses in secondary schools. The data was collected using a well-designed, six-point Likert scale questionnaire, which was based on the research literature on motivation of $\mathrm{L} 2^{10}$ Mandarin and English learning. This study found that Chinese culture motivates participants the most in learning Mandarin and revealed significant correlations between motivation and intended effort. Furthermore, it found that cultural interest and travelling have a positive predictive effect on intended effort. In terms of vision, it proved that participants have developed vivid visualization in using Mandarin.
\end{abstract}

Keywords : Mandarin, motivation, vision, Mandarin Excellence Programme, Chinese culture

\section{Introduction}

As China is playing an important role on the international stage in the $21^{\text {st }}$ century, the interest in learning Mandarin as a second language has increased greatly. To exploit this trend and promote the Mandarin language and Chinese culture, China launched an ambitious project and established the non-profit Confucius Institute initiative in 2004, which aimed to provide various opportunities for learners from all over the world who want to learn about the Mandarin language. By 2019, 539 Confucius Institutes and 1,129 Confucius Classrooms have been established in a total of 155

\footnotetext{
${ }^{8} \mathrm{PhD}$ candidate in Culture, Communication and Media, University College London, Institute of Education, UK, email: qing.li.17@ucl.ac.uk

${ }^{9}$ In this dissertation, Chinese refers to entities such as people, roles, culture, society and institutions, while Mandarin refers to language.

${ }^{10} \mathrm{~L} 2$ refers to a language that a person acquires as his or her first language. In this specific context, it refers to Mandarin.
} 
countries around the world. Among them, there were 29 Confucius Institutes and 148 Confucius Classrooms in the UK. In June 2012, the Institute of Education (IOE) Confucius Institute at University College London (UCL) was established. Until now, it has provided ongoing support to more than 45 IOE Confucius Classrooms, comprising over 9,000 students, as well as organizing the largest Mandarin conference in the UK on a yearly basis. The IOE Confucius Institute also launched the Mandarin Excellence Programme (MEP) in 2016, one year after Chinese President Xi visited the UK in 2015. The MEP is a unique yet intensive language programme. Pupils involved in this programme are expected to spend an average of eight hours per week studying Mandarin over a period of four years, while the normal Mandarin classes are only two hours per week on average. As of 2019, 63 secondary schools had taken part in this programme.

The London secondary school involved in this empirical study joined the MEP in 2016, the year the programme was launched. I worked as a Mandarin teacher in the same secondary school before and witnessed the growing number of students who wanted to study Mandarin and their desire to be enrolled on this intensive and demanding Mandarin training programme. As a Mandarin teacher, I wondered what motivated them to learn Mandarin, which is a very different type of language compared with English and other European languages. Copious research has been conducted on learning English as a second language in different countries, while a few of studies have explored learning Mandarin as a second language (Liu, 2014),

\section{Literature Review}

\subsection{L2 motivational self-system and vision}

In the field of L2 language learning, motivation is believed to be the second most important index of success in second-language learning after aptitude (Skehan, 1989; Gardner, 1985; Dörnyei, 2001; Dörnyei, 2003; Gardner, 2006; Gass and Selinker, 2008) and generally understood in terms of the willingness to begin learning a L2 language and the commitment shown in order to keep learning it (Ortega, 2009). Dörnyei (2005) observed that motivation serves as a primary impetus and a driving force for learners to start L2 learning and sustain the learning process.Dörnyei then proposed a new approach to investigate motivation in 2005 , which has been considered as the most promising approach in the field of L2 motivation within a 'self' framework (Csizer and Kormos, 2009; MacIntyre et al., 2009; Ortega, 2009; Taguchi et al., 2009). This 'self' framework was mainly informed by Higgins' (1987) self-discrepancy theory, which pointed out that people are motivated to reduce the inconsistency between one's ideal and actual selves in order to become their ideal self (Higgins, 1987). This conceptualization led Dörnyei to propose the L2 motivational self system, as he observed that L2 learners are motivated to reduce the gap between the ideal and actual selves when learning and speaking a second language (Dörnyei, 2005). Apart from the theoretical basis, a series of empirical studies also influenced the development of this motivational self-system. Conducted in Hungary in 1993, 1999 and 2004, the stratified national study of L2 learning motivation got involved with 13,000 L2 learners of English, German, French, Italian and Russian. This largest-ever L2 motivation study laid a solid foundation for Dörnyei's self-system work, which is constructed around three primary components:

(1) Ideal L2 self. This 'concerns a desirable self-image of the kind of L2 user one would ideally like to become in the future' (You and Dörnyei, 2016), which reflects the individual's vision of being an effective L2 user (Dörnyei and Ushioda, 2011). An example in this case would be that I can imagine myself as someone who is able to speak Mandarin fluently. The ideal L2 self is regarded as the most powerful motive in one's L2 learning process, as the unease caused by the 
discrepancy between one's actual and ideal self-image will act as a potent motivation source and has a more direct relationship with motivated behavior' (Ryan, 2009, p.137).

(2) Ought-to L2 self. This concerns the imported self-image such as when someone believes that they should possess certain attributes to meet others' expectations and avoid possible negative outcomes. For instance, I consider learning Mandarin important because the people I respect think that I should do it. This is less powerful than the ideal L2 self as it refers to external factors instead of being generated from learners' inner desires.

(3) L2 learning experience. This is a motivation that is associated experiencing the immediate learning environment, in terms of the influence of the teacher, the curriculum, peer groups or how success is felt (Dörnyei, 2009.). For example, I think time passes faster while studying Mandarin. Unlike the first two components, which derived directly from self-discrepancy, L2 learning experience is conceptualized at a different level.

Within this model, the three components in the L2 motivational self-system are not completely independent of each other (e.g., Papi, 2010; Taguchi, 2013; Taguchi et al., 2009). The learning experience affects future images of individual's self and the imagined future possible self also projects onto reality and has an effect on the learning experience (Dörnyei and Chan, 2013).

Apart from the inter-relation between the three components, another important feature of this model is concerned with the dynamic nature of future possible selves. As early as 2005, Dörnyei noted that the future self-guides (i.e., ideal L2 self and ought-to L2 self) involve mental images, which are neural representations of an individual's imagination (You et al., 2016). You and Chan (2015) suggested that mental imagery related to an individual's future self is always subject to change during the L2 learning process in terms of its content, elaborateness, and frequency. For example, the ideal L2 self may be different after the completion of a task, while the individual may also reset their goal to ease the inconvenience caused by the gap between the actual self and ideal self. When imagery is associated with ensuing behaviour, it is understood as vision (You et al., 2016). Dörnyei and Kubanyiova (2014) pointed out, vision offers a broad view to explore the overall commitment needed to successfully learn a language as vision particularly involves a vivid mental image, which depicts a desired future status. Visualization capacity is 'an individual's capacity of forming vivid, controllable images and retaining them for sufficient time to effect the desired imagery rehearsal' (Morris, 1997, p. 37). Visualization capacity is usually measured by vividness of imagery (Morris, Spittle and Watt, 2005). Dörnyei and Kubanyiova (2014) explained that, without being able to produce intense imagery during visualization, a desirable self-image may be ineffective in motivating someone into action. A typical example for this is I can usually have both vivid mental pictures and/or sounds of situations when I'm imagining myself using Mandarin skillfully in the future. Mental imagery is greatly stimulated by senses, which includes sight, touch, taste, sound and smell (Kosslyn, Thompson and Ganis, 2006). In the field of L2 language learning, mental imagery is typically associated with sight and sound, which closely connect with the two main learning styles: visual and auditory style (You et al., 2016; Dörnyei and Chan, 2013).

\subsection{Main research findings on motivation in second-language learning}

\section{Major studies on L2 English}

Since the L2 motivational self-system was proposed at the beginning of the 21 stcentury, it has attracted a great deal of attention from researchers, who have gone onto test and validate its values in various countries and context (e.g., Csizer and Kormos, 2009; Taguchi et al., 2009; Ryan, 2009; Lamb, 2009; Kim, 2009). Taguchi et al. (2009) noted that there is certain connection between the 
L2 motivational self system and the socio-education model, which was the first L2 motivational framework proposed by Gardner and Smythe (1975). In that model, L2 motivation contains three main factors: integrativeness, instrumentality and attitude towards the learning situation (e.g., teachers, classmates, the course materials). Integrative motivation reflects a strong desire to learn another language and communicate with it in order to engage with others from the target language population (Gardner and Lambert, 1972). Instrumentality motivation refers to learning a second language for more practical reasons, such as to get a job. However, instrumental motivation is not considered as significant as integrative motivation in the index of learners' motivation (Gardner, 2001). Dörnyei $(2005,2009)$ proposed that the traditional promotional instrumentality exerts a pulling power when learning a second language to facilitate professional development, whereas prevention instrumentality has an avoidance focus, such as when studying a second language in order not to fail a course or disappoint others. The distinction between these two kinds of instrumentality is important as promotional instrumentality relates to the ideal L2 self and prevention instrumentality relates to the ought-to L2 self (Dörnyei and Chan, 2013). Csizer and Kormos carried out a study on motivation towards L2 English among secondary school and university students in Hungary. It found that ideal L2 self and L2 learning experience were almost equally important in students learning behaviour, while ought-to L2 self was a weaker contributor. Furthermore, L2 learning experience exercised more importance for secondary school learners (Csizer and Kormos, 2009). Conducted in Japan, China and Iran, Taguchi et al.'s (2009) study, revealed that ideal L2 self, better predicts intended efforts compared with other motivations.

Recently, the number of studies on motivation and vision has been growing, especially in terms of future L2 self-guides, visualization capacity, learning styles and motivated L2 behaviour. To investigate motivation and vision, Dörnyei and Chan (2013) conducted a survey among 172 Year 8 Chinese students of L2 English. This survey confirmed that ought-to L2 self was not as energizing as ideal L2 self. It also revealed a significant correlation between future self-guides and intended effort. Furthermore, the imagery capacity was especially reflected in participants' future self-guides. By investigating secondary schools and university students, AI-Shehri (2009) found a highly correlation between imagination, the ideal L2 self and motivated performance. Meanwhile, Kim (2009b) conducted a survey in primary schools in Korea and discovered that the auditory learning style is significantly related to imagination, the ideal L2 self and motivated behaviour. Later, Kim and Kim (2011) expanded this research by involving secondary school students, revealing visual and auditory learning preferences and visual capacity play key roles in the formation of a vivid ideal L2 self. By applying mixed methods, You and Chan (2015) revealed that motivation makes a great deal of difference between students who engaged in the visualization as L2 users and those who did not. Other studies have also suggested a positive correlation between visualization and motivation, that is to say, increased in visualization usually results in improved motivation after purposeful training (e.g., Chan, 2014; Mackay, 2014; Magid, 2014; Sampson, 2012). However, it was not until 2016 that a full and robust model integrating vision and motivation was constructed by You, Dörnyei and Csizer, as presented in Figure 1 below. The right side of this model shows the L2 motivation self system and intended effort. You et al. (2016) found out that the ideal L2 self, oughtto L2 self and L2 learning experience significantly predict intended effort. The left side of this model shows the relationship between vision-specific variables and the L2 motivational self-system. Visual and auditory styles are generally understood as having connection with L2 learning experience (Dörnyei and Chan, 2013). Indeed, the more visual or auditory skills students develop, the more successful they are in L2 learning, and thus the more they enjoy the learning experience in classroom (You et al., 2016). Visual style and auditory style are also believed to naturally connect 
with vividness of imagery, as it is through them that imagery is generated (Dörnyei and Chan, 2013). The system represents an overarching model with which to explain how motivation specifically relates to language learning (Ortega, 2009).

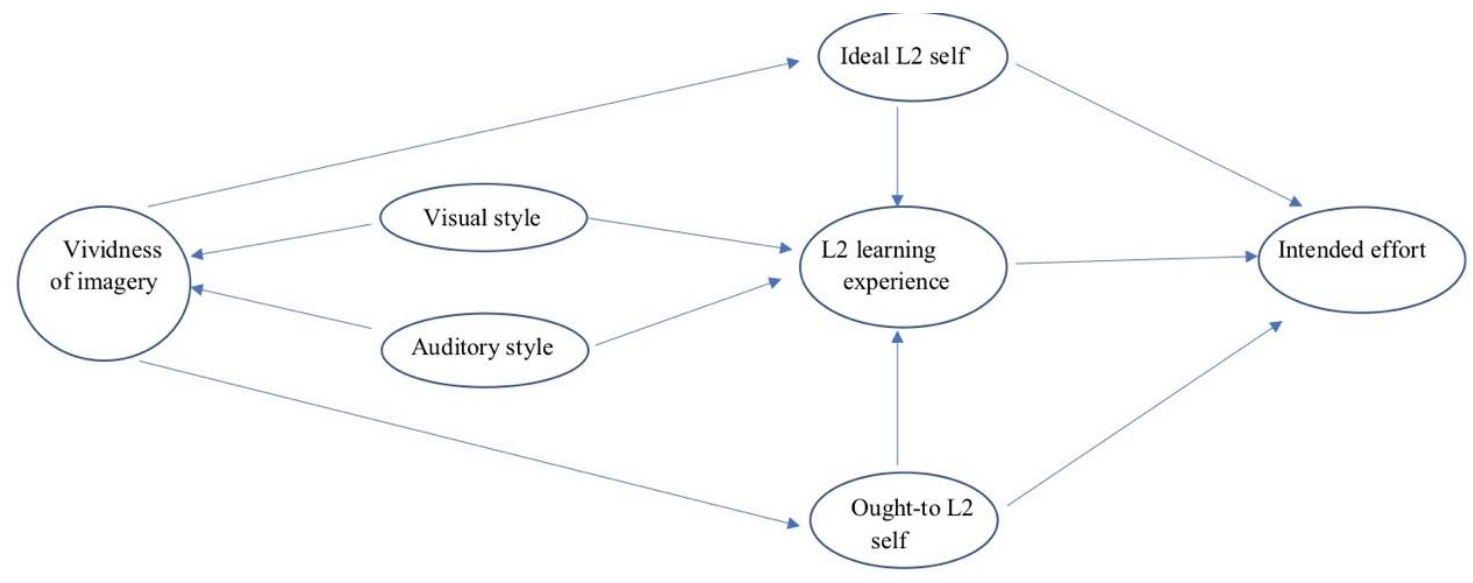

Figure 1 Full Structural Model (You, Dörnyei and Csizer, 2016)

\section{Major studies on L2 Mandarin}

Though studies of L2 Mandarin learning have only started to flourish, it is worthy introducing some of the main findings in the L2 Mandarin context. Wen (1997) conducted a survey amongst university students in America, who were from Asian or Asian American families. The results revealed that these learners were mostly motivated by Chinese culture. Yu (2009) compared the motivation towards L2 Mandarin learning among 151 Australian university students and towards L2 English learning among 344 Chinese university students. By comparing the results from both countries, it revealed that Chinese students' motivation towards learning English was more instrumentality oriented (e.g. to improve their career or academic opportunities in future), while Australian students of L2 Mandarin were more likely motivated in terms of integrativeness (e.g. to communicate with Chinese native speakers). It also revealed that there was a significant correlation between their L2 language motivations and L2 language achievements. Wen (2013) explored the relationship between motivation and the language learning environment, as well as ethnicity, and language proficiency. The study revealed that instrumentality and L2 learning experience were the strongest forms of motivation among beginners and intermediate learners, while self-confidence was the strongest predictor for advanced learners. Using a mixed-methods approach, Liu (2014) conducted a survey among 130 university-level L2 Mandarin learners involving the L2 motivational self-system. The results confirmed the effectiveness of the self system in L2 Mandarin and revealed some significant correlations: the ideal L2 self, had a stronger explanatory power towards intended efforts than other types of motivation; the ideal 12 self significantly correlated with promotional instrumentality; and the ought-to L2 self-had a stronger correlation with prevention instrumentality than promotional instrumentality.

\subsection{Research questions}


This study investigates students' motivation towards learning Mandarin as a second language in the UK, as well as further explores the role of vision played in L2 Mandarin motivation. Specifically, in this study, the questions concerning motivation and vision are:

1. What does students' motivation look like in the context of learning Mandarin as a second language in the UK? What does motivation look like between groups according to year (7/8) and gender?

2. What are the relationships between motivation and intended effort? To what extent does motivation contribute to participants' intended effort?

3. Have L2 Mandarin learners ever engaged in the visualization of using Mandarin? If they have, does vision make a difference to the L2 motivational self system between the vision-yes and visionno groups?

4. What is the relationship between vision-specific variables (i.e., vividness of imagery, visual style and auditory style) and L2 motivational self system among the vision-yes group?

\section{Methodology and Data Sources}

\section{Participants}

Participants in this study are Mandarin students $(n=40)$ in Year $7(n=20)$ and Year $8(n=20)$. All of them are from the same secondary school in the north of London in the UK, where Mandarin is a compulsory subject for all Year 7 students but an option from Year 8 onwards. The participants in this study are all enrolled on the MEP.

\section{Instrument}

The instrument used in this study is an anonymous questionnaire composed of three parts. The first part concerns the motivation domain and contains 30 six-point Likert scale question items. The second part concerns vision domain and contains 12 six-point Likert scale question items. The third part concerns background information and contains seven questions such as gender, nationality and length of learning Mandarin.

The variables in the motivation domain are ideal L2 self (e.g., I can imagine myself as someone who is able to speak Mandarin fluently), cultural interest (e.g., I would like to know more about people from China), traveling (e.g., I would like to travel to Mandarin-speaking countries or areas), instrumentality (promotion) (e.g., Studying Mandarin may be important to me because I think I'll need it will someday to get a good job and/or make money.), ought-to L2 self (e.g., I consider learning Mandarin important because the people I respect think that I should do it.), family influence (e.g., My parents encourage me to practice my Mandarin as much as possible) and instrumentality (prevention) (e.g., Studying Mandarin is important to me, because I would feel ashamed if I got bad grades in Mandarin), L2 learning experience (e.g., I think time passes faster while studying Mandarin) and intended efforts (e.g., I am prepared to expend a lot of effort in learning Mandarin). The questions in this selection are mainly based on You and Dörnyei's (2016) investigation and Dörnyei (2010), which have been broadly applied to surveys on motivation in L2 learning. Each variable covers three to four question items (see Table 1). All question items included are considered as being the most typical question items for the purpose of this study. 
The vision part mainly contains vision-specific variables, which are vividness of imagery (e.g., I can have several vivid mental pictures and/or sounds of situations when I'm imagining myself using Mandarin skillfully in the future), visual style (e.g., When I listen to a teacher, I imagine pictures, numbers or words) and auditory style (e.g., I remember things I have heard in class better than things I have read). Each variable covers four question items. This is an optional part and supposed to be answered by those who experience visualizing the use L2 Mandarin. Therefore, it separates students into two groups: vision-yes group and vision-no group. It is introduced by the following: Have you ever imagined yourself using Mandarin in the future when you have learned it? If so, please answer the next few questions. If not, please go to Part 3. T Table 2 gives a brief introduction to the question items.

\section{Data collection procedure}

Data was collected at the end of the academic year. The consent forms were voluntarily signed by the students and agreed by their parents/guardians for their participation. The process of answering the questionnaires was conducted at the beginning of two Mandarin classes (one for Year 7 and one for Year 8), which took about 10 to 15 minutes.

\section{Data analysis}

Data was first input into Microsoft Excel and organized according to the category of variables. For each participant, the scores for all the question items in the same variable were added and then divided by the number of items. Therefore, an average score was determined for each participant in the case of each variable. The results were then converted to and analysed by SPSS 25.0. The consistency reliability coefficients of the variables from the results of all the questionnaires were above the threshold 0.70 .

\section{Results}

\subsection{Motivation domain: general findings and findings broken down by year and gender}

\section{General findings}

In the whole sample, the mean values vary from 3.14 to 5.26 (table 1). Seven out of nine motivation variables exceed the midpoint of 3.50. Cultural interest has the highest mean value $(\mathrm{M}=5.26)$ among all motivation variables. The second factors are instrumentality (promotion) and travelling $(\mathrm{M}=5.11)$, followed by the ideal L2 self $(\mathrm{M}=4.56)$ and L2 learning experience $(\mathrm{M}=4.60)$. The figures for intended effort ( $\mathrm{M}=4.92)$, suggests a strong commitment towards making efforts in this L2 language. Family influence is also a relatively high motivation $(\mathrm{M}=4.41)$. Obviously, the two lowest mean values fall on instrumentality (prevention) $(\mathrm{M}=3.14)$ and ought-to L2 self $(\mathrm{M}=3.43)$. 
Table 1: Motivational Variables

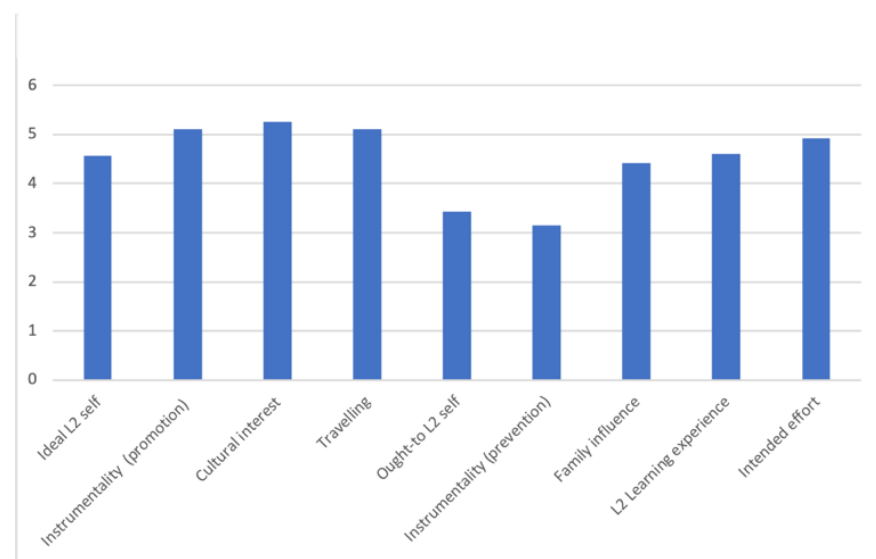

\section{Motivation findings broken down by year}

As can be seen from Table 2, the figures for Year 7 range from 2.95 to 5.33 and Year 8 from 3.33 to 5.20. From both groups, the strongest motivations are still cultural interest and the weakest motivations are Instrumentality (prevention) and ought-to L2 self, which are in line with the whole sample. To find out whether there is a significant difference between Year 7 and Year 8 in all motivation variables, an independent-samples $\mathrm{T}$ test was performed. The result showed that there was a significant difference for ideal $\mathrm{L} 2$ self in the scores for Year $7(\mathrm{M}=4.86, \mathrm{SD}=0.69)$ and Year 8 $(\mathrm{M}=4.27, \mathrm{SD}=0.96)$ conditions; $\mathrm{t}(34.442)=2.239, \mathrm{p}=.032$. Concerning L2 learning experience, there was a significant difference for the Year $7(\mathrm{M}=4.98, \mathrm{SD}=0.92)$ and Year $8(\mathrm{M}=4.23$, $\mathrm{SD}=1.09)$ conditions: $\mathrm{t}(38)=2.342, \mathrm{p}=.025$. For intended effort, there was also a significant difference in the scores for the Year $7(\mathrm{M}=5.21, \mathrm{SD}=0.67)$ and Year $8(\mathrm{M}=4.64, \mathrm{SD}=0.88)$ conditions: $\mathrm{t}(37)=2.299, \mathrm{p}=.027$. Therefore, we can conclude that the duration of learning Mandarin does have significant effect on ideal L2 self, L2 learning experience and intended effort but it does not make a difference in the case of other types of motivation.

Table 2 Group Statistics

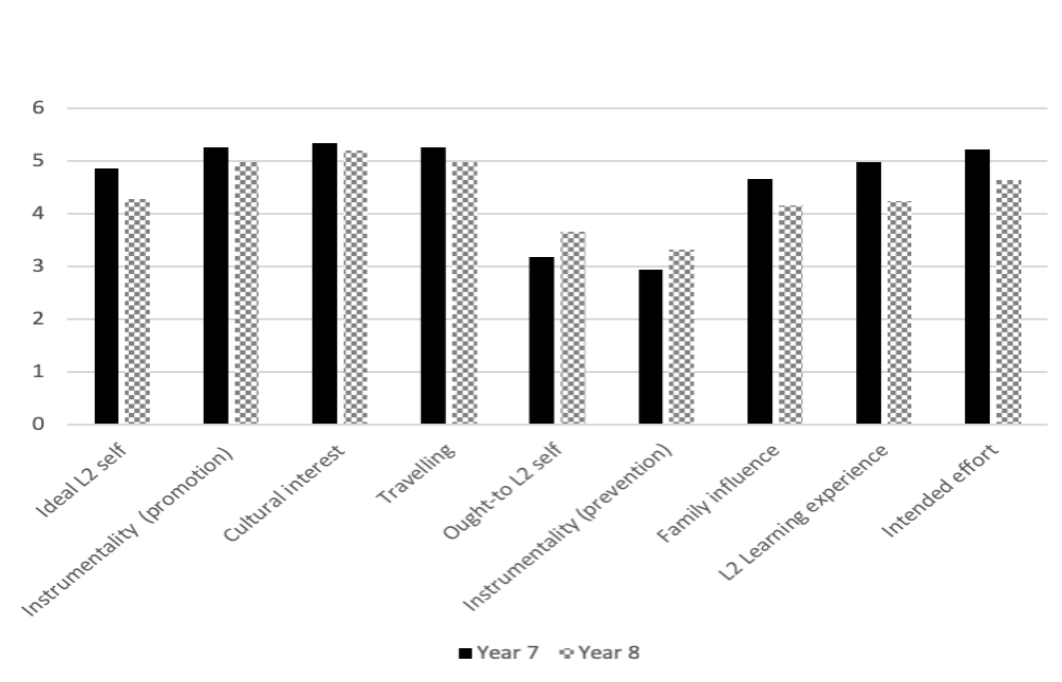

\section{Motivation findings by gender}

In this study of 40 students, there are 12 males and 22 females, with six students choosing not to indicate their gender. As Table 3 shows, apart from travelling and L2 learning experience, males exceed females for the remaining motives. The independent-samples $\mathrm{T}$ test found that there was a 
significant difference for ought-to L2 self in the scores for male $(\mathrm{M}=4.01, \mathrm{SD}=0.98)$ and female $(\mathrm{M}=3.00, \mathrm{SD}=0.93)$ conditions; $\mathrm{t}(34)=3.116, \mathrm{p}=.004$. Another significance difference was noted for family influence in the scores for male $(\mathrm{M}=4.86, \mathrm{SD}=0.69)$ and female $(\mathrm{M}=4.12, \mathrm{SD}=1.04)$ conditions; $\mathrm{t}(33)=2.336, \mathrm{p}=0.026$. Therefore, gender does make significant difference on ought-to L2 self and family influence.

Table 3 Groups Statistics

\subsection{Significance of motivation}

The question most concerned with motivation in L2 learning is always about how it can reflect actual learning behaviours (You and Dörnyei, 2016). Research in this field usually examines the correlation between motivation variables and intended effort, that is, how much effort given by L2 learners to learning an L2 language is affected by motivation variables. The results of Pearson correlation performed in this study suggest that six out of eight correlations between motivation variables and intended effort are statistically significant, namely, cultural interest $(\mathrm{r}(39)=+.593$, $\left.\mathrm{p}<0.001^{11}\right)$, ideal L2 self $(\mathrm{r}(39)=+.578, \mathrm{p}<0.001)$, instrumentality (promotion) $(\mathrm{r}(39)=+.567$, $\mathrm{p}<0.001)$, L2 learning experience $(\mathrm{r}(39)=0.564, \mathrm{p}<0.001)$, travelling $(\mathrm{r}(39)=+.711, \mathrm{p}<0.001)$, and family influence $(\mathrm{r}(39)=+.401, \mathrm{p}<0.05)$. Family influence is significantly correlated but plays a relatively moderate role in the correlation with intended effort. Conversely, ought-to L2 self $(\mathrm{r}(39)=-.147, \mathrm{p}=0.371)$ and instrumentality (prevention) $(\mathrm{r}(39)=-.254, \mathrm{p}=0.119)$ have no significant correlation with participants' intended effort. However, correlation is not an indication of a causeand-effect relationship. In order to calculate to what extent each variable predicts participants' intended effort, a multiple linear regression was performed. According to the results, this model indicates that $79.1 \%$ of the variations can be explained. The Durbin-Watson statistic is 1.909 , which is very close to 2.00 and suggests that this model is well constructed. The significance value of .000 attained in the ANOVA further confirms that the model is a good significant predictor. A significant regression equation was found $(\mathrm{F}(8,29)=10.958, \mathrm{p}=.000)$, with an $\mathrm{R}^{2}$ of .791 . Participants' intended effort is equal to $.175+.341 *$ cultural interest $+.416 *$ travelling $-.239 *$ instrumentality (prevention). The most affective variable is travelling and cultural interest, which suggests that, when the other variables are held, a one-unit increase in travelling and cultural interest will result in an increase of .416 and .341 respectively in intended effort. Conversely, a one-unit increase in instrumentality (prevention) leads to a decrease of .239 in intended effort. Other variables offer no prediction of participants' intended effort.

\footnotetext{
${ }^{11}$ All results are two-tailed.
} 
Volume 1, Issue 2, December 2019 Journal of Education, Innovation, and Communication (JEICOM) 


\subsection{Vision domain: significance of vision}

As discussed before, those who chose to answer the optional part in the vision domain were those who have developed the ability to visualize the use of L2 Mandarin and hence were assigned to the vision-yes group.

As can be seen from Table 4, the vision-yes group $(\mathrm{N}=33)$ has a higher score than the vision-no group ( $\mathrm{N}=7)$ for two out of the three variables (i.e., ideal L2 self and L2 learning experience). The result of the independent-samples $\mathrm{T}$ test shows a significant difference in the L2 learning experience in the scores for the vision-yes $(M=4.86, S D=0.98, n=33)$ and vision-no $(M=3.64 \mathrm{SD}=1.03, \mathrm{n}=7)$ groups; $\mathrm{t}(38)=2.832, \mathrm{p}=.007<.05$. However, vision does not make any significant differences in the case of ideal L2 self and ought-to L2 self.

Table 4 Group Statistics by Comparing the Motivational Variables in the Vision-yes and Vision-no Subgroups

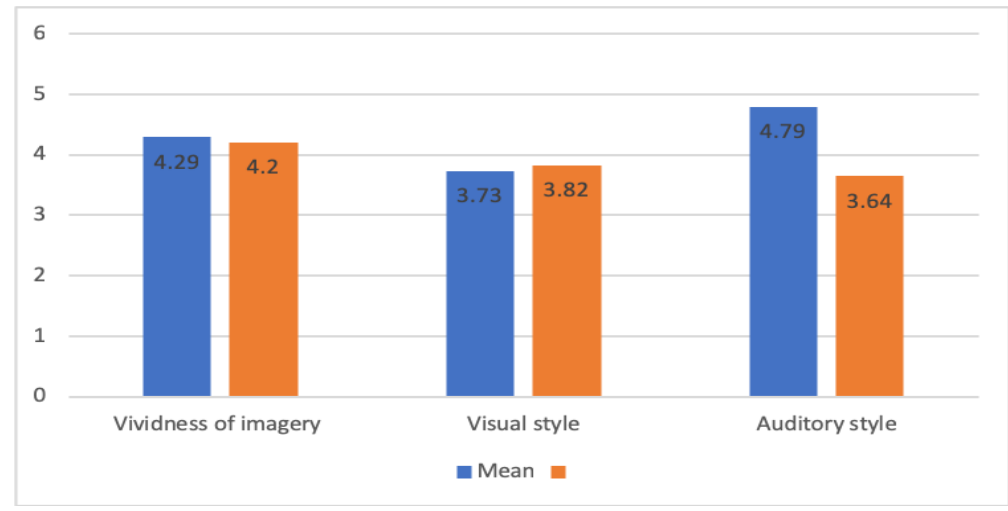

\subsection{Roles of vision-specific variables in motivation}

Among those who experienced the visualization of using Mandarin, the mean scores for visionspecific variables (i.e., vividness of imagery, visual style and auditory style) exceeded the mid-point (Table 5). Specifically, the figure for vividness of imagery is 4.29 , which suggests a strong visualization capacity. Interestingly, the mean value for auditory style $(M=4.79)$ is much higher than visual style $(M=3.73)$. This indicates a tendency that participants prefer auditory styles over visual styles in learning, which could also explain the phenomenon whereby learners always pick up Mandarin pronunciation faster and easier, compared with remembering and recognizing Mandarin words. However, no significant correlation was found between vision-specific variables and the L2 motivational self-system. 
Table 5 Descriptive Statistics of Vision-specific Variables

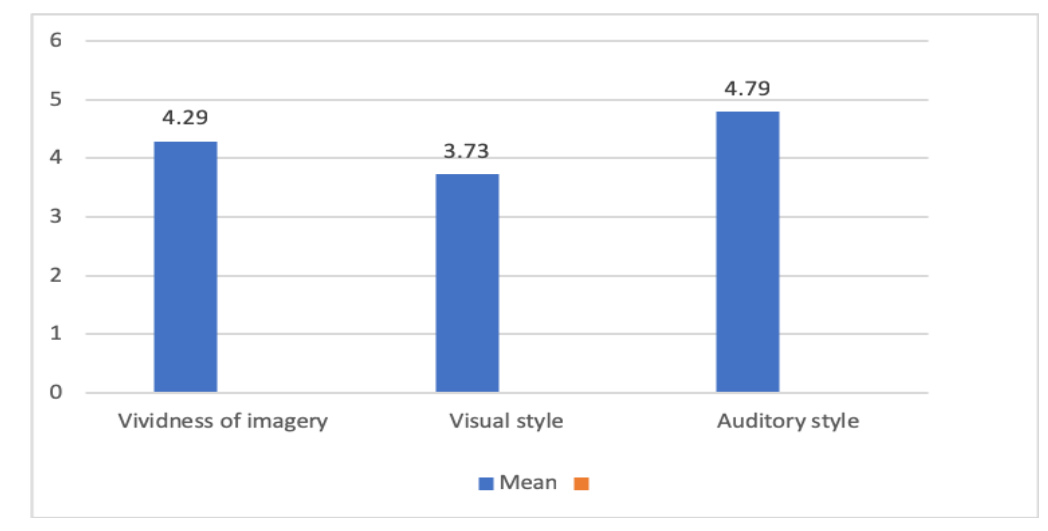

\section{Discussion}

\subsection{Answering questions}

Question 1: What does students' motivation look like in the context of learning Mandarin as a second language in the UK? What does motivation look like between groups according to year (Years 7/8) and gender?

The results show that students are highly motivated towards learning Mandarin as seven out of nine motivation variables exceed the midpoint (3.50), apart from ought-to L2 self and instrumentality (prevention). (1) Among all the motivation variables, cultural interest is the most attractive factor for participants (M=5.26). Wen's study (1997), conducted among university students from Asian and Asian American families, also reported that the interest in Chinese culture motivated learners the most. (2) Ideal L2 self ( $M=4.56)$ and L2 learning experience ( $M=4.60)$ play important roles in learners' motivation. Interestingly, the mean scores for both are very close in this study. Similarly, Csizer and Kormos's (2009) study also found that ideal L2 self and L2 learning experience were almost equally important regarding secondary schools learners' motivation towards L2 English in Hungary. Wen's (2013) study revealed that L2 learning experience highly motivated American students' Mandarin learning. (3) The mean values for ought-to L2 self and instrumentality (prevention) are the lowest, which indicates that UK learners are less compelled and personally choose to pursue L2 Mandarin learning. A closer look at ideal L2 self and ought-to L2 self, reveals that the mean values for the former are much higher than those for the latter, which has been considered to be a general tendency in L2 language learning (Dörnyei and Chan., 2013; Liu, 2014; You and Dörnyei., 2016).

(1) In terms of the findings broken down by year, significant differences were found for ideal L2 self, intended effort and L2 learning experience between Year 7 and Year 8. That is, Year 8 show a less ideal L2 self, positive experience and intended effort than Year 7 in using Mandarin.

(2) In terms of the motivation difference between males and females, the results show that the mean values for males $(\mathrm{N}=14)$ exceeded those for females $(\mathrm{N}=22)$ in the case of seven motivation variables, apart from travelling and L2 learning experience. Significant differences between males and females can be observed for ought-to L2 self and family influence, where males exceed females. Conversely, most of the research on L2 language learning shows an opposite tendency in terms of gender difference. Henry (2010) proposed that the core difference between males and females is that females show more 
interdependency during and commitment to interpersonal interaction than males. Therefore, females are more likely to invest in self-other relationships. Henry and Cliffordson (2013) further explained that females view their involvement in communication as being much easier than males, which in turn shapes their motivational future self-guides. That is to say, in terms of L2 language learning motivation, females are supposed to be motivated more than males. A large-scale survey of L2 English learners conducted in Chinese secondary schools also revealed the tendency that female learners are more motivated than males (You and Dörnyei, 2016). However, the results of this study pointed to an opposite phenomenon where males are more motivated than females for most of these motivation variables. Just as Henry (2010) suggested that further surveys should be conducted in different contexts to test his own speculations, this L2 Mandarin-specific feature also needs to be investigated in more detail in future.

\section{Question 2: What are the relationships between motivation variables and intended effort? To what extent does motivation contribute to participants' intended effort in learning Mandarin?}

This survey found out that ideal L2 self, instrumentality (promotion), cultural interest, travelling and L2 learning experience have significant correlations with intended effort. Family influence also significantly correlates with intended effort but plays a relatively moderate role. Meanwhile, according to a survey of L2 English learning conducted in China (You and Chen,2016; Chen et al., 2005), Chinese L2 English learners showed that there was a strong correlation between intended effort and family influence. Therefore, Chinese learners of L2 English face more external pressure than UK learners of L2 Mandarin. This is in accordance with the striking contrast between ideal L2 self and ought-to L2 self in terms of the correlation with intended effort. Similarly, Yu's (2009) study, which compared the Australian learners of L2 Mandarin and Chinese learners of L2 English, revealed that Australian leaners were more motived by internal interests than Chinese learners in L2 language learning.

The results of regression further revealed that cultural interest, travelling and instrumentality (prevention) have a significant prediction effect in terms of intended effort ( $p<.05)$. Participants' intended effort is equal to $.175+.341 *$ cultural interest $+.416 *$ travelling $-.239 *$ instrumentality (prevention).

\section{Question 3: Have L2 Mandarin learners engaged in the visualization of using Mandarin? If they have, does vision make a difference to the $\mathrm{L} 2$ motivational self system between the vision- yes and vision-no groups?}

This survey found that the majority of the participants have already developed vision in L2 Mandarin learning as the numbers of participants in the vision-yes group $(\mathrm{N}=33)$ outnumbers those in the vision-no group $(\mathrm{N}=7)$. The independent-samples $\mathrm{T}$ test proved that vision does have a statistical difference concerning L2 learning experience between the vision-yes and vision-no groups but no significant difference for ideal L2 self and ought-to L2 self. A general trend whereby most L2 learners from secondary schools have developed visualization in an L2 language has been confirmed by Dörnyei and Chan (2013) and Chan (2015), which further revealed that the vision-yes group scored higher than the vision-no group in terms of ideal L2 self and L2 learning experience. 
Question 4: What is the relationship between vision-specific variables (i.e., vividness of imagery, visual style and auditory style) and $L 2$ motivational self system among the vision-yes group?

According to the analysis, the mean values for vision-specific variables exceeded the midpoint, which means that the participants have developed vivid visualization. The figures for auditory style $(M=4.79)$ exceed those for visual style $(M=3.73)$, which could explain why speaking and listening are always easier than reading when the students acquire such skills. However, considering that the number of participants is small, this inference needs to be further confirmed. In the survey conducted by You et al. (2016), significant correlations were found between vision-specific variables and the L2 motivational self system. However, no correlation between vision-specific variables and the system was found in this study.

\subsection{Overall limitations and suggestions for further study}

Due to the current nature of the MEP, this study was only able to investigate the participants who have studied Mandarin for one or two years. More dynamic changes in motivation and vision could be found in future along with the development of this programme. This study only used a questionnaire to collect data. Although general findings were produced using quantitative methodology to some extent, this study was limited in terms of investigating the reasons such as why the participants are highly motivated by travelling in China and why Year 8 are less motivated than Year 7. Based on the limitations discussed above, this study can be mainly expanded in the following respects:

\section{(1) Samples}

On the one hand, focusing on MEP students offers some advantages in research as they all attend the same school, follow the same Mandarin curriculum and are taught by the same teachers. On the other hand, these MEP students are at a relatively higher level of L2 Mandarin than the non-MEP students. It would be interesting to investigate what non-MEP students' motivation looks like and whether they have experienced the visualization of using L2 Mandarin. Therefore, a comparison between the MEP and non-MEP groups would provide a more comprehensive view of motivation towards L2 Mandarin among students from UK secondary schools.

\section{(2) Time}

It would be productive to conduct this survey on repeated basis at different times to find out whether there are significant changes in motivation and vision during the whole learning process, as well as further identify general trends concerning such changes.

\section{(3) Methodology}

Qualitative methods such as interviewing are recommended for gathering data in more details (Johnson and Onwuegbuzie, 2004) such as the reason why Year 8 students experienced less fun in their L2 learning experience than Year 7. Further research could also be considered in which intended effort is replaced with the actual results of Mandarin language tests, in order to find out to what extent motivation might affect students' actual achievement. 
Volume 1, Issue 2, December 2019 Journal of Education, Innovation, and Communication (JEICOM) 


\section{Conclusion}

By conducting the survey among 40 students on MEP from a secondary school in London, this study presented a profound insight into motivation and vision in L2 Mandarin learning. The participant learners are highly motivated and intend to make great efforts towards learning Mandarin. The attraction of Chinese culture is the strongest reason given for learning Mandarin, followed by wishing to travel to China, personal development (instrumentality promotion) and L2 learning experience. A striking contrast was noted between ideal L2 self and ought-to L2 self. The latter, which is less internalized by learners, has a less powerful influence on learners' motivation. It was further revealed that cultural interest and travelling positively predicts participants' intended effort, while instrumentality prevention has a negative prediction effect. Among the participants in this study, Year 7 learners scored significantly higher than those in Year 8 on ideal L2 self, L2 learning experience and intended effort. Males scored significantly higher than females on ought-to L2 self and family influence. In vision domain, this study revealed that, although the learners in the study were only in their first or second year of learning Mandarin, most of them have already visualized speaking/using the language. Having visualization experience makes a significant difference to L2 learning experience, given that those who are able to visualize the use of Mandarin have a better experience of learning it. In general, this study shared features that have been characteristics of the majority of other studies. For example, the contrast between ideal L2 self and ought-to L2 self is striking as ideal L2 self is much stronger than ought-to L2 self (Ryan, 2009; Dörnyei and Chan, 2013; You and Dörnyei., 2016). Meanwhile, gender makes a differences to motivation (Henry and Cliffordson, 2013; You et al., 2016) and the majority of the participants have engaged in vision and experienced changes in this regard (Dörnyei and Chan, 2013; Chan, 2015; You et al., 2016). However, this study also revealed certain unique traits as follows: instrumentality (promotion) is stronger than ideal L2 self; males' motivation in L2 Mandarin is significantly stronger than that of females; future self-guidance has no prediction effect in terms of intended effort; vision only makes a significant difference to L2 learning experience but not ideal L2 self and ought-to L2 self; no significant correlation has been found between vision-specific variables and the L2 motivational self system.

Theoretically, it is the first study on L2 Mandarin motivation to be conducted in the context of the MEP in the UK. Although this study is a small-scale study, it makes a small but profound step towards expanding the research scope for L2 Mandarin motivation. This study is also one of the few studies to have applied Dörnyei's L2 motivational self system in the context of L2 Mandarin learning. To some aspects, the results are comparable to the results of previous studies on this system conducted in the context of L2 English. Most importantly, they revealed that, although the L2 Mandarin learners had only been learning the language for one or two years, they are highly motivated and most of them have already developed the capacity to visualize using Mandarin.

Practically, the results of this research can be used by teachers and other educators to contribute to L2 Mandarin teaching or curriculum designs in the following respects: (1) According to the findings, the most compelling reason why participants desire to learn Mandarin is the attraction of Chinese culture. Thus, a teaching curriculum where teachers integrate cultural components into Mandarin language teaching would be a must (2) It is worth noting that Year 8 learners' L2 learning experience and intended effort are not as high as in Year 7. If this represents a tendency, it could affect the teaching process and further influence students' achievement in the language in the long term. (3) As learners' intended effort is significantly connected with most of the motivation variables, teachers should always motivate learners using various approaches, especially in relation 
to cultural interest and travelling, which have a positive prediction effect on intended effort. (4) Teachers could proactively guide learners to practice their visualization, concerning future selfimages, to promote their motivation as the results of this study show that vision makes a significant difference to L2 Mandarin learning experience.

\section{References}

Al-Shehri, A. S. (2009). Motivation and vision: The relation between the ideal L2 self, imagination, and visual style. In Z. Dörnyei \& E. Ushioda (Eds.), Motivation, language identity and the L2 self (pp. 164-171). Bristol: Multilingual Matters. Chan, L. (2014). Effects of an imagery training strategy on Chinese university students' possible second language selves and learning experiences. In K. Csize' $r$ \& M. Magid (Eds.), The impact of self-concept on language learning (pp. 357-376). Bristol, UK: Multilingual Matters.

Chen, J. (2010). Introduction: Teaching and learning Chinese in a global era. In J. Chen, C. Wang \& J. Cai (Eds.), Teaching and learning Chinese: Issues and perspectives (pp. ix- xx). NC: Information Age Publishing. Chen, J. F., C. A. Warden, and H. Chang. (2005). Motivators that do not motivate: The case of Chinese EFL learners and the influence of culture on motivation. TESOL Quarterly(pp. : 609-63), Vol.39

Comanaru, R., \& Noels, K. (2009). Self-determination, motivation, and the learning of Chinese as a heritage language. Canadian Modern Language Review(pp.131-158), Vol.66, No1

Csizer, K., \& Kormos, J. (2009). Modelling the Role of Inter-Cultural Contact in the Motivation of Learning English as a Foreign Language. Applied Linguistics, Vol.30, No2

Dörnyei, Z. (1994). Understanding second language motivation: On with the challenge! Modern Language Journal, Vol. 78, No4

Dörnyei, Z. (2001). Motivational strategies in the language classroom. Cambridge: Cambridge University Press.

Dörnyei, Z. (2003). Attitudes, orientations, and motivations in language learning: Advances in theory, research and applications. Language Learning, Vol.53,No1

Dörnyei, Z. (2005). The psychology of the language learner: Individual differences in second language acquisition. Mahwah, NJ: Lawrence Erlbaum.

Dörnyei, Z. (2009). The L2 motivational self system. In Z. Dörnyei \& E. Ushioda (Eds.), Motivation, language identity and the L2 self (pp. 9-42). Bristol: Multilingual Matters.

Dörnyei, Z. (2010). Questionnaires in second language research: Construction, administration, and processing (2nd ed.). London: Routledge.

Dörnyei, Z., \& Chan, L. (2013). Motivation and vision: An analysis of future L2 self images, sensory styles, and imagery capacity across two target languages. Language Learning, Vol.63, No3

Do r̈nyei, Z., Ibrahim, Z., \& Muir, C. (2015). "Directed Motivational Currents": Regulating complex dynamic systems through motivational surges. In Z. Do rnyei, P. D. MacIntyre, \& A. Henry (Eds.), Motivational dynamics in language learning (pp. 95-106). Bristol, UK: Multilingual Matters.

Dörnyei, Z., \& Kubanyiova, M. (2014). Motivating learners, motivating teachers: Building vision in the language classroom. Cambridge: Cambridge University Press. 
Dörnyei, Z., \& Ushioda, E. (2011). Teaching and researching motivation (2nd ed.). Harlow: Longman.

Higgins, E. T. (1987). Self-discrepancy: A theory relating self and affect. Psychological Review, Vol.94

Kormos, J., Kiddle, T., \& Csize' r, K. (2011). Systems of goals, attitudes, and self-related beliefs in second-language-learning motivation. Applied Linguistics, Vol 32

Kosslyn, S. M., Thompson, W. L., \& Ganis, G. (2006). The case for mental imagery. New York: Oxford University Press.

Gardner, R. C., \& Lambert, W. E. (1959). Motivational Variables in Second-Language Acquisition. Canadian Journal of Psychology, Vol.13, No4

Gardner, R. C., \& Lambert, W. E. (1972). Attitudes and motivation in second-language learning. Rowley, MA: Newbury House.

Gardner, R. C. (1985). Social psychology and second language learning: The role of attitudes and motivation. London: Edward Arnold.

Gardner, R. C. (2001). Integrative motivation and second language acquisition. In Z. Dörnyei \& R. Schmidt (Eds.), Motivation and second language acquisition (pp. 1-19). Honolulu, HI: University of Hawaii Press.

Gardner, R. C. (2006). The socio-educational model of second language acquisition: A research paradigm. In S. H. Foster-Cohen, M. M. Krajnović \& J. M. Djigunović (Eds.), Eurosla Yearbook, Volume 6 (pp. 237-260). Amsterdam, Netherlands: John Benjamins.

Gardner, R. C., \& Smythe, P. C. (1975). Motivation and second-language acquisition. Canadian Modern Language Review, Vol.31

Gass, S. M., \& Selinker, L. (2008). Second language acquisition: An introductory course (3rd ed.). New York, NY: Routledge.

Henry, A. (2010). Gender differences in L2 motivation: A reassessment. In S. Davies (Ed.), Gender gap: Causes, experiences and effects (pp. 81-102). New York: Nova Science.

Henry, A., \& Cliffordson, C. (2013). Motivation, gender, and possible selves. Language Learning, Vol.63

Higgins, E. T. (1987). Self-discrepancy: A theory relating self and affect. Psychological Review, Vol.94

Higgins, E. T. (1998). Promotion and prevention: Regulatory focus as a motivational principle. Advances in Experimental Social Psychology, Vol.30

Johnson, R. B., \& Onwuegbuzie, A. J. (2004). Mixed Methods Research: A Research Paradigm Whose Time Has Come. Educational Researcher, Vol.33, No7

Kim, T. (2009). The sociocultural interface between ideal self and ought-to self: A case study of two Korean students' ESL motivation. In Z. Dörnyei \& E. Ushioda (Eds.), Motivation, language identity and the L2 self (pp. 274-294). Bristol: Multilingual Matters.

Kim, Y. K., \& Kim, T. Y. (2011). The effect of Korean secondary school students' perceptual learning styles and ideal L2 self on motivated L2 behavior and English proficiency. Korean Journal of English Language and Linguistics, 11, 21-42.

Kim, T. Y. (2009). Korean elementary school students' perceptual learning style, ideal L2 self, and motivated behaviour. Korean Journal of English Language and Linguistics, Vol 9 
Lamb, M. (2009). Situating the L2 self: Two Indonesian school learners of English. In Z. Dörnyei \& E. Ushioda (Eds.), Motivation, language identity and the L2 self (pp. 229-247). Bristol: Multilingual Matters.

Liu, Y. (2014). A Study of L2 Chinese Learners' Motivational Self System. Published by ProQuest LLC.

Mackay, J. (2014). Applications and implications of the L2 Motivational Self System in a Catalan EFL context. In K. Csize $r$ \& M. Magid (Eds.), The impact of self-concept on language learning (pp. 377-400). Bristol, UK: Multilingual Matters.

MacIntyre, P. D., Mackinnon, S. P., \& Clément, R. (2009). The baby, the bathwater, and the future of language learning motivation research. In Z. Dörnyei \& E. Ushioda (Eds.), Motivation, language identity and the L2 self (pp. 43-65). Bristol: Multilingual Matters.

Magid, M. (2014). A motivational programme for learners of English: An application of the L2 Motivational Self System. In K. Csize'r \& M. Magid (Eds.), The impact of self-concept on language learning (pp. 333-356). Bristol, UK: Multilingual Matters.

Morris, T. (1997). Psychological skills training in sport: An overview (2nd ed.). Leeds, UK: National Coaching Foundation.

Morris, T., Spittle, M., \& Watt, A. P. (2005). Imagery in sport. Champaign, IL: Human Kinetics.

Ortega, L. (2009). Understanding second language acquisition. London: Hodder Arnold.

Papi, M. (2010). The L2 motivational self system, L2 anxiety, and motivated behavior: A structural equation modeling approach. System, 38

Rueda, R., \& Chen, C. B. (2005). Assessing motivational factors in foreign language learning: Cultural variation in key constructs. Educational Assessment, Vol.10, No3

Ryan, S. (2009). Self and identity in L2 motivation in Japan: The ideal L2 self and Japanese learners of English. In Z. Dörnyei \& E. Ushioda (Eds.), Motivation, language identity and the L2 self (pp. 120-143). Bristol: Multilingual Matters.

Ryan, R., \& Deci, E. (2000). Self-determination theory and the facilitation of intrinsic motivation, social development, and well-being. American Psychologist, Vol.55

Ryu Yang, J. S. (2003). Motivational orientations and selected learner variables of East Asian language learners in the United States. Foreign Language Annuals, Vol.36, No1

Sampson, R. (2012). The language-learning self, self-enhancement activities, and self perceptual change. Language Teaching Research, Vol.16

Skehan, P. (1989). Individual differences in second-language learning. London: Edward Arnold.

Taguchi, T., M. Magid, \& M. Papi. (2009). The L2 motivational self system among Japanese, Chinese and Iranian learners of English: A comparative study. In Z. Dörnyei and E. Ushioda (eds): Motivation, Language Identity and the L2 Self (pp. 66-97). Multilingual Matters.

Taguchi, N. (2013). Motivation, attitudes and selves in the Japanese context: A mixed methods approach. In M. T. Apple, D. Da Silva, \& T. Fellner (Eds.), Language learning motivation in Japan (pp. 169-188). Bristol, UK: Multilingual Matters.

Wang, A. H. (2010). Motivating U.S. students to learn Chinese as a second language: Understanding the interactions between motivation, ethnicity, and teaching strategies. In J. Chen, C. Wang \& J. Cai (Eds.), Teaching and learning Chinese: Issues and perspectives (pp. 117-135). NC: Information Age Publishing.

Watt,N., \& Adams, R. (2013,December 5). David Cameron urges British students to ditch French and learn Mandarin. The Guardian. 
Wen, X. (1997). Motivation and language learning with students of Chinese. Foreign Language Annals, Vol.30

Wen, X. (2011). Chinese language learning motivation: A comparative study of heritage and nonheritage learners. Heritage Language Journal, Vol.8, No3

Wen, X. (2013). Chinese language learning motivation: Studies of ethnic background and proficiency level. Shijie Hanyu Jiaoxue, 2013 No1

Xie, Y. (2011). Representations of L2 motivational self system with beginning Chinese language learners at college level in the United States: Heritage and non-heritage language learners (Doctoral dissertation). Retrieved from ProQuest Dissertations and Theses database.

You, C. J., \& Chan, L. (2015). The dynamics of L2 imagery in future motivational self guides. In Z. Dörnyei, P. MacIntyre, \& A. Henry (Eds.). Motivational dynamics in language learning (pp. 397-418). Bristol, UK: Multilingual Matters.

You, C. J., \& Dörnyei, Z. (2016). Language learning motivation in China: Results of a large-scale stratified survey. Applied Linguistics, Vol.37, No4

You, C. J., Dörnyei, Z., \& Csizér, K. (2016). Motivation, vision, and gender: A survey of learners of English in China. Language Learning, Vol.66, No1

$\mathrm{Yu}, \mathrm{Y}$. (2009). A study of foreign language learning motivation and achievement: From a perspective of sociocultural theory. CELEA Journal, Vol.32, No3

Yu, B., \& Watkins, D. (2008). Motivational and cultural correlates of second language acquisition: An investigation of international students in the universities of the People's Republic of China. Australian Review of Applied Linguistics, Vol.31, No2 


\title{
The Effect of Face-to-Face and non-Face-to-Face Synchronously Collaborative Writing Environment on Student Engagement and Academic Performance
}

\author{
Mengying Han ${ }^{12 *}$ \\ Yushun $\mathrm{Li}^{13}$
}

\begin{abstract}
Collaborative Writing (CW) tools such as Google Docs provide an efficient way for students to perform collaborative writing tasks. This research is based on a novel $\mathrm{CW}$ tool called Cooperpad, with a group awareness functionality, which continuously gathers group members' writing behaviour, analyzes and visualize their engagement intensity for group members to compare their participation with that of others. The comparative experiment is carried out in two different online learning environments: face-to-face and non-face-to-face, with an experimental group $(\mathrm{N}=72)$ and a control group $(\mathrm{N}=48)$. Through systematic data and post-test design we have examined in which environment the students showed more engagement in the group-writing task. The results showed that Cooperpad writing system is more helpful to enhance the student engagement and improve students' academic performance on certain levels in face-to-face online learning environment compared with non-face-to-face. Moreover, the student engagement was positively correlated to the academic performance. Students have a high degree of the system, which has a positive promoting effect on learning initiative and teamwork ability.
\end{abstract}

\section{Key Words}

collaborative learning, synchronously collaborative writing system of Cooperpad, student engagement, academic performance, learning environment

\section{Introduction}

In the 21st century, Information and Communication Technology (ICT) accelerates global competition and collaboration (Dicerbo, 2012). The Partnership for the 21st century skills also proposed that the students must have the essential skills to be successful in the life and workplace, such as innovative thinking skills, communication and collaboration skills, critical thinking and problem solving skills. With the development of information technology, exploring how technology enables learners to study more efficiently has become an important mission of educators in the 21st century (Fadel, Trilling \& Charles, 2009).

Computer Supported Collaborative Learning (CSCL) plays an important role in helping learners acquire knowledge, skills and improving learning effect, by combining computer technology with collaborative learning (Stahl, 2010). As a form of CSCL, Collaborative Writing (CW) is an iterative and social process that involves a group focused on a common objective that negotiates,

\footnotetext{
${ }^{12}$ Postgraduate,Beijing Normal University, School of Educational Technology, China, mengying han@126.com

${ }^{13} \mathrm{PhD}$, Faculty of Education, School of Educational Technology, Beijing Normal University, China, lyshun@bnu.edu.cn
} 
coordinates, and communicates during the creation of a common document (Lowry et al., 2004). It not only improves the quality of collaborative learning, but also enhances students' ability to analyze and solve problems in the online learning environment (Yarrow et al., 2011). In recent years, Collaborative Writing $(\mathrm{CW})$ has obtained many educational researchers' interests because of its potential pedagogical benefits. However, most of the research is limited to non-real-time collaborative writing tools (such as Wiki), but it pays less attention to real-time collaborative writing tools (such as Google Docs). The CW tools often lack of behavioural analysis in the process of writing, which cannot provide effective feedback in time (Wheeler et al., 2010). Studies have shown that the real-time collaborative writing tools have the timeliness and identity of writing behaviour and writing process, which can stimulate students' group motivation and improve the learning enthusiasm (Pymm \& Hay, 2014).

But few studies have compared the effects of real-time collaborative writing in different online learning environments. More important, it is not easy for learners to cooperate effectively in online learning. (Zurita \& Nussbaum, 2010). And it often produces different learning effects in different online learning environments between face-to-face and distributed in CSCL (Mochizuk et al., 2002). Studies have shown that the impact of non-face-to-face online learning may be greater than that of face-to-face, because online learning is easy to remove irrelevant factors such as interpersonal relationship and real environment from the interaction relationship (Tran, Raikundalia \& Yang, 2006). Compared with face-to-face communication, non-face-to-face communication in $\mathrm{CW}$ is more helpful to promote the equal participation of learners in discussion (Warschauer, 1996) and enhance the interaction of collaborative learning (Abuseileek, 2012). From the perspective of social support (Cohen \& Wills, 1985), the design of CSCL need to fully consider the differences between face-to-face and non-face-to-face interactions to further enhance collaborative learning.

In this article, an online Synchronously collaborative writing tool with group awareness functionality called Cooperpad has been applied to create an online synchronously collaborative writing environment. The tool can analyze each group member's writing behavior and visualizes his or her behavioral engagement with a writing task (Liu Ming, 2018). The "Advanced Web Application Development" course is taken as an example to conduct empirical research, which is carried out in two different online learning environments: face-to-face and non-face-to-face.

The major highlights of our work can be described as follows:

- Can the Cooperpad tool improve collaborative student engagement in the synchronously collaborative writing environment? What is the difference in the improvement of student engagement between face-to-face and non-face-to-face?

- Can the Cooperpad tool improve students' academic performance in the synchronously collaborative writing environment? What is the relationship between student engagement and academic achievement, and how relevant is it?

- Exploring how students evaluate Cooperpad tools through face-to-face interviews? 


\section{Literature Review}

In educational, CSCL involves Collaborative Writing, where "students produce a joint text by writing a piece of text each” (Bradley, Lindström, Rystedt \& Vigmo, 2010). Collaborative Writing, which consists of one or more participants modifying, by editing, and revising the text of the participants (Witney \& Smallbone, 2011), are assumed to have the potential to enhance the effectiveness of peer learning interactions (Wang, 2016). Collaborative Writing (CW) has been defined in many ways. One of the earliest definitions is "participants producing a shared document by engaging in substantial interaction and sharing decisions and responsibility for it (Allen, 1987)". On the other hand, it focuses on the quality of interaction in collaborative writing, stressing the context of the writing situation and the relationships of the students (Donato, 1994). Collaborative writing is an iterative and social process that involves a group focused on a common text during the creation of a common document (Lowry et al, 2004) through interactions, shared knowledge and joint decision-making throughout the whole process (Neumann \& McDonough, 2015).

Collaborative writing is underpinned by Vygotsky's sociocultural learning theory (Kuteeva, 2011), which assumes that collaboration among participants can achieve more in terms of learning benefits than individuals (Hadjerrouit, 2014). An aspect of this theory relevant to collaborative writing is the concept of the Zone of Proximal Development (ZPD), where group members use mediational means collaboratively to create, obtain, and communicate meaning (Vygotsky, 1978). By collaborating with each other, learners are able to engage in the composition process with more clarity and understanding. Students' writings were found to be more grammatically accurate (Zhila \& Parisa, 2015), organization and vocabulary (Shehadeh, 2011). In general, the students had positive perceptions of collaborative writing.

From the perspective of time dimension, there are two collaborative writing modes, non-real-time and real-time (Storch, 2005). At present, common collaborative writing tools include wiki, Google Docs and Etherpad, etc. In China, most researches are carried out on non-real-time wiki, with less exploration on real-time tools. In addition, studies have pointed out that in the process of non-realtime collaborative writing, students often have the problem of low engagement in the group-writing task (Wheeler, Yeomans \& Wheeler, 2010), and the collaborative writing effect is often not ideal. Most students often stay on the surface of browsing content and editing text, without in-depth communication and reflection between groups (Heng, Niiya \& Warschauer, 2015). The real-time collaborative writing tools have the timeliness and identity of writing behavior and writing process (Erkens et al., 2005). The participants can see the jointly edited documents synchronously, which is helpful to enhance the enthusiasm of team members in writing, to improve the sense of team belonging and collaborative student engagement (Pymm \& Hay, 2014).

From the perspective of spatial dimension, there are two modes of collaborative writing: non-faceto-face and face-to-face, that is, collaborative writing under the non-face-to-face and face-to-face online learning environments (Storch, 2005). Computer-based interaction is the premise and specific performance of collaborative writing. It is not easy for students to study effectively. Collaborative learning in face-to-face and non-face-to-face online learning environments of common tasks often produces different learning effects. Some studies have pointed out that face-toface online learning environment can reduce the loneliness brought by social network, enhance the sense of real-time and presence, and make it easier to communicate (Helms, 2014). However, some studies have also found that compared with face-to-face learning environment, non-face-to-face 
online learning environment can reduce the interference of complex factors such as students' interpersonal relationship, and is more conducive to promoting equal communication among learners (Chew \& Ng, 2016). In a word, it is necessary to conduct further research on real-time collaborative writing tools to explore their specific application value in different online learning environments, face-to-face and non-face-to-face.

\section{Methodology}

This paper aims to explore the impact of Cooperpad tool, an online real-time collaborative writing system, on student engagement and academic achievement in face-to-face and non-face-to-face synchronously collaborative writing environment, and to further explore the relationship between student engagement and academic performance.

Cooperpad (Liu et al., 2013) is a web-based system that provides real-time collaborative writing environment. Its function is to support the creation and management of online writing tasks, and the creation of online documents. It can stimulate students' collaborative writing through visual data analysis.

In this study, 87 sophomore students majoring in software engineering in a university in China were selected as experimental subjects ( 58 male, 29 female), with an average age of 20 and balanced computer operation level. They were randomly divided into face-to-face group and non-face-to-face group. On the one hand, the face-to-face group (42 persons, 29 male and 13 female) use the Cooperpad to carry out "face-to-face" synchronously collaborative writing, that is, seats are arranged together and they use oral language to communicate, and the group chat function of the system is turned off. On the other hand, the non-face-to-face group (45 persons, 29 male, 16 female) use the Cooperpad to carry out "non-face-to-face" synchronously collaborative writing, that is, the seating order is out of order, and they only use the chat window provided by the Cooperpad to communicate with each other in different places. The experimental group and control group were randomly divided into 3 persons in each group.

Students were asked to collaboratively write a project proposal in the "Advanced Web Application Development" course in the synchronously collaborative writing environment, which required students to discuss what system they will build using the web technologies and what are the distinct features of the system. Students had unrestricted access to the Internet or their textbooks for information to complete all parts of the project proposal (at least 1000 words). Before class, students spent time on thinking about what project they are going to build, so the writing task is manageable in a two-hour time frame based on our experience. The comparative experiment based on the Cooperpad was carried out in two networked computer labs with the same conditions. One week before the experiment, the teacher introduced the related operations of the Cooperpad, and the students had a certain degree of understanding of it.

Before the experiment, the teacher publishes the pre-designed homework questions and writing templates. After the teacher introduced the topic and the requirements, the non-face-to-face group and the face-to-face group started writing at the same time in the synchronously collaborative writing environment. 
During the experiment, neither the teacher nor the researcher communicated with the subject. At the end of the experiment, a semi-structured interview was conducted on 30 students (at least one in each group) in the form of face-to-face contact, conducted in a voluntary manner. The feelings of the learners using the Cooperpad were investigated, and Table 1 is an example of the interview questions.

Table 1. an example of the interview questions

Q1. Satisfaction with the use of the collaborative writing tools for collaborative learning, such as Do you think that using the Cooperpad in the synchronously collaborative writing environment for collaborative learning can improve learning interest and learning enthusiasm? What are the reasons?

Q2. About the experience of using the collaborative writing tools to interact with peers, such as Can you express your thoughts freely in peer discussions in the Cooperpad? Do you prefer face-toface or non-face-to-face?

Q3. General questions about using the Cooperpad, such as

What do you think are the advantages and disadvantages of using the Cooperpad for collaborative learning? What suggestions do you have for using the Cooperpad to help learning or improve the system itself?

\section{Results}

At the end of the experiment, two researchers graded the students' submissions according to a scale provided by the teacher. The student engagement data recorded in the system were exported and SPSS 23.0 was used for statistical analysis. Table 2 shows the comparison results of the student engagement of the face-to-face group and the non-face-to-face group in the collaborative writing process. The average student engagement of the face-to-face group was 1131.133, while the nonface-to-face group was 1455.644. It can be seen that the engagement of non-face-to-face groups is higher than that of face-to-face groups. The differences was significant $(\mathrm{t}=-2.079$, sig $=0.047$, $\mathrm{p}<0.05)$, tested using a t-test for independent samples. This indicates that in practical application, the Cooperpad can enhance the learning enthusiasm of students and improve student engagement of cooperative learning in the synchronously collaborative writing environment. Especially in the nonface-to-face online learning environment, it has more obvious effect on improving the student engagement, which further indicates that the Cooperpad is more suitable for collaborative writing in the non-face-to-face synchronously collaborative writing environment. On the one hand, this result is consistent with the Sinatra et al. (2015) study which showed that active participation is the key to effective learning, and high students' engagement will affect students' knowledge acquisition and ability improvement. On the other hand, with the non-face-to-face synchronously collaborative writing environment compared with the face-to-face, the Cooperpad frees itself from the influence of other complex factors such as interpersonal relationships, collaborative environments and helps students to communicate and interact equally (Chew \& Ng, 2016). The interaction of information technology has always been regarded as one of the influencing factors that promote student engagement in learning (Dixson, 2010). 
Table 2. student engagement analysis and $\mathrm{T}$ test results of face-to-face group and non-face-to-face group in the synchronously collaborative writing

\begin{tabular}{|c|c|c|c|c|c|}
\hline Group & $\mathrm{N}$ & Mean & $\mathrm{F}$ & $\mathrm{t}$ & $\mathrm{ES}$ \\
\hline face-to-face & 14 & 1131.133 & \multirow{2}{*}{0.046} & \multirow{2}{*}{-2.079} & .047 \\
\hline non-face-to-face & 15 & 1455.644 & & & \\
\hline
\end{tabular}

Table 3. bivariate correlation test results of concentration and score in the synchronously collaborative learning

\begin{tabular}{l|l|l|l}
\hline & student engagement & Number of words & Academic performance \\
\hline $\mathrm{P}$ & 1 & .240 & $.693^{* *}$ \\
\hline $\mathrm{ES}$ & & .210 & .000 \\
\hline $\mathrm{N}$ & 29 & 29 & 29 \\
\hline
\end{tabular}

Note: ** was at the level of 0.01 (bilateral), and the correlation was significant. * at the level of 0.05 (double-tailed), the correlation was significant

To further explore the relationship between student engagement and academic performance, a bivariate correlation test was conducted. It can be seen from the data results that there is a positive correlation between student engagement and their academic performance, which is significant at the level of 0.01 (see table 3). The results showed that the enhancement of the student engagement was helpful to the academic performance, and the higher the engagement was, the higher the performance was. This conclusion is consistent with the results of previous studies, which believed that student engagement is of great help to improve academic performance and is an important factor of it (Liu et al., 2015; Liu et al., 2018).

After the interview, the information obtained from the interviewees' answers can be summarized according to the following aspects (see table 4). Most of the participants said that the Cooperpad with group awareness functionality helped them enhance their sense of belonging and actively participate in team tasks of the synchronously collaborative writing environment. They also affirmed the real-time interaction and feedback capabilities of the tool. However, several other students put forward suggestions to improve the system function: single resource, it is recommended to provide more vivid and rich information, such as pictures, audio, video, etc. Moreover, the interactive tools provided by the platform have certain limitations; In order to address those limitations it is suggested to provide some tools for discussion, such as audio and video calls.

Table 4. the interview results of the Students' perceptions of the Cooperpad.

Q1: Satisfaction

Do you think that using the Cooperpad for collaborative learning can improve learning interest and learning enthusiasm? What are the reasons?

Answer1: In group writing, we can see the writing content of other members and provide suggestions at any time.

Answer2: The ability to edit in real time creates a positive competition for to work harder at the task.

Answer3: The student engagement graph can remind us to fulfill our responsibilities. We can also see the progress of other groups and encourage the enthusiasm in our group. 
Q2. Interactive preferences

Can you express your thoughts freely in peer discussions in the Cooper pad ? Do you prefer face-toface or non-face-to-face environment?

Answer 1: Online communication makes me feel more comfortable. I use the Internet to analyze and solve problems or urge team members to complete tasks. If this kind of conversation is carried out face to face, I will feel embarrassed.

Answer 2: In the discussion, I can express what I want to say. I am very comfortable, do not care about the other party's expressions and emotions, and do not feel too embarrassed.

Answer 3: Directly edit and modify on the platform, do not need to use Microsoft Word and other software, which is very convenient.

Answer 4: There is no need to upload or send a file, or even upload or send a modified job, saving time and effort

Q3. Suggestions

What do you think are the advantages and disadvantages of using the Cooperpad for collaborative learning? What suggestions do you have for using the Cooperpad to help learning or improve the system itself?

Answer 1: The system is very simple to use, the layout of the web page is clear, you can quickly find the group work page, chat discussion area.

Answer 2: The student engagement real-time graph is very cool, just to prevent some students becoming lazy, play a certain role in supervision and motivation.

Answer 3: The learning resources are relatively simple, which are all texts. I hope to provide more vivid learning resources.

Answer 4: Sometimes, my Suggestions take a long time to be answered, and I like to communicate synchronously with my partner so that problems can be solved quickly.

Answer 5: Synchronous chat is more helpful for discussing problems, and group members can schedule a time for voice chat, which is more convenient.

\section{Discussion and Conclusion}

With the development of the Internet, new ideas, new technologies and new tools have changed our learning and life. The society has higher and higher requirements for talents in the 21 st century. The ability to solve problems through collaboration has become a basic requirement. CSCL combines collaborative learning with computer technology, focusing on the collaborative learning theory and technical design, providing a broad space for collaborative learning. It plays an important role in helping students better acquire knowledge and skills. However, most of the relevant researches are limited to the non-real-time collaborative learning field, with insufficient attention to real-time collaboration and less control over student engagement.

In this article, an online collaborative writing tool with group awareness functionality called Cooperpad is applied to create the synchronously collaborative writing environment. And the "Advanced Web Application Development" course is taken as an example to conduct empirical research, which carried out in two different synchronously collaborative writing environments: face-to-face and non-face-to-face, to evaluate the collaborative learning effect of the Cooperpad and explore its educational application value.

The experimental results show that: 
- Compared with face-to-face synchronously collaborative writing environment, the Cooperpad improves the student engagement more significantly in non-face-to-face. That is non-face-to-face synchronously collaborative writing environment can help students to get rid of the interference of other complex factors such as interpersonal relationship and real environment to a certain extent, and promote equal communication and interaction between students (Chew \& $\mathrm{Ng}, 2016$ ). Moreover, the interaction of information technology plays an important role in promoting students' active participation and collaboration (Duque \& Lola, 2014).

- There is a significant correlation between student engagement and academic performance. The higher student engagement, the higher the academic performance, which has an impact on promoting student engagement and is a key factor affecting the learning effect (Pizzimenti \& Axelson, 2015).

- The interview results show that learners have a high evaluation of such functions as real-time interaction and visual feedback provided by Cooperpad, which confirms that the tool plays a positive role in promoting students' learning enthusiasm and team cooperation ability. Some students also put forward some suggestions to improve the existing functions of it, such as resource richness and functional diversity.

In summary, this study only verified the effect of online real-time collaborative writing system on student engagement and academic performance in different synchronously collaborative writing environments, nevertheless did not further explore the influence of other factors such as group division of labor and role arrangement. Secondly, as for the measurement and evaluation of the engagement of the tool, only the behavioral engagement is considered, while the evaluation of cognitive engagement and emotional engagement is insufficient. Finally, due to browser compatibility and other reasons during the experiment, the display effect of the real-time graph may affect the experimental results.

This study introduces a new perspective for exploring the educational practice of CSCL system in different online learning environments. However, we should not only pay attention to the learning effect, but also pay attention to the influence of students' cooperative ability and engagement. This research focuses on the impact of the synchronously collaborative writing environment on student engagement and academic performance, whilst not going deep into the interactive process analysis. The Cooperpad's group mutual evaluation function provides a ground for further research.

\section{References}

AbuSeileek, A. F. (2012). The effect of computer-assisted cooperative learning methods and group size on the EFL learners' achievement in communication skills. Computers \& Education, 58(1), 231-239.

Allen, N., Atkinson, D., Morgan, M., Moore, T., \& Snow, C. (1987). What experienced collaborators say about collaborative writing. Iowa State Journal of Business and Technical Communication, 1(2), 70-90.

Bradley, L., Lindström, B., \& Rystedt, H. (2010). Rationalities of collaboration for language learning in a wiki. ReCALL, 22(2), 247-265.

Cohen, S., \& Wills, T. A. (1985). Stress, social support, and the buffering hypothesis. Psychological bulletin, 98(2), 310. 
DiCerbo, K. (2014). Assessment and teaching of 21 st century skills.

Dixson, M. D. (2010). Creating effective student engagement in online courses: What do students find engaging?. Journal of the Scholarship of Teaching and Learning, 1-13.

Donato, R. (1994). Collective scaffolding in second language learning. Vygotskian approaches to second language research, 33456.

Duque, L. C. (2014). A framework for analysing higher education performance: students' satisfaction, perceived learning outcomes, and dropout intentions. Total Quality Management \& Business Excellence, 25(1-2), 1-21.

Erkens, G., Jaspers, J., Prangsma, M., \& Kanselaar, G. (2005). Coordination processes in computer supported collaborative writing. Computers in Human Behavior, 21(3), 463-486.

Hadjerrouit, S. (2014). Wiki as a collaborative writing tool in teacher education: Evaluation and suggestions for effective use. Computers in Human Behavior, 32, 301-312.

Helms, J. L. (2014). Comparing Student Performance in Online and Face-to-Face Delivery Modalities. Journal of asynchronous learning networks, 18(1), n1.

Kuteeva, M. (2011). Wikis and academic writing: Changing the writer-reader relationship. English for Specific Purposes, 30(1), 44-57.

Liu, M., Calvo, R. A., \& Pardo, A. (2013, July). Tracer: A tool to measure and visualize student engagement in writing activities. In 2013 IEEE 13th International Conference on Advanced Learning Technologies (pp. 421-425). IEEE.

Liu, M., Calvo, R. A., Pardo, A., \& Martin, A. (2014). Measuring and visualizing students' behavioral engagement in writing activities. IEEE Transactions on learning technologies, 8(2), 215-224.

Liu, M., Liu, L., \& Liu, L. (2018). Group awareness increases student engagement in online collaborative writing. The Internet and Higher Education, 38, 1-8.

Lowry, P. B., Curtis, A., \& Lowry, M. R. (2004). Building a taxonomy and nomenclature of collaborative writing to improve interdisciplinary research and practice. The Journal of Business Communication (1973), 41(1), 66-99.

Mochizuki, T., Egi, H., Ozawa, S., Shibahara, Y., Inoshita, O., \& Kato, H. (2002, December). Analysis of relationship between face-to-face collaborative learning and CSCL activities. In International Conference on Computers in Education, 2002. Proceedings. (pp. 387-391). IEEE.

Mohammadnia, Z., \& Ayaz, P. (2015). The Effects of Guided vs. Unguided Pressured Planning on EFL Learners' Writing Fluency. English Language Teaching, 8(3), 169-176.

Neumann, H., \& McDonough, K. (2015). Exploring student interaction during collaborative prewriting discussions and its relationship to L2 writing. Journal of Second Language Writing, 27, 84-104.

Pizzimenti, M. A., \& Axelson, R. D. (2015). Assessing student engagement and self-regulated learning in a medical gross anatomy course. Anatomical sciences education, 8(2), 104-110.

Pymm, B., \& Hay, L. (2014). Using etherpads as platforms for collaborative learning in a distance education LIS course. Journal of Education for Library and Information Science, 133-149.

Shehadeh, A. (2011). Effects and student perceptions of collaborative writing in L2. Journal of Second Language Writing, 20(4), 286-305.

Sinatra, G. M., Heddy, B. C., \& Lombardi, D. (2015). The challenges of defining and measuring student engagement in science. 
Stahl, G., Koschmann, T. D., \& Suthers, D. D. (2006). Computer-supported collaborative learning. na.

Storch, N. (2005). Collaborative writing: Product, process, and students' reflections. Journal of second language writing, 14(3), 153-173.

Tran, M. H., Raikundalia, G. K., \& Yang, Y. (2006). Using an experimental study to develop group awareness support for real-time distributed collaborative writing. Information and Software Technology, 48(11), 1006-1024.

Trilling, B., \& Fadel, C. (2009). 21st Century Skills.: Learning for Life in Our Times. John Wiley \& Sons.

Vygotsky, L. S. (1978). Mind in society (M. Cole, V. John-Steiner, S. Scribner, \& E. Souberman, Eds.).

Wang, D. (2016, February). How people write together now: Exploring and supporting today's computer-supported collaborative writing. In Proceedings of the 19th ACM Conference on Computer Supported Cooperative Work and Social Computing Companion (pp. 175-179). $\mathrm{ACM}$.

Warschauer, M. (1995). Comparing face-to-face and electronic discussion in the second language classroom. CALICO journal, 7-26.

Wheeler, S., YEoMAnS, P., \& WHEElER, D. (2008). The good, the bad and the wiki: Evaluating student-generated content for collaborative learning. British journal of educational technology, 39(6), 987-995.

Witney, D., \& Smallbone, T. (2011). Wiki work: can using wikis enhance student collaboration for group assignment tasks?. Innovations in Education and Teaching International, 48(1), 101110.

Yarrow, F., \& Topping, K. J. (2001). Collaborative writing: The effects of metacognitive prompting and structured peer interaction. British journal of educational psychology, 71(2), 261-282.

Zheng, B., Niiya, M., \& Warschauer, M. (2015). Wikis and collaborative learning in higher education. Technology, Pedagogy and Education, 24(3), 357-374.

Zurita, G., \& Nussbaum, M. (2007). A conceptual framework based on activity theory for mobile CSCL. British Journal of Educational Technology, 38(2), 211-235. 


\title{
Investigating the Relationships among College Students' Online Self-Regulated Learning, Grit and $5 \mathrm{C}^{14}$ Competences
}

\author{
Wei Sun ${ }^{15}$ \\ Chang $\mathrm{Xu}^{16}$ \\ \& Yan Dong ${ }^{17}$
}

\begin{abstract}
The competences of communication, collaboration, critical thinking, complex problem solving and creativity (5C) have already been widely emphasized by scholars and educators as important abilities in the $21^{\text {st }}$ century society (Hwang, Lai, Liang, Chu, \& Tsai, 2017). This study aims to investigate the effects of grit and self-regulated learning on learners' $5 \mathrm{C}$ competences in an online learning environment and measuring it through a quantitative survey. 103 Higher Education students participated in the study. The results of the study are: (1) communication can also be subdivided into two sub-dimensions: communication ways and communication feeling; (2) students' consistency of interests is not related to their self-regulated learning and 5C competences; (3) the results of linear regression indicated that students' perseverance of effort could predictor their 5C competences, and students' self-regulated learning especially goal setting, environment structuring, task strategies, help seeking and self-evaluation all positive impact their 5C competences. The findings suggested us the important meaning to develop students' characteristic and quality of grit to help students monitor, reflect and adjust their online learning, and develop their key skills ultimately. Implications of the findings for additional research and instruction are discussed.
\end{abstract}

Keywords : Online Self-Regulated Learning, Grit, Collaboration, Complex Problem Solving, Creativity, Communication, Critical Thinking

\section{Introduction}

The current era is a knowledge-based economy based on knowledge and brainpower, and an era of rapid development of information technology based on computers and the Internet. With the rapid development of technology being present in various sectors of society it is also very prominent in the field of education by changing its learning environment and learning ways (Bruin, \& Merriënboer, 2017). Students can acquire knowledge not only from their teachers, but also from the Internet. Online learning is becoming a new way to learn and something you seek to know.In response to the development of technology, nowadays many countries are promoting education information and accelerating the use of information technology to promote the effectiveness of teaching and learning. In China, the Chinese government has attached great importance to the application of technology in the field of education. It has published several documents which emphasize the importance of the application of technology in teaching and learning. This is

\footnotetext{
${ }^{14} 5 \mathrm{C}$ : communication, collaboration, critical thinking, complex problem solving and creativity

${ }^{15}$ Master, Faculty of Education, Beijing Normal University, China, e-mail: bnusw0512@ mail.bnu.edu.cn

${ }^{16} \mathrm{PhD}$, Faculty of Education, Beijing Normal University, China, ,e-mail: merryxc_1991@163.com

${ }^{17}$ Corresponding author, Professor, Faculty of Education, Beijing Normal University, China, e-mail: yan.dong@bnu.edu.cn
} 
evidenced in various publications over time (National Medium and Long-term Education Reform and Development Plan, 2010, Ministry of Education of People's Republic of China, 2010, National Development Plan for ICT in Education (2011-2020).

Online learning can make full use of computing technology and Internet technology to ensure learners can learn anytime, anywhere. Use of fragmentation time to learn, can break the limitation of time and space in traditional education. However, if the learner does not have good self-control, they can be easily distracted by other web news during the learning process. Lack of accompanying teachers who can supervise students is also a variable and some students will drop out before they finish a course. This paper aims to determine the relationships amongst students' personality traits, self-regulation and 5C of online learning students. The results are expected to help students clearly understand their traits, self-regulation and how to affect their online learning outcomes and whether online learning experience will affect their 5c.

\section{Literature Review}

\section{Concepts}

\subsection{Grit}

The concept of Grit was first presented by A.L. Duckworth, an Asian American psychologist and associate professor at the University of Pennsylvania. Duckworth (2005) discussed the role of selfdiscipline in an article entitled "Self - discipline outdoes IQ in predicting academic performance of adolescents". This pioneering research was labelled as the "Grit research" and was inspired by the film True Grit(Henry Hathaway, 1969). During a speech, Duckworth defines the concept as the quality of "working towards a long-term goal and maintaining a passionate state. That is, encountering failure and setbacks, and still making unremitting efforts"(Duckworth, 2005).

In China, the focus on grit quality can be traced back to Zenzione of the Confucius' students, which states that 'an educated gentleman cannot but be resolute and broad-minded, for he has taken up a heavy responsibility and a long course. Is it not a heavy responsibility, which is to practice benevolence? Is it not a long course, which will end only with his death?' The Analects of Confucius Tabe. Grit has always been one of the evaluation criteria for people, and people have been encouraging each other to have this quality of life, such as encouraging friends not to give up or speaking out of turn.

\subsection{Self-regulated learning}

Self-regulated Learning (SRL) was first defined by Bandura in 1986 and he defined self-regulated Learning as a three-regulated process: self-observation, self-judgment, and self-reflection. Learners first need to systematically observe their learning behaviors through the aspects of learning progress and learning quality, so as to obtain their learning progress information in the learning process; Secondly, learners need to compare the current learning state with the set learning goal, which is self-judgment. The gap between the current learning situation and the set goal can be found through self-judgment. Some scholars pointed out that self-judgment can not only provide learning feedback information but also play a role in influencing learning motivation (Guotao, 1995) . Thirdly, after self-judgment and finding the gap between the current state and the expectation, learners also need to self-react, evaluate whether they are satisfied with the current learning results, adjust their learning behavior and adjust the learning environment, so as to prepare for more effective learning in the future. 
Zimmermann (1989) pointed out that self-regulation learning refers to learners using cognitive regulation strategy and strategy of motivation to promote their own learning, by choosingtheir own learning method which favors the construction and the process of creating a favorable learning environment. He also summarized three characteristics of self-regulated learning :(1) self-regulated learners can actively participate in their own learning process in metacognition, motivation and behavior; (2) self-regulation learning is a process of constant circulation and repeated adjustment; (3) learners can control themselves (Zimmerman, \& Schunk, 2004).

\section{$1.35 \mathrm{C}$}

Key literacy, also known as 21st century learning skills, is the main focus of the process of shaping the blueprint of future education at home and abroad, which has triggered a series of teaching innovation practices. Each country has their own definition of key literacy; in China some scholars use the $5 \mathrm{C}$ which consists of five abilities, communication, collaboration, critical thinking, complex problem solving and creativity (Hwang, Lai, Liang, Chu, \& Tsai, 2017).

\section{Literature review}

The Grit questionnaire contains two aspects: consistency of interests and perseverance of effort. Wolters and Hussain (2015) found that the second part is very strongly associated with selfregulation, whilst self-regulation serves as a mediator of grit. Cho, Kim and Choi (2017) conducted a study about whether learners' self-regulation will affect their outcomes during online learning. They found that there are positive correlations between self-regulated levels and self-efficacy and students with high self-regulation will have a high self-efficacy than students with low selfregulation. Eastin et al (2000) carried out a survey about students' internet self-efficacy and proved that students' internet self-efficacy had a significant relationship to their experience. They further argued that internet stress is negatively related to efficacy beliefs, while prior internet experience will affect the outcome of their online learning. Chuang, Lin and Tsai (2015) explored the relationship between Internet self-efficacy and sources of Internet self-efficacy among Taiwanese university students. The result of the study suggested that if students use the Internet to solve problems, communicate with others, verify information, apply software, and learn new things in the Internet-based environment, students' psychological and affective states might play an important role.

ChihHsuan et al (2013) carried out a survey about students' characteristics, self-regulated learning, technology self-efficacy, and course outcomes in online learning. The survey showed that students' self-regulated learning and their technology self-efficacy have an important effect on their online learning outcomes. Prior et al (2016) studied students' attitude, digital literacy and self-efficacy and whether they affect their online learning behavior. They found that students' positive learning attitude will enhance their self-efficacy, then will affect their outcomes of online learning. Finally, Lim and Kim (2003) looked into students' online learning motivation and their characteristics and whether they affect their learning outcomes. They came to the conclusion that students' characteristics and their motivation types will affect undergraduate students' online learning outcomes. 


\section{Methodology}

\section{Sample}

The participants of this study included 102 university students with online learning experience (including 29 males and 73 females) in Beijing Normal University. They were either undergraduate or graduate students, of which were 23 freshmen, 74 masters and $5 \mathrm{PhD}$ students. They were 80 Chinese students and 22 international students.

\section{Data collection tools}

In this study a five-point Likert-type scale questionnaire was used: a score of 1 indicated "not at all true of me" and 5, "very true of me". The questionnaire includes three different scales. They are grit, 5C, online self-regulatedlearning. (Please see Appendix A)

The grit scale was developed by Duckworth et al (2007). It consists of two dimensions, one is consistency of Interests, and the other is perseverance of effort, with a total of 12 items.

The 5C questionnaire has 22 items developed by Hwang et al (2017), which include communication, collaboration, critical thinking, complex problem solving and creativity. Over a yearly period they aimed to investigate the relationships between students' perceptions and their tendencies of their five kind of abilities of online.

The online self-regulated questionnaire has 24 items in total, which was developed by Barnard et al (2008), this questionnaire included goal setting, environmental construction, task strategy, time management, help seeking and self-evaluation.

\section{Results analysis}

\section{a. Descriptive analysis}

The descriptive analysis includes gender, countries and gradesanalysis. Participants were 29 males and 73 females. The 102 valid questionnaires included 80 Chinese studentsand 22 international students.

\section{b. Reliability analysis}

The grit scale's reliability is 0.709 , the $5 \mathrm{C}$ scale's reliability is 0.874 , the self-regulated scale's reliability is 0.863 .

Table1Reliabilityanalysisresults

\begin{tabular}{c|c|c}
\hline Scales & Cronbach's Alpha & Items \\
\hline Grit & .709 & 12 \\
\hline SRL & .863 & 24 \\
\hline 5C & .874 & 22 \\
\hline
\end{tabular}

\section{c. Factor analysis}

(1) Grit

The data analysis results show that the KMO statistic is 0.734 , indicating that the structural validity of the questionnaire is good, and the Bartlett sphere test value is 166.876. The 
(2) SRL

significance level of the chi-square statistical value is 0.000 , less than 0.01 , and there is a high correlation between the indicators. The data is suitable for factor analysis.

The data analysis results show that the KMO statistic is 0.773 , indicating that the structural validity of the questionnaire is good, and the Bartlett sphere test value is 798.318. The significance level of the chi-square statistical value is 0.000 , less than 0.01 , and there is a (3) $5 \mathrm{C}$

high correlation between the indicators. The data is suitable for factor analysis.

The data analysis results show that the KMO statistic is 0.742 , indicating that the structural validity of the questionnaire is good, and the Bartlett sphere test value is 653.464. The significance level of the chi-square statistical value is 0.000 , less than 0.01 , and there is a high correlation between the indicators. The data is suitable for factor analysis.

d. Correlation analysis

As we wanted to explore the relationship amongst the four aspects, we conducted the correlation analysis. The analysis results showed that these four aspects all have a significant correlation amongst each other, where the correlation of grit with efficacy and regulation is very small, as shown in table 2 .

Table2 Correlation analysis results

\begin{tabular}{|c|c|c|c|c|c|c|c|c|c|c|c|c|c|c|c|c|}
\hline & $M$ & $S D$ & G1 & G2 & Cl1 & $\mathrm{Cl}$ & $\mathrm{C} 2$ & C3 & $C 4$ & C5 & SRL1 & SRL2 & SRL3 & SRL4 & SRL5 & SRL6 \\
\hline G1 Consistency of Interests & 2.94 & 0.81 & 1 & & & & & & & & & & & & & \\
\hline G2 Perseverance of Effort & 3.66 & 0.65 & 0.79 & 1 & & & & & & & & & & & & \\
\hline C11 Communication Ways & 4.02 & 0.75 & 0.92 & $0.59^{* *}$ & 1 & & & & & & & & & & & \\
\hline C12 Communication Feels & 3.84 & 0.64 & -0.11 & $0.35^{* *}$ & $0.41^{* *}$ & 1 & & & & & & & & & & \\
\hline C2 Collaboration & 3.20 & 0.63 & -0.06 & $0.38^{* *}$ & $0.42^{* *}$ & $0.54^{* *}$ & 1. & & & & & & & & & \\
\hline C3 Critical thinking & 3.60 & 0.61 & -0.01 & $0.44^{* *}$ & $0.22^{* x}$ & $0.25^{* *}$ & $0.44^{* *}$ & & & & & & & & & \\
\hline $\begin{array}{l}\text { C4 Complex problem } \\
\text { solving }\end{array}$ & 3.60 & 0.64 & $-0.25^{* x}$ & $0.39^{* *}$ & 0.17 & $0.41^{* *}$ & $0.39^{* *}$ & $0.31^{* *}$ & & & & & & & & \\
\hline C5 Creativity & 3.96 & 0.76 & -0.14 & $0.27^{* *}$ & $0.20^{* x}$ & $0.28^{* *}$ & $0.27^{* *}$ & $0.45^{* *}$ & $0.26^{* *}$ & 1 & & & & & & \\
\hline SRLI Target Setting & 3.29 & 0.70 & 0.02 & $0.45^{* *}$ & $0.53^{* x}$ & $0.46^{*}$ & $0.45^{* *}$ & $0.29^{* *}$ & $0.53^{* *}$ & 0.12 & 1 & & & & & \\
\hline SRL2Environmental & 3.66 & 0.73 & -0.17 & $0.48^{* *}$ & $0.32^{* x}$ & $0.38^{* *}$ & $0.48^{* *}$ & $0.29^{* *}$ & $0.26^{* *}$ & 0.19 & $0.41^{* *}$ & 1 & & & & \\
\hline Construction & & & & & & & & & & & & & & & & \\
\hline SRL3 Task Strategies & 2.79 & 0.85 & 0.01 & $0.40^{* *}$ & -0.05 & $0.21^{* *}$ & $0.40^{* *}$ & $0.29^{* *}$ & -0.46 & 0.10 & $0.27^{* *}$ & $0.34^{* *}$ & 1 & & & \\
\hline SRL4 Time Management & 3.40 & 0.75 & -0.29 & $0.44^{* *}$ & $0.24^{* *}$ & $0.22^{* *}$ & $0.44^{* *}$ & $0.31^{* *}$ & 0.19 & 0.17 & $0.35^{* x}$ & $0.45^{* *}$ & 0.18 & 1 & & \\
\hline SRL5 Help Seeking & 3.53 & 0.74 & -0.58 & -0.38 & $-0.23^{* *}$ & 0.17 & -0.19 & 0.09 & 0.18 & -0.18 & $0.28^{* *}$ & 0.00 & 0.91 & 0.74 & 1 & \\
\hline SRL6 Self-Evaluation & 3.42 & 0.68 & -0.18 & $0.34^{* *}$ & 0.17 & $0.50^{\mathrm{*} *}$ & $0.30^{* *}$ & $0.21^{* *}$ & $0.43^{* *}$ & 0.18 & $0.49^{* x}$ & $0.27^{* *}$ & 0.19 & $0.24^{* *}$ & $0.23^{* *}$ & 1 \\
\hline
\end{tabular}

\section{e. Regression Analysis}

Nowadays, more and more countries realize that students' core literacies such as communication, collaboration, critical thinking, complex problem solving and creativity are important (Hwang, Lai, Liang, Chu, \& Tsai, 2017). Specifically in the field of education research discusses how to improve students' literacies (Bruin, \& Merriënboer, 2017; ChihHsuan, David, \& Margaret, 2013). However, currently research is focused on factors, such as the learning activities, teaching methods, teaching strategies and so on, that teachers adopt. Whilst recognizing the importance of these factors, students' own characteristics will also have an impact on their literacy development. Some studies 
(Wolters, \& Hussain, 2015; Cho, Kim, \& Choi, 2017) have shown that students' self-regulated learning ability and perseverance are two important characteristics and these also have an impact on their academic performance. The present study aims to explore whether students' self-regulated learning and grit will impact their 5C abilities development and to bridge the research gap with the previous studies. Through the regression analysis we found a model, as presented in table 3 .

Table 3 Regression analysis results

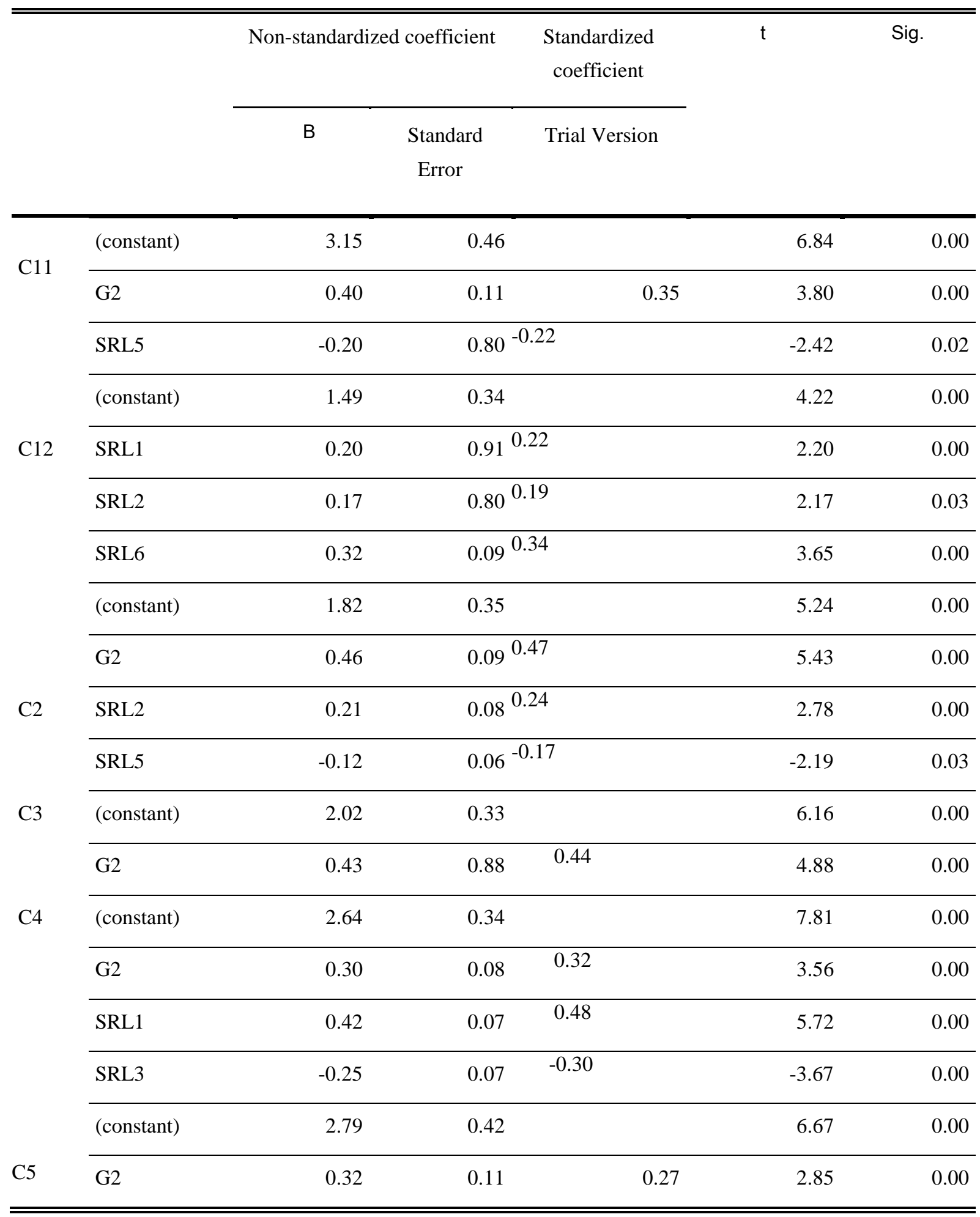




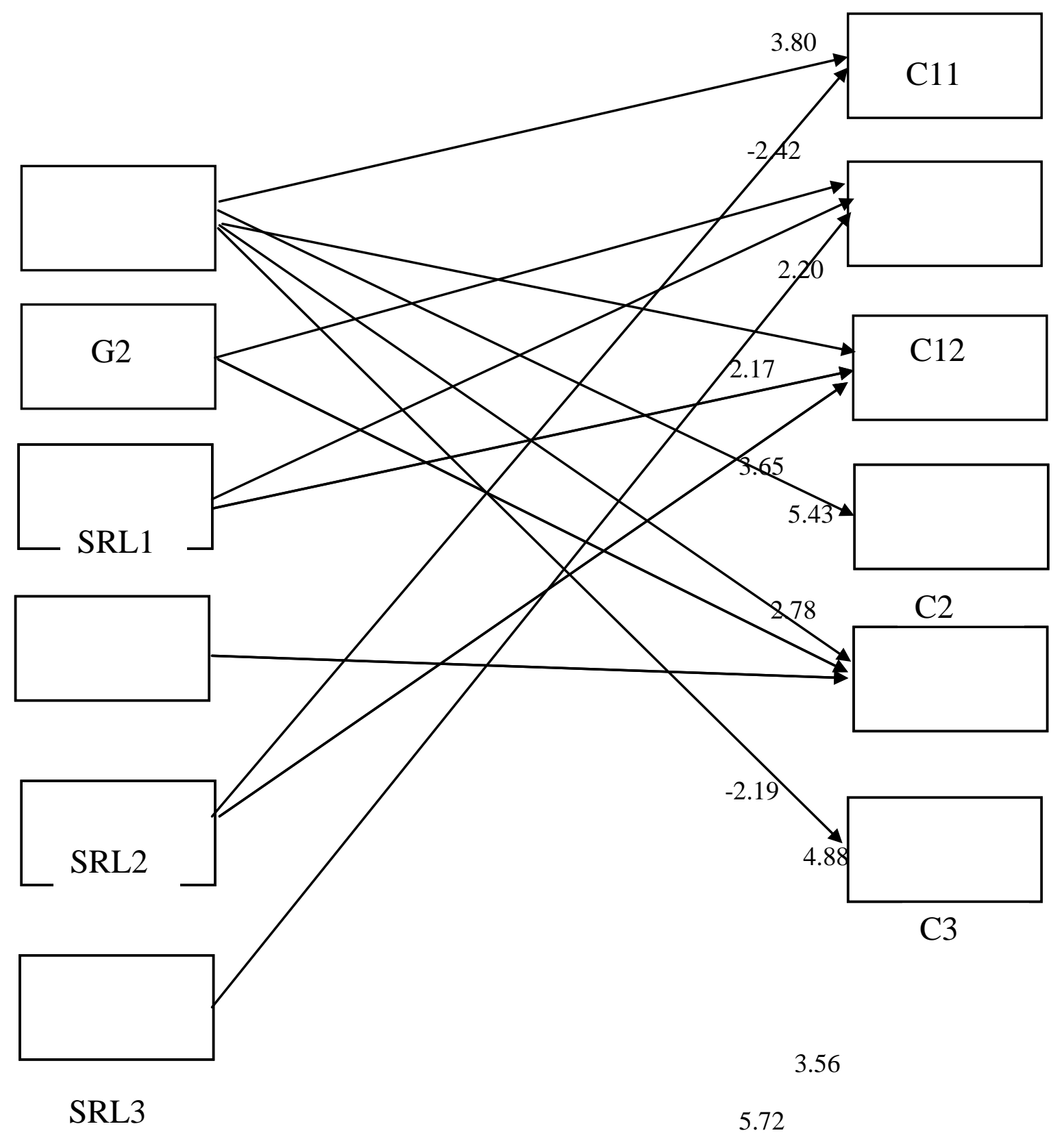

C4 
SRL6

\section{Discussion and Conclusion}

(1)Communication can be subdivided into two sub-dimensions: communication ways and communication feeling.

When we explore the factors analysis (EFA), we found the dimension "communication" cannot be integrated into one factor. We have carefully studied the items under the "communication" dimension and found some items describing the way people communicate with others, such as "I try to be warm when communicating with others". While some items describe the feelings when someone talks with others, such as "While I'm talking, I think about how the other person feels".

The communication ways are considered from the perspective of the speaker.The speaker wants to make a good impression on others. The feeling during the communication is that the speaker fully considers the feelings of others, and then changes the way of communication, making the other person feel comfortable.

(2)Students' consistency of interests is not related to their self-regulated learning and $5 \mathrm{C}$ competences.

We usually think that when someone has a firm goal, one will adjust the learning style, and then work towards a goal to improve their own multi-faceted ability. With technology however, we need to constantly adjust our direction and plan. Interest is just a personal trait or goal for a period of time, which does not affect a person's usual way of doing things and their personal ability.

Our research found that students' consistency of interests is not related to their self-regulated learning and $5 \mathrm{C}$ competences. Therefore, we need to change our thinking, especially in China, which believes that only with a firm goal we can continue to make progress.

(3)The results of linear regression indicated that students' perseverance of effort could predict their 5C competences, and students' self-regulated learning; especially goal setting, environment structuring, task strategies, help seeking and self-evaluation all have a positive impact on their $5 \mathrm{C}$ competences.

Previous studies have explored that grit and self-regulated learning can effectively predict students' academic performance. We believe that the academic performanceis just a formal expression of students. This study wants to verify whether perseverance and self-regulated learning can predict students' 5C abilities. So we use 5C as the dependent variable, while grit and self-regulated learning as an independent variable to explore their relationship.

From the result we find that students' perseverance of effort has a positive influence on 5C, although it is taken into account that people will meet some difficulties whilst trying to achieve their dream. The key is to never give up and learn from the way to growth. So, from this result, we learn 
that as teacher we should teach students not to give up easily, and encourage them to try their best. Teachers should also think how to organize teaching when they cultivate this quality with their students.

As for students' self-regulated learning, only "time management" cannot predict their 5C abilities. Other dimensions such as goal setting, environment structuring, task strategies, help seeking and self-evaluation are all positive impact their 5C competences. So this result suggests a more personalized approach. Teachers should guide students to set their own targets, choose the right place for them to learn well, choose suitable strategies to solve problems and when they meet difficulties they should know who to ask for help so that they can self-reflect and evaluate.

This research looked into students' characteristics, telling us how to cultivate students' 5C competences. Teachers and parents could get some ideas on how to teach their students and children. Whilst there are some limitations, first there are only 103 students participated in this research, with a future study to aim to collect data from a larger sample. Secondly, we collected data by self-reporting methods, which may lack objectivity.A future study could try some accurate measurement tools during the data collection process.

\section{References}

Barnard, L., Lan, W. Y., To, Y. M., Paton, V. O., \& Lai, S. L. (2009). Measuring self-regulation in online and blended learning environments. The internet and higher education, 12(1), 1-6.

Bruin, A. B., \& Merriënboer, J. J. (2017). Bridging cognitive load and self-regulated learning research: A complementary approach to contemporary issues in educational research. Learning and Instruction, 51, 1-9.

ChihHsuan Wang, David M. Shannon, \& Margaret E. Ross. (2013). Students' characteristics, selfregulated learning, technology self-efficacy, and course outcomes in online learning. Distance Education, 34(3), 302-323.

Cho, M. H., Kim, Y., \& Choi, D. H. (2017). The effect of self-regulated learning on college students' perceptions of community of inquiry and affective outcomes in online learning. Internet \& Higher Education, 34, 10-17.

Chuang, S. C., Lin, F. M., \& Tsai, C. C. (2015). An exploration of the relationship between internet self-efficacy and sources of internet self-efficacy among taiwanese university students. Computers in Human Behavior, 48(C), 147-155.

Eastin, M. S., \& Larose, R. (2000). Internet self - efficacy and the psychology of the digital divide. Journal of Computer - mediated Communication, 6(1), 0-0.

Hwang, G. J., Lai, C. L., Liang, J. C., Chu, H. C., \& Tsai, C. C. (2017). A long-term experiment to investigate the relationships between high school students' perceptions of mobile learning and peer interaction and higher-order thinking tendencies. Educational Technology Research \& Development (6), 1-19. 
Lim, D. H., \& Kim, H. (2003). Motivation and learner characteristics affecting online learning and learning application. Journal of Educational Technology Systems, 31(4), 423-439.

Prior, D. D., Mazanov, J., Meacheam, D., Heaslip, G., \& Hanson, J. (2016). Attitude, digital literacy and self efficacy: flow-on effects for online learning behavior. Internet \& Higher Education, 29, 91-97.

Wolters, C. A., \& Hussain, M. (2015). Investigating grit and its relations with college students' selfregulated learning and academic achievement. Metacognition \& Learning, 10(3), 293-311.

Zimmerman, B. J. (1989). A social cognitive view of self-regulated academic learning. Journal of educational psychology, 81(3), 329-339.

Zimmerman, B. J., \& Schunk, D. H. (2004). Self-regulating intellectual processes and outcomes: A social cognitive perspective. Motivation, emotion, and cognition: Integrative perspectives on intellectual functioning and development, 323-349.

GuotaoZ.(1995). The Theory of Self-regulated Learning_—New Progress in Bandura's Learning Theory. Foreign Education Research, (3), 1-3.

Ministry of Education of People's Republic of China. (2010). National Development Plan for ICT in Education (2011-2020). Accessed March 2019 from http://old.moe.gov.cn//publicfiles/business/htmlfiles/moe/s5889/201204/134096.html.

Ministry of Education of People's Republic of China. (2010). National Medium and Long-term Education Reform and Development Plan. Online. Accessed March 2019 from http://old.moe.gov.cn/publicfiles/business/htmlfiles/moe/s3342/201203/xxgk_133322.html. 


\section{Appendix A}

\begin{tabular}{|c|c|c|c|c|c|c|}
\hline NO & Items & 1 & 2 & 3 & 4 & 5 \\
\hline \multicolumn{7}{|l|}{$5 \mathrm{C}$} \\
\hline 1 & I try to make the other person feel good. & & & & & \\
\hline 2 & I try to make the other person feel important. & & & & & \\
\hline 3 & I try to be warm when communicating with others. & & & & & \\
\hline 4 & While I'm talking I think about how the other person feels. & & & & & \\
\hline 5 & I am verbally and nonverbally supportive of other people. & & & & & \\
\hline 6 & I disclose at the same level that others disclose to me. & & & & & \\
\hline 7 & $\begin{array}{l}\text { I believe our team can cooperate successfully when I conduct } \\
\text { collaborative learning. }\end{array}$ & & & & & \\
\hline 8 & $\begin{array}{l}\text { I try to provide useful and sufficient information when I conduct } \\
\text { collaborative learning. }\end{array}$ & & & & & \\
\hline 9 & $\begin{array}{l}\text { I have good communication with my team members when I conduct } \\
\text { collaborative learning. }\end{array}$ & & & & & \\
\hline 10 & $\begin{array}{l}\text { I can finish my work efficiently when I conduct collaborative } \\
\text { learning. }\end{array}$ & & & & & \\
\hline 11 & $\begin{array}{l}\text { Work is split based on our abilities when I conduct collaborative } \\
\text { learning. }\end{array}$ & & & & & \\
\hline 12 & I ask myself periodically if I am meeting my goals. & & & & & \\
\hline 13 & I consider several alternatives to a problem before I answer. & & & & & \\
\hline 14 & I find myself pausing regularly to check my comprehension. & & & & & \\
\hline 15 & I ask myself questions about how well I am doing once I finish a task. & & & & & \\
\hline 16 & When facing problems, I believe I have the ability to solve them. & & & & & \\
\hline 17 & I believe I can put effort into solving problems. & & & & & \\
\hline 18 & I can solve problems that I have met before. & & & & & \\
\hline 19 & I am willing to face problems and make an effort to solve them. & & & & & \\
\hline 20 & $\begin{array}{l}\text { I like to observe something I haven't seen before and understand it in } \\
\text { detail. }\end{array}$ & & & & & \\
\hline 21 & I like to try something new. & & & & & \\
\hline 22 & I like to do something by myself. & & & & & \\
\hline \multicolumn{7}{|c|}{ SRL } \\
\hline 1 & I set standards for my assignments in online courses. & & & & & \\
\hline 2 & $\begin{array}{l}\text { I set short-term (daily or weekly) goals as well as long-term goals } \\
\text { (monthly or for the semester). }\end{array}$ & & & & & \\
\hline 3 & I keep a high standard for my learning in my online courses. & & & & & \\
\hline 4 & I set goals to help me manage studying time for my online courses. & & & & & \\
\hline 5 & I don't compromise the quality of my work because it is online. & & & & & \\
\hline 6 & I choose the location where I study to avoid too much distraction. & & & & & \\
\hline 7 & I find a comfortable place to study. & & & & & \\
\hline 8 & I know where I can study most efficiently for online courses. & & & & & \\
\hline 9 & $\begin{array}{l}\text { I choose a time with few distractions for studying for my online } \\
\text { courses. }\end{array}$ & & & & & \\
\hline 10 & $\begin{array}{l}\text { I try to take more thorough notes for my online courses because notes } \\
\text { are even more important for learning online than in a regular }\end{array}$ & & & & & \\
\hline
\end{tabular}


Volume 1, Issue 2, December 2019 Journal of Education, Innovation, and Communication (JEICOM)

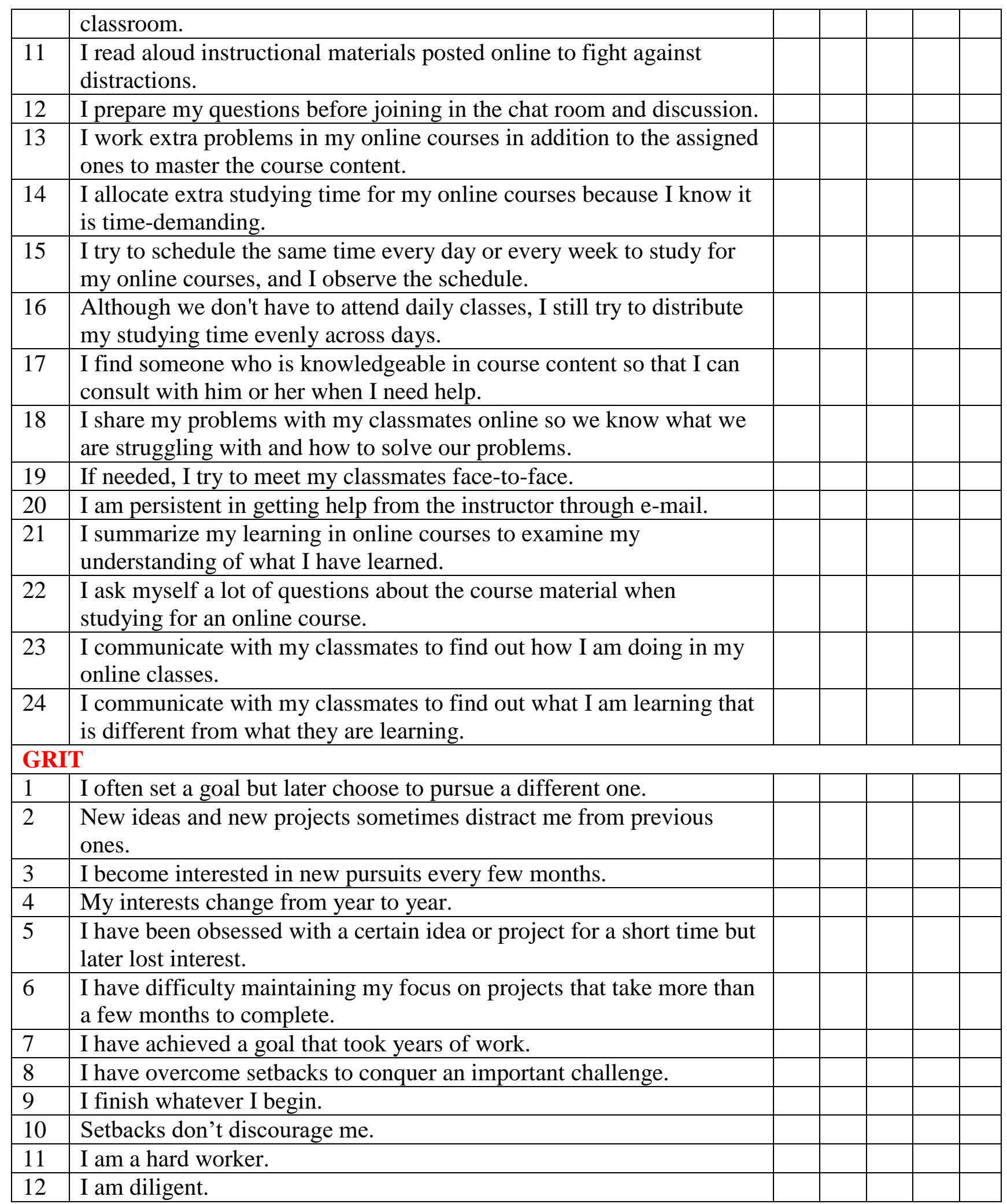

